\title{
FIRM HETEROGENEITY AND CREDIT RISK DIVERSIFICATION
}

\author{
SAMUEL HANSON \\ M. HASHEM PESARAN \\ TIL SCHUERMANN
}

CESIFO WORKING PAPER NO. 1531

CATEGORY 10: EMPIRICIAL AND THEORETICAL METHODS

August 2005

An electronic version of the paper may be downloaded
- from the SSRN website: $\quad$ www.SSRN.com
- from the CESifo website: Www.CESifo-group.de 


\title{
FIRM HETEROGENEITY AND CREDIT RISK DIVERSIFICATION
}

\begin{abstract}
This paper considers a simple model of credit risk and derives the limit distribution of losses under different assumptions regarding the structure of systematic and idiosyncratic risks and the nature of firm heterogeneity. The theoretical results obtained indicate that if firm-specific risk exposures (including their default thresholds) are heterogeneous but come from a common parameter distribution, for sufficiently large portfolios there is no scope for further risk reduction through active credit portfolio management. However, if the firm risk exposures are draws from different parameter distributions, say for different sectors or countries, then further risk reduction is possible, even asymptotically, by changing the portfolio weights. In either case, neglecting parameter heterogeneity can lead to underestimation of expected losses. But, once expected losses are controlled for, neglecting parameter heterogeneity can lead to overestimation of risk, whether measured by unexpected loss or value-at-risk. The theoretical results are confirmed empirically using returns and credit ratings for firms in the U.S. and Japan across seven sectors. Ignoring parameter heterogeneity results in far riskier credit portfolios.
\end{abstract}

JEL Code: C33, G13, G21.

Keywords: risk management, correlated defaults, heterogeneity, diversification, portfolio choice.

Samuel Hanson

Federal Reserve Bank of New York

Til Schuermann

Federal Reserve Bank of New York and Wharton Financial Institutions Center
M. Hashem Pesaran

University of Cambridge

Sidgwick Avenue

Cambridge, CB3 9DD

United Kingdom

mhp1@econ.cam.ac.uk

We would like to thank Richard Cantor, Paul Embrechts, Joshua Rosenberg, Jose Scheinkman, Zhenyu Wang, and participants at the 13th Annual Conference on Pacific Basin Finance, Economics, and Accounting at Rutgers University, June 2005, seminar participants at the Newton Institute, University of Cambridge, UMass Amherst and the Federal Reserve Bank of New York for helpful comments and suggestions, and Chris Metli for excellent research assistance with the empirical application.

Any views expressed represent those of the authors only and not necessarily those of the Federal Reserve Bank of New York or the Federal Reserve System. 


\section{Introduction}

The importance of modeling correlated defaults has been recognized in the credit risk literature for some time. Early treatment can be traced to the single homogeneous factor model due to Vasicek (1987, 1991), which also forms the basis of New Basel Accord (BCBS, 2004) as outlined in detail by Gordy (2003). Extensions to multiple factors were proposed by Wilson (1997a,b) and Gupton, Finger and Bhatia (1997) in the form of the industry credit portfolio model CreditMetrics. ${ }^{1}$ Practically all of these models are adaptations of Merton's (1974) options based approach, which develops a simple model of firm performance with a threshold value below which the firm defaults.

In this paper we build on the seminal work of Vasicek and Gordy and examine the scope for diversification of a credit portfolio by allowing for firm-specific heterogeneity of the return process as well as allowing for the default thresholds to vary across firm types, such as for instance by credit rating. Our theoretical results indicate that if the firm parameters are heterogeneous but come from a common distribution, there is no scope for further risk reduction for a sufficiently large portfolio, i.e. one where idiosyncratic risk has already been diversified away. This would preclude gains from active portfolio management by changing the exposure weights (unless the portfolio is small, of course). However, if the firm parameters come from different distributions, say for different sectors or countries, there will be further scope for credit risk diversification by changing the portfolio weights, even in the case of sufficiently large portfolios. In either case, neglecting parameter heterogeneity can lead to underestimation of expected losses (EL). But once EL is controlled for, neglecting parameter heterogeneity can lead to overestimation of unexpected losses or risk, whether measured by loss volatility, i.e. unexpected loss (UL), or value-at-risk (VaR).

Different degrees of heterogeneity are also assumed for the default thresholds which introduces new complications. For the same return correlation, default correlations may be different across firms due to differences in default thresholds. In empirical applications the default threshold is typically modeled as a function of the firm's balance sheet. Not only is accounting information a noisy and possibly unreliable indicator of a firm's potential health, but in a multi-country setting it presents additional challenges of different accounting standards and bankruptcy rules. In view of these measurement problems, Pesaran, Schuermann, Treutler, and Weiner (2005) propose an alternative approach to estimating the default thresholds using firm-specific credit ratings and historical default frequencies that we also adopt here.

We present empirical results for a portfolio of over 800 firms across U.S. and Japan. Return regressions with different degrees of parameter heterogeneity are estimated recursively using tenyear rolling estimation windows, with the loss distributions simulated for six out-of-sample oneyear periods, allowing for differences in default thresholds by credit ratings. The results are found

\footnotetext{
${ }^{1}$ For a summary of this and other industry models, see Saunders and Allen (2002), and for detailed comparisons, see Koyluoglu and Hickman (1998), Crouhy et al. (2000), and Gordy (2000).
} 
to be robust across the six years. We show that, for a given EL, risk is significantly reduced when parameter heterogeneity is taken into account. Importantly, the introduction of parameter heterogeneity allows one to exploit whatever diversification potential that might exist in the selected sample portfolio. Allowing for the differences in default thresholds across firms with different ratings also proves to be of crucial importance. This is perhaps not surprising, considering that cross firm default correlations tend to increase significantly with a fall in credit ratings even if return correlations remain fixed across all firms in the portfolio. Note that ceteris paribus it is the default correlations, and not the return correlations, that determine the shape of a credit loss distribution.

Our results have bearing on risk and capital management as well as the pricing of credit assets. For example, in the case of a commercial bank, ignoring heterogeneity may result in underprovisioning for loan losses since EL is underestimated, and may result in overcapitalization against (bank) default since risk is overestimated. The risk assessment and pricing of complex credit asset such as collateralized debt obligations (CDOs) may be adversely affected since they are driven by the shape of the loss distribution which is segmented into tranches.

The most important distinction between our approach and the literature is around firm (or asset) heterogeneity: the risky asset pricing literature typically develops a model for a representative bond or firm. ${ }^{2}$ Naturally, there will always be idiosyncratic or firm-specific differences, also allowed for in the risky asset pricing models. But our interest is in explicitly allowing for firm heterogeneity with respect to both the default threshold (or distance to default) and systematic risk sensitivity, an important dimension of diversification. Along the way we are able to derive fat-tailed correlated losses from Gaussian (i.e. non-fat-tailed) risk factors and explore the potential for (and limits of) cross-sector and/or cross-country risk diversification.

At a technical level we are able to generalize the theoretical results of Vasicek $(1987,1991)$ and others (discussed in Gordy, 2000, 2003)) in a number of directions. By working with densities rather than cumulative distribution functions we are able to derive a number of closed form solutions for the loss density function under alternative assumptions regarding the probability distributions of systematic and idiosyncratic shocks, as well as heterogeneous risk exposures across firms in the portfolio. The earlier theoretical studies by Vasicek and others focus on the derivation of the cumulative distribution function which limit closed form analysis to the relatively simple case of the double-Gaussin shocks where the systematic and idiosyncratic shocks are both assumed to be Gaussian.

The plan for the remainder of the paper is as follows: Section 2 introduces the basic model of firm value and default. Section 3 considers the problem of correlated defaults. Section 4 derives the portfolio loss distribution under different heterogeneity assumptions, starting with the simple case of a homogeneous portfolio as introduced by Vasicek. The potential of sectoral and geographic

\footnotetext{
${ }^{2}$ To be sure, one can find mention of multi-factor risk sensitivity (e.g. Duffie and Singleton (2003, Section 11.3.3)), but to our knowledge this topic has received at best casual treatment.
} 
diversification is discussed in Section 5. Section 6 provides more detail regarding the specification and identification of the default threshold needed for the empirical application, which is presented in Section 7. There we explore the impact of heterogeneity empirically using returns for firms in the U.S. and Japan across seven sectors and analyze the resulting loss distributions by simulation. Section 8 provides some concluding remarks. A technical Appendix presents generalizations of some material in Sections 3 and 4.

\section{Firm Value and Default}

Much of the research on credit risk modelling is based on the option theoretic default model of Merton (1974). Merton recognized that a lender is effectively writing a put option on the assets of the borrowing firm; owners and owner-managers (i.e. shareholders) hold the call option. If the value of the firm falls below a certain threshold, the owners will put the firm to the debt-holders. Thus a firm is expected to default when the value of its assets falls below a threshold value determined by its liabilities.

Following Pesaran, Schuermann, Treutler, and Weiner (2005), hereafter PSTW, consider a firm $i$ having asset value $V_{i t}$ at time $t$, and an outstanding stock of debt, $D_{i t}$. Under the Merton model default occurs at the maturity date of the debt, $t+h$, if the firm's assets, $V_{i, t+h}$, are less than the face value of the debt at that time, $D_{i, t+h}$. A more nuanced approach is taken by the first-passage models (e.g. Black and Cox, 1976) where default would occur the first time that $V_{i t}$ falls below a default boundary (or threshold) over the period $t$ to $t+h .^{3}$ The default probabilities are computed with respect to the probability distribution of asset values at the terminal date, $t+h$ in the case of the Merton model, and over the period from $t$ to $t+h$ in the case of the first-passage model. Therefore, the Merton approach may be thought of as a European option and the first-passage approach as an American option.

The value of the firm at time $t$ is the sum of debt and equity, namely

$$
V_{i t}=D_{i t}+E_{i t}, \text { with } D_{i t}>0
$$

Conditional on time $t$ information, default will take place at time $t+h$ if $V_{i, t+h} \leq D_{i, t+h}$. In the Merton model debt is assumed to be fixed over the horizon $h$. Because default is costly and violations to the absolute priority rule in bankruptcy proceedings are common, in practice debtholders have an incentive to put the firm into receivership even before the equity value of the firm hits the zero value. ${ }^{4}$ Similarly, the bank might also have an incentive of forcing the

\footnotetext{
${ }^{3}$ For a review of these models, see, for example, Lando (2004, Chapter 3). More recent modeling approaches also allow for strategic default considerations, as in Mella-Barral and Perraudin (1997).

${ }^{4}$ See, for instance, Leland and Toft (1996) who develop a model where default is determined endogenously, rather than by the imposition of a positive net worth condition. More recently, Broadie, Chernov, and Sundaresan (2004) show that in the presence of APR default can be optimal when $E_{i t}>0$ even in the case of a single debt class.
} 
firm to default once the firm's equity falls below a non-zero threshold. ${ }^{5}$ Importantly, default in a credit relationship is typically a weaker condition than outright bankruptcy. An obligor may meet the technical default condition, e.g. a missed coupon payment, without subsequently going into bankruptcy. As a result we shall assume that default takes place if

$$
0<E_{i, t+h}<C_{i, t+h}
$$

where $C_{i, t+h}$ is a positive default threshold which could vary over time and with the firm's particular characteristics (such as region or industry sector). Natural candidates include quantitative factors such as leverage, profitability, firm age (most of which appear in models of firm default), as well as more qualitative factors such as management quality. ${ }^{6}$

We are now in a position to consider the evolution of firm equity value which we assume follows a standard geometric random walk model:

$$
\ln \left(E_{i, t+1}\right)=\ln \left(E_{i t}\right)+\mu_{i}+\xi_{i, t+1}, \quad \xi_{i, t+1} \sim i i d N\left(0, \sigma_{\xi_{i}}^{2}\right),
$$

with a non-zero drift, $\mu_{i}$, and idiosyncratic Gaussian innovations with a zero mean and firmspecific volatility, $\sigma_{\xi_{i}}$. Consequently, the equity value of firm $i$ at time $t+h$ is $\ln \left(E_{i, t+h}\right)=$ $\ln \left(E_{i t}\right)+h \mu_{i}+\sum_{s=1}^{h} \xi_{i, t+s}$, and by (2) default occurs if

$$
\ln \left(E_{i, t+h}\right)=\ln \left(E_{i, t}\right)+h \mu_{i}+\sum_{s=1}^{h} \xi_{i, t+s}<\ln \left(C_{i, t+h}\right),
$$

or if the $h$-period change in equity value or return falls below the log-threshold-equity ratio, $\lambda_{i, t+h}$, defined by

$$
\ln \left(\frac{E_{i, t+h}}{E_{i t}}\right)<\ln \left(\frac{C_{i, t+h}}{E_{i t}}\right)=\lambda_{i, t+h} .
$$

Equation (5) tells us that the relative (rather than absolute) decline in firm value must be large enough over the horizon $h$ to result in default. Using (4), default occurs if $h \mu_{i}+\sum_{s=1}^{h} \xi_{i, t+s}<\lambda_{i, t+h}$. Therefore, under (3) the probability that firm $i$ defaults at the terminal date $t+h$ is given by

$$
\pi_{i, t+h}=\Phi\left(\frac{\lambda_{i, t+h}-h \mu_{i}}{\sigma_{\xi_{i}} \sqrt{h}}\right),
$$

where $\Phi(\cdot)$ is the standard normal cumulative distribution function. In the theoretical discussions that follows we shall assume that the firm-specific default thresholds are given, and do not consider the effects of their sampling uncertainty on the analysis of loss distributions.

\footnotetext{
${ }^{5}$ For a treatment of this scenario, see Garbade (2001).

${ }^{6}$ For models of bankruptcy and default at the firm level, see, for instance, Altman (1968), Lennox (1999), Shumway (2001), and Hillegeist, Keating, Cram and Lundstedt (2004).
} 


\section{Cross Firm Default Correlations}

In the context of the Merton model the cross firm default correlations can be introduced by assuming that shocks to the value of a firm's equity, $\xi_{i, t+1}$, defined by (3), have the following multifactor structure

$$
\xi_{i, t+1}=\gamma_{i}^{\prime} \mathbf{f}_{t+1}+\sigma_{i} \varepsilon_{i, t+1}, \quad \varepsilon_{i, t+1} \sim i i d(0,1)
$$

where $\mathbf{f}_{t+1}$ is an $m \times 1$ vector of common factors, $\gamma_{i}$ is the associated vector of factor loadings, and $\varepsilon_{i, t+1}$ is the firm-specific idiosyncratic shock, assumed to be distributed independently across $i .^{7}$ The common factors could be treated as unobserved or observed through macroeconomic variables such as output growth, inflation, interest rates and exchange rates. ${ }^{8}$ In what follows we suppose the factors are unobserved, distributed independently of $\varepsilon_{i, t+1}$, and have constant variances. ${ }^{9}$ Thus, without loss of generality we assume that $\mathbf{f}_{t+1} \sim\left(\mathbf{0}, \mathbf{I}_{m}\right)$, where $\mathbf{I}_{m}$ is an identity matrix of order $m . .^{10}$

The above multifactor model plays a central role in the analysis of market risk, and its use in credit risk analysis seems a natural step towards a more cohesive understanding of the two types of risks and their relationships to one another. A homogeneous version of the factor model has also been used extensively for the analysis of credit portfolio risk by Vasicek $(1987,1991)$, as we shall see to good effect. But under homogeneity of factor loadings where $\gamma_{i}=\boldsymbol{\gamma}$ and $\boldsymbol{\gamma}_{i}^{\prime} \mathbf{f}_{t+1}=\boldsymbol{\gamma}^{\prime} \mathbf{f}_{t+1}$, the distinction between a one factor and multifactor models is redundant.

Using (7) in (3) we now have

$$
\ln \left(E_{i, t+1}\right)-\ln \left(E_{i t}\right)=r_{i, t+1}=\mu_{i}+\gamma_{i}^{\prime} \mathbf{f}_{t+1}+\sigma_{i} \varepsilon_{i, t+1}
$$

Under our assumptions

$$
\sigma_{\xi_{i}}^{2}=\gamma_{i}^{\prime} \gamma_{i}+\sigma_{i}^{2}
$$

\footnotetext{
${ }^{7}$ A separate line of research has focused on correlated default intensities as in Schönbucher (1998), Duffie and Singleton (1999), Duffie and Gârleanu (2001) and Duffie and Wang (2004). There are a host of other approaches, including the contagion model of Davis and Lo (2001) as well as Giesecke and Weber's (2004) indirect dependence approach, where default correlation is introduced through local interaction of firms with their business partners as well as via global dependence on economic risk factors. The idea of generalizing default dependence beyond correlation using copulas is discussed in Li (2000), Embrechts, McNeil, and Straumann (2001), Schönbucher (2002) and Frey and McNeil (2003).

${ }^{8}$ PSTW provide an empirical implementation of this model by linking the (observable) factors, $\mathbf{f}_{t+1}$, to the variables in a global vector autoregressive model.

${ }^{9}$ The more general case where the factors may exhibit time varying volatility can be readily dealt with by allowing the factor loadings to vary over time, in line with market volatilities. But in this paper we shall not pursue this line of research, primarily because the focus of our empirical analysis is on quarterly and annual default risks, and over such horizons asset return volatilities appear to be rather limited and of second order importance.

${ }^{10}$ The issues concerning the empirical implementation of the multifactor models in the context of credit risk models is discussed in Section 7.
} 
which decomposes the conditional return variance into the part due the systematic risk factors, $\gamma_{i}^{\prime} \gamma_{i}$, and the residual or idiosyncratic variance, $\sigma_{i}^{2}$. The presence of the common factors also introduces a varying degree of asset return correlations across firms, which in turn leads to variation in cross firm default correlations for a given set of default thresholds, $\lambda_{i, t+1}$. The extent of default correlation depends on the size of the factor loadings, $\gamma_{i}$, the importance of the idiosyncratic shocks, $\sigma_{i}$, the values of the default thresholds, $\lambda_{i, t+1}$, and the shape of the distribution assumed for $\varepsilon_{i, t+1}$, particularly its left tail properties. The correlation coefficient of returns of firms $i$ and $j$ is given by

$$
\rho_{i j}=\frac{\boldsymbol{\delta}_{i}^{\prime} \boldsymbol{\delta}_{j}}{\left(1+\boldsymbol{\delta}_{i}^{\prime} \boldsymbol{\delta}_{i}\right)^{1 / 2}\left(1+\boldsymbol{\delta}_{j}^{\prime} \boldsymbol{\delta}_{j}\right)^{1 / 2}},
$$

where $\boldsymbol{\delta}_{i}=\gamma_{i} / \sigma_{i}$ is the standardized $m \times 1$ vector of factor loadings (systematic risk exposures) of firm $i$.

To derive the cross correlation of firm defaults, which we denote by $\rho_{i j, t+1}^{*}$, let $z_{i, t+1}$ to be the default outcome for firm $i$, over a single period such that ${ }^{11}$

$$
z_{i, t+1}=I\left(\lambda_{i, t+1}-r_{i, t+1}\right)
$$

where $I(A)$ is an indicator function that takes the value of unity if $A \geq 0$, and zero otherwise. Then

$$
\rho_{i j, t+1}^{*}=\frac{E\left(z_{i, t+1} z_{j, t+1}\right)-\pi_{i, t+1} \pi_{j, t+1}}{\sqrt{\pi_{i, t+1}\left(1-\pi_{i, t+1}\right)} \sqrt{\pi_{j, t+1}\left(1-\pi_{j, t+1}\right)}}
$$

where $\pi_{i, t+1}=E\left(z_{i, t+1}\right)$ is firm $i^{\prime} s$ default probability over the period $t$ to $t+1$. It is clear that the default correlation, $\rho_{i j, t+1}^{*}$, depends on the default thresholds, $\lambda_{i, t+1}$, as well as the return correlation, $\rho_{i j}$, defined by (10). For given values of the thresholds, $\lambda_{i, t+1}$, a relatively simple expression for $\rho_{i j, t+1}^{*}$ can be obtained if conditional on $\mathbf{f}_{t+1}, \varepsilon_{i, t+1}$ and $\varepsilon_{j, t+1}$ are cross sectionally independent and $\mathbf{f}_{t+1}$ and $\varepsilon_{i, t+1}$ have a joint Gaussian distribution. In this case

$$
\pi_{i, t+1}=\Phi\left(\frac{\lambda_{i, t+1}-\mu_{i}}{\sqrt{\sigma_{i}^{2}+\gamma_{i}^{\prime} \gamma_{i}}}\right)
$$

The argument of $\Phi(\cdot)$ in (13) is commonly referred to as a "distance to default" $(D D)$ such that

$$
D D_{i, t+1}=\Phi^{-1}\left(\pi_{i, t+1}\right)=\left(\lambda_{i, t+1}-\mu_{i}\right) / \sqrt{\sigma_{i}^{2}+\gamma_{i}^{\prime} \gamma_{i}}
$$

To derive an expression for $E\left(z_{i, t+1} z_{j, t+1}\right)$ we first note that conditional on $\mathbf{f}_{t+1}, z_{i, t+1}$ and $z_{j, t+1}$ are independently distributed and

$$
\begin{aligned}
E\left(z_{i, t+1} z_{j, t+1}\right) & =E_{f}\left[E\left(z_{i, t+1} z_{j, t+1} \mid \mathbf{f}_{t+1}\right)\right] \\
& =E_{f}\left[E\left(z_{i, t+1} \mid \mathbf{f}_{t+1}\right) E\left(z_{j, t+1} \mid \mathbf{f}_{t+1}\right)\right] .
\end{aligned}
$$

\footnotetext{
${ }^{11}$ To simplify the exposition, and without any loss of generality, we set $h=1$.
} 
Also

$$
\begin{aligned}
E\left(z_{i, t+1} \mid \mathbf{f}_{t+1}\right) & =E\left(I\left(\lambda_{i, t+1}-\mu_{i}-\gamma_{i}^{\prime} \mathbf{f}_{t+1}-\sigma_{i} \varepsilon_{i, t+1}\right) \mid \mathbf{f}_{t+1}\right) \\
& =\Phi\left(\frac{\lambda_{i, t+1}-\mu_{i}-\gamma_{i}^{\prime} \mathbf{f}_{t+1}}{\sigma_{i}}\right)=\Phi\left(a_{i, t+1}-\boldsymbol{\delta}_{i}^{\prime} \mathbf{f}_{t+1}\right),
\end{aligned}
$$

where as before $\boldsymbol{\delta}_{i}=\boldsymbol{\gamma}_{i} / \sigma_{i}$ and $a_{i, t+1}=\sigma_{i}^{-1}\left(\lambda_{i, t+1}-\mu_{i}\right) .{ }^{12}$ Hence, unconditionally

$$
E\left(z_{i, t+1} z_{j, t+1}\right)=E_{f}\left[\Phi\left(a_{i, t+1}-\boldsymbol{\delta}_{i}^{\prime} \mathbf{f}_{t+1}\right) \Phi\left(a_{j, t+1}-\boldsymbol{\delta}_{j}^{\prime} \mathbf{f}_{t+1}\right)\right]
$$

where the expectations are now taken with respect to the distribution of the common factors, $\mathbf{f}_{t+1}$. As noted by Crouhy, Galai and Mark (2000), under the double Gaussian assumption $E\left(z_{i, t+1} z_{j, t+1}\right)$ is also given by

$$
E\left(z_{i, t+1} z_{j, t+1}\right)=\Phi_{2}\left[\Phi^{-1}\left(\pi_{i, t+1}\right), \Phi^{-1}\left(\pi_{j, t+1}\right), \rho_{i j}\right]
$$

where $\Phi_{2}[\cdot]$ is the bivariate standard normal cumulative distribution function.

\section{Losses in a Credit Portfolio}

Consider now a credit portfolio composed of $N$ different credit assets such as loans, each with exposures or weights $w_{i t}$, at time $t$, for $i=1,2, . ., N$, such that ${ }^{13}$

$$
\sum_{i=1}^{N} w_{i t}=1, \sum_{i=1}^{N} w_{i t}^{2}=O\left(N^{-1}\right), w_{i t} \geq 0 .
$$

A sufficient condition for (18) to hold is given by $w_{i t}=O\left(N^{-1}\right)$, which is the standard granularity condition where no single exposure dominates the portfolio. ${ }^{14}$ Suppose further that loss-givendefault (LGD) of obligor $i$ is denoted by $\varphi_{i, t+1}$ which lies in the range $[0,1] .{ }^{15}$ Under this set-up the portfolio loss over the period $t$ to $t+1$ is given by

$$
\ell_{N, t+1}=\sum_{i=1}^{N} w_{i t} \varphi_{i, t+1} z_{i, t+1} .
$$

In cases where for each $i, \varphi_{i, t+1}$ and $z_{i, t+1}$ are independently distributed, the analysis can be conducted conditional on given values of LGD. In such a case the $\varphi_{i, t+1}$ 's could be treated as fixed values and absorbed in the portfolio weights without loss of generality. However, a more interesting,

\footnotetext{
${ }^{12}$ Note that $a_{i, t+1}$ reduces to the distance to default, $D D_{i, t+1}$, defined by (14) when $\gamma_{i}=0$.

${ }^{13}$ The assumption that $N$ is time-invariant is made for simplicity and can be relaxed.

${ }^{14}$ Conditions (18) on the portfolio weights was in fact embodied in the initial proposal of the New Basel Accord in the form of the Granularity Adjustments which was designed to mitigate the effects of significant single-borrower concentrations on the credit loss distribution. See BCBS (2001, Ch.8).

${ }^{15} \mathrm{LGD}$ is often modelled by assuming that $\varphi_{i, t+1}$ follows a Beta distribution across $i$ with parameters calibrated to match the mean and standard deviation of historical observations on the severity of credit losses.
} 
and arguably practically more relevant case, arises where $\varphi_{i, t+1}$ and $z_{i, t+1}$ are correlated through common business cycle effects. This case presents new technical difficulties and is addressed briefly in Appendix A. For now, and without loss of generality, let $\varphi_{i, t+1}=1 \forall i, t$, meaning that a defaulted asset has no recovery value, and write (19) as

$$
\ell_{N, t+1}=\sum_{i=1}^{N} w_{i t} z_{i, t+1} .
$$

The probability distribution function of $\ell_{N, t+1}$ can now be derived both conditional on an information set available at time $t, \mathcal{I}_{t}$, or unconditionally. The two types of distributions coincide when the factors, $\mathbf{f}_{t+1}$, are assumed to be serially independent, a case often maintained in the literature. In this paper we consider a dynamic factor model and allow the factors to be serially correlated. In particular, we shall assume that $\mathbf{f}_{t+1}$ follows a covariance stationary process, and $\mathcal{I}_{t}$ contains at least $\mathbf{f}_{t}$ and its lagged values, or their determinants (proxies) when they are unobserved. A simple example of a dynamic factor model is the Gaussian vector autoregressive specification

$$
\mathbf{f}_{t+1}=\boldsymbol{\Lambda} \mathbf{f}_{t}+\boldsymbol{\eta}_{t+1}, \boldsymbol{\eta}_{t+1} \mid \mathcal{I}_{t} \sim i i d N\left(\mathbf{0}, \boldsymbol{\Omega}_{\eta \eta}\right)
$$

where $\mathcal{I}_{t}$ is the public information known at time $t$, and $\boldsymbol{\Lambda}$ is an $m \times m$ matrix of fixed coefficients with all its eigenvalues inside the unit circle such that

$$
\operatorname{Var}\left(\mathbf{f}_{t+1} \mid \mathcal{I}_{t}\right)=\sum_{s=0}^{\infty} \boldsymbol{\Lambda}^{s} \boldsymbol{\Omega}_{\eta \eta} \boldsymbol{\Lambda}^{\prime s}=\mathbf{I}_{m}
$$

Along with much of the literature on credit risk, the focus of our analysis will be on the limit distribution of $\ell_{N, t+1} \mid \mathcal{I}_{t}$, as $N \rightarrow \infty$. The limit properties of this conditional loss distribution establishes the degree to which diversification of the credit portfolio is possible. ${ }^{16}$ Not surprisingly, the limit distribution of $\ell_{N, t+1}$ depends on the nature of the return process $\left\{r_{i, t+1}\right\}$ and the extent to which the returns are cross-sectionally correlated. Our discussion shall be in terms of the variance of the loss distribution, though occasionally we refer to the standard deviation or loss volatility, also known as unexpected loss (UL).

\subsection{Credit Risk under Firm Homogeneity}

Vasicek (1987) was among the first to consider the limit distribution of $\ell_{N, t+1}$ using asset return equations with a factor structure. However, he focused on the perfectly homogeneous case with the same factor loadings, $\gamma_{i}=\gamma$, the same default thresholds, $\lambda_{i, t+1}=\lambda$, the same firm-specific volatilities, $\sigma_{i}=\sigma$, and zero unconditional returns, $\mu_{i}=0$, for all $i$ and $t$. As noted earlier a

\footnotetext{
${ }^{16}$ The concept of "diversity" of financial markets has been recently discussed by Fernholz, Karatzas and Kardaras (2003), who provide a formal analysis in the context of the standard geometric Brownian motion model of asset returns.
} 
multifactor model with homogeneous factor loadings is equivalent to a single factor model. Under Vasicek's homogeneity assumptions we have

$$
r_{i, t+1}=\gamma f_{t+1}+\sigma \varepsilon_{i, t+1}
$$

where the single factor $f_{t+1}$ is also assumed to be serially independent. In this model the pair-wise asset return correlations, $\rho_{i j}$, is identical for all obligor pairs in the portfolio and is given by

$$
\rho_{i j}=\rho=\frac{\gamma^{2}}{\sigma^{2}+\gamma^{2}}
$$

Furthermore, since default depends on the sign of $\lambda-r_{i, t+1}=\lambda-\left(\gamma f_{t+1}+\sigma \varepsilon_{i, t+1}\right)$, and not its magnitude, without loss of generality the normalization, $\sigma^{2}+\gamma^{2}=1$ is often used in the literature, thus yielding $\gamma= \pm \sqrt{\rho}$. The remaining parameter, $\lambda$, is then calibrated to a pre-specified default probability, $\pi$, assuming a joint Gaussian distribution for $f_{t+1}$ and $\varepsilon_{i, t+1}$ :

$$
\left(\begin{array}{c}
\varepsilon_{i, t+1} \\
f_{t+1}
\end{array}\right) \mid \mathcal{I}_{t} \sim \operatorname{iidN}\left(\mathbf{0}, \mathbf{I}_{2}\right)
$$

Under the above assumptions it is easily seen that

$$
\pi=E\left(\ell_{N, t+1}\right)=\sum_{i=1}^{N} w_{i t} E\left(z_{i, t+1}\right)=E\left(z_{i, t+1}\right)=\operatorname{Pr}\left(r_{i, t+1} \leq \lambda\right)=\Phi(\lambda) .
$$

Vasicek's model, therefore, takes the following simple form

$$
r_{i, t+1}=\sqrt{\rho} f_{t+1}+\sqrt{1-\rho} \varepsilon_{i, t+1},
$$

with the default threshold given by

$$
\lambda=\Phi^{-1}(\pi),
$$

so that the distance to default and default thresholds are the same, and $\lambda$ can be easily estimated from historical default frequency of the portfolio. When default thresholds are allowed to vary across firms, identification issues arise which are discussed in Section 6. In Vasicek's model the pair-wise correlation of firm defaults is given by (see (12) and (17))

$$
\rho^{*}(\pi, \rho)=\frac{\Phi_{2}\left[\Phi^{-1}(\pi), \Phi^{-1}(\pi), \rho\right]-\pi^{2}}{\pi(1-\pi)} .
$$

For example, for the typical parameter values of $\pi=0.01$, and $\rho=0.30$, we have $\rho^{*}=0.05$. In Figure 1, the top left chart labeled "Gaussian" (we shall return to the other charts in this figure in Section 4.4 below) provides plots of $\rho^{*}(\rho, \pi)$ against $\rho$, for a few selected values of $\pi$. It is clear that the default correlation, $\rho^{*}$, is related non-linearly to $\rho$, and tends to be considerably lower than $\rho$. Also there is a clear tendency for the $\left(\rho^{*}, \rho\right)$ relationship to shift downwards as $\pi$ is reduced. For 
very small values of $\pi$, sizable default correlations are predicted only for very high values of return correlations. ${ }^{17}$

\section{[Insert Figure 1 about here]}

\subsection{Limits to Diversification - Vasicek's Model}

Since the underlying returns are correlated, there is a non-zero lower bound to the unconditional loss variance, $\operatorname{Var}\left(\ell_{N, t+1}\right)$, and full diversification will not be possible. Under the Vasicek model

$$
\operatorname{Var}\left(\ell_{N, t+1} \mid \mathcal{I}_{t}\right)=\pi(1-\pi)\left(\sum_{j=1}^{N} w_{j t}^{2}\right)+\pi(1-\pi) \rho^{*}\left(\sum_{j \neq j^{\prime}}^{N} w_{j t} w_{j^{\prime} t}\right),
$$

where $\pi=E\left(z_{j, t+1}\right)$ and $\rho^{*}$ is defined by $(27)$. Since, $\sum_{j=1}^{N} w_{j}=1$, it is easily seen that

$$
\sum_{j=1}^{N} w_{j t}^{2}+\sum_{j \neq j^{\prime}}^{N} w_{j t} w_{j^{\prime} t}=1
$$

so that

$$
\operatorname{Var}\left(\ell_{N, t+1} \mid \mathcal{I}_{t}\right)=\pi(1-\pi)\left\{\rho^{*}+\left(1-\rho^{*}\right) \sum_{j=1}^{N} w_{j t}^{2}\right\} .
$$

Under the granularity condition, (18), for $N$ sufficiently large the second term in brackets becomes negligible. Hence, in the limit

$$
\lim _{N \rightarrow \infty} \operatorname{Var}\left(\ell_{N, t+1} \mid \mathcal{I}_{t}\right)=\pi(1-\pi) \rho^{*} .
$$

The larger the default correlation, $\rho^{*}$, the larger will be the portfolio loss variance. For a finite value of $N$, loss variance is minimized by adopting an equal weighted portfolio, with $w_{j t}=1 / N$. For sufficiently large $N$, only the granularity condition (18) matters, and nothing can be gained by further optimization with respect to the weights, $w_{j t}$.

\subsection{Vasicek's Limit Distribution}

The loss distribution for the perfectly homogeneous model is derived in Vasicek $(1991,2002)$ and Gordy (2000). Denoting the fraction of the portfolio lost to defaults by $x$, the following limiting density is obtained (as $N \rightarrow \infty$ ):

$$
f_{\ell}\left(x \mid \mathcal{I}_{t}\right)=\sqrt{\frac{1-\rho}{\rho}}\left\{\frac{\phi\left[\frac{\sqrt{1-\rho} \Phi^{-1}(x)-\Phi^{-1}(\pi)}{\sqrt{\rho}}\right]}{\phi\left[\Phi^{-1}(x)\right]}\right\}, \text { for } 0<x \leq 1, \rho \neq 0,
$$

\footnotetext{
${ }^{17}$ Determinants of $\rho^{*}$ in the case where the errors have Student- $t$ distribution with the same degree of freedom is discussed below. In particular, see (32).
} 
where $\phi(\cdot)$ is the density function of a standard normal. The associated cumulative loss distribution function is

$$
F_{\ell}\left(x \mid \mathcal{I}_{t}\right)=\Phi\left[\frac{\sqrt{1-\rho} \Phi^{-1}(x)-\Phi^{-1}(\pi)}{\sqrt{\rho}}\right] .
$$

As can be seen, Vasicek's credit loss limit distribution is fully determined by two parameters, namely the default probability, $\pi$, and the pair-wise return correlation coefficient, $\rho$. The former fixes the expected loss of the portfolio, while the latter controls the shape of the loss distribution. In effect one parameter, $\rho$, controls all aspects relating to the shape of the loss distribution: its volatility, skewness and kurtosis. It would not be possible to calibrate two Vasicek loss distributions with the same expected and unexpected losses, but with different degrees of fat-tailedness, for example.

In Appendix B.1 we generalize the portfolio loss density under firm homogeneity to the case where $f_{t+1}$ and $\varepsilon_{i, t+1}$ may have non-Gaussian distributions. We show that Vasicek's distribution is just a special case. As an illustration of this general class of distributions, we derive the loss density for the case where idiosyncratic shocks are Gaussian but the common factor is Student $t$ distributed with $v$ degrees of freedom.

\subsection{Default Correlations of Vasicek's Model under Non-Gaussian Distributions}

It is well known that asset return distributions are fat-tailed and its neglect might result in under estimation of default correlations. In the context of Vasicek's model the importance of this issue can be investigated by considering the Student $t$ distribution for the innovations $\left(\varepsilon_{i, t+1}\right.$ and/or $\left.f_{t+1}\right)$ with low degrees of freedom, $t_{v}$, where $v>2$ denotes the degrees of freedom of the distribution. When $\varepsilon_{i, t+1}$ is Gaussian but $f_{t+1} \sim i i d t_{v}$, the computation of the default correlation coefficient, $\rho^{*}$, is straightforward and can be carried out using (16) with $f_{t+1}$ generated as draws from iid $t_{v}$.

However, the derivations are more complicated when $\varepsilon_{i, t+1}$ is $t$ distributed. In this case we must assume that $\varepsilon_{i, t+1}$ and $f_{t+1}$ are both $t$ distributed with the same degrees of freedom, otherwise $r_{i, t+1}$, given by (25), will have a non-standard distribution and the threshold parameter, $\lambda$, can not be derived analytically in terms of $\pi$. But when $\varepsilon_{i, t+1}$ and $f_{t+1}$ are both $t$ distributed with the same degrees of freedom, $v$, then $r_{i, t+1}$ will also be $t$ distributed with $v$ degrees of freedom and we have

$$
\pi=\operatorname{Pr}\left(r_{i, t+1} \leq \lambda\right)=T_{v}(\lambda)
$$

where $T_{v}(\cdot)$ denotes the cumulative distribution function of $t_{v}$, and hence, $\lambda=T_{v}^{-1}(\pi)$. Also

$$
\begin{aligned}
E\left(z_{i, t+1} \mid f_{t+1}\right) & =E\left[I\left(\lambda-\sqrt{\rho} f_{t+1}-\sqrt{1-\rho} \varepsilon_{i, t+1}\right) \mid f_{t+1}\right] \\
& =T_{v}\left(\frac{\lambda}{\sqrt{1-\rho}}-\sqrt{\frac{\rho}{1-\rho}} f_{t+1}\right) .
\end{aligned}
$$

Using this result in (15) and then in (12) now yields

$$
\rho^{*}(\pi, \rho, v)=\frac{E_{f}\left\{\left[T_{v}\left(\frac{T_{v}^{-1}(\pi)}{\sqrt{1-\rho}}-\sqrt{\frac{\rho}{1-\rho}} f_{t+1}\right)\right]^{2}\right\}-\pi^{2}}{\pi(1-\pi)},
$$


which is comparable to (27) obtained for Gaussian innovations. Expectations here are taken with respect to the distribution of $f_{t+1}$ assumed to be distributed as $t_{v}$.

Figure 1 contains simulated plots of $\rho^{*}(\rho, \pi, v)$ against $\rho$, for a few selected values of $\pi$ and for three values of $v: 10,5$ and 3 . As the innovations become increasingly fat-tailed, i.e. as $v$ declines, the curve becomes steeper meaning that default correlation $\rho^{*}$ increases more dramatically as return correlation, $\rho$, goes up. Moreover, differences in the default probability, $\pi$, matter less as the lines collapse on top of one another. Note the Gaussian case in the upper left represents $v=\infty$. Taken together it is clear that as innovations become more fat-tailed, the return correlation becomes the more important determinant of credit risk compared to the average default probability $\pi$, and they can potentially generate extremely large tail losses. For example, using (29) and (27), the unexpected loss of a Gaussian portfolio with $\pi=0.01, \rho=0.3$ is 0.021 , while the unexpected loss of the same portfolio but with $t_{3}$ or $t_{5}$ distributed shocks are 0.038 and 0.027 , respectively. The unexpected loss with $t_{10}$ distributed shocks is essentially indistinguishable from the UL in the double-Gausian case. ${ }^{18}$

\subsection{Credit Risk with Firm Heterogeneity}

Building on Vasicek's work we now consider models that allow for firm heterogeneity across a number of relevant parameters. In this section we provide some analytical derivations and show how the theoretical work of Vasicek's can be generalized. An empirical evaluation of the importance of allowing for firm heterogeneity in credit risk analysis is discussed in Section 7.

Under the heterogeneous multifactor return process (8), the portfolio loss, $\ell_{N, t+1}$, can be written as

$$
\ell_{N, t+1}=\sum_{i=1}^{N} w_{i t} I\left(a_{i, t+1}-\boldsymbol{\delta}_{i}^{\prime} \mathbf{f}_{t+1}-\varepsilon_{i, t+1}\right),
$$

where, as before $\boldsymbol{\delta}_{i}=\gamma_{i} / \sigma_{i}$ are the standardized factor loadings, and $a_{i, t+1}=\left(\lambda_{i, t+1}-\mu_{i}\right) / \sigma_{i}$. In addition to allowing for parameter heterogeneity, we also relax the assumption that the conditional on $\mathcal{I}_{t}$ the common factors, $\mathbf{f}_{t+1}$, and the idiosyncratic shocks, $\varepsilon_{i, t+1}$, are normally distributed with zero means. Accordingly we assume that

$$
\begin{array}{c|l}
\varepsilon_{i, t+1} & \mid \mathcal{I}_{t} \sim \text { iid }(0,1), \text { for all } i \text { and } t \\
\mathbf{f}_{t+1} & \mid \mathcal{I}_{t} \sim \text { iid }\left(\boldsymbol{\mu}_{f t}, \mathbf{I}_{m}\right), \text { for all } t,
\end{array}
$$

where under the dynamic factor model $(21), \boldsymbol{\mu}_{f t}=\Lambda \mathbf{f}_{t}$. Allowing $\boldsymbol{\mu}_{f t}$ to be time-varying enables us to explicitly consider the possible effects of business cycle variations on the loss distribution. In the credit risk literature $\boldsymbol{\mu}_{f t}$ is usually set to zero. ${ }^{19}$ For future use we shall denote the $\mathcal{I}_{t}$-conditional

\footnotetext{
${ }^{18}$ This latter result is obtained using (29) and (32),

${ }^{19}$ With the possible exception of Wilson $(1997 \mathrm{a}, \mathrm{b})$.
} 
probability density and the cumulative distribution functions of $\varepsilon_{i, t+1}$ and $\mathbf{f}_{t+1}$, by $f_{\varepsilon}(\cdot)$ and $F_{\varepsilon}(\cdot)$, and $f_{\mathbf{f}}(\cdot)$ and $F_{\mathbf{f}}(\cdot)$, respectively.

To deal with parameter heterogeneity across firms we abstract from time variations in the default thresholds (namely set $a_{i, t+1}=a_{i}$ ) and adopt the following random coefficient model

$$
\boldsymbol{\theta}_{i}=\boldsymbol{\theta}+\mathbf{v}_{i}, \quad \mathbf{v}_{i} \backsim i i d\left(\mathbf{0}, \Omega_{v v}\right), \text { for } i=1,2, \ldots, N,
$$

where

$$
\boldsymbol{\theta}_{i}=\left(a_{i}, \boldsymbol{\delta}_{i}^{\prime}\right)^{\prime}, \boldsymbol{\theta}=\left(a, \boldsymbol{\delta}^{\prime}\right)^{\prime}, \mathbf{v}_{i}=\left(v_{i a}, \mathbf{v}_{i \delta}^{\prime}\right)^{\prime}
$$

and

$$
\boldsymbol{\Omega}_{v v}=\left(\begin{array}{cc}
\omega_{a a} & \omega_{a \delta} \\
\omega_{\delta a} & \boldsymbol{\Omega}_{\delta \delta}
\end{array}\right),
$$

is a positive semi-definite symmetric matrix, and $\mathbf{v}_{i}$ 's are distributed independently of $\left(\varepsilon_{j, t+1}, \mathbf{f}_{t+1}\right)$ for all $i, j$ and $t$. Allowing for such parameter heterogeneity may be desirable when firms have different sensitivities to the systematic risk factors $\mathbf{f}_{t+1}$, and those sensitivities or factor loadings are known only up to their distributional properties described in (34). A practical example might be assessing the credit risk for a portfolio of borrowers which are privately held, i.e. not publicly traded. This is typically the case for much of middle market and most of small business lending. For such firms it would be very difficult to obtain individual estimates of $\boldsymbol{\theta}_{i}$, and an average estimate based on $\boldsymbol{\theta}$ may need to be used.

\subsection{Limits to Unexpected Loss under Parameter Heterogeneity}

The extent to which credit losses are diversifiable can be investigated using a number of different measures. For reasons of analytical tractability here we focus on loss variance, $\operatorname{Var}\left(\ell_{N, t+1} \mid \mathcal{I}_{t}\right)$, or its square root, unexpected loss, and note that in general

$$
\operatorname{Var}\left(\ell_{N, t+1} \mid \mathcal{I}_{t}\right)=E_{f}\left[\operatorname{Var}\left(\ell_{N, t+1} \mid \mathbf{f}_{t+1}, \mathcal{I}_{t}\right)\right]+\operatorname{Var}_{f}\left[E\left(\ell_{N, t+1} \mid \mathbf{f}_{t+1}, \mathcal{I}_{t}\right)\right]
$$

Because of the dependence of the default indicators, $z_{i, t+1}$, across $i$, through the common factors $\mathbf{f}_{t+1}$, unexpected loss remains even with a portfolio of infinitely many exposures. The problem of correlated defaults can be dealt with by first conditioning the analysis on the source of crossdependence (namely $\mathbf{f}_{t+1}$ ) and noting that conditional on $\mathbf{f}_{t+1}$ the default indicators, $z_{i, t+1}=$ $I\left(a_{i}-\boldsymbol{\delta}_{i}^{\prime} \mathbf{f}_{t+1}-\varepsilon_{i, t+1}\right), i=1,2, \ldots, N$, are independently distributed.

The conditional variance of $z_{i, t+1}$ is bounded since

$$
\operatorname{Var}\left(z_{i, t+1} \mid \mathbf{f}_{t+1}, \mathcal{I}_{t}\right)=E\left(z_{i, t+1} \mid \mathbf{f}_{t+1}, \mathcal{I}_{t}\right)-\left[E\left(z_{i, t+1} \mid \mathbf{f}_{t+1}, \mathcal{I}_{t}\right)\right]^{2} \leq \frac{1}{4}
$$

Then by the conditional independence of the $z_{i, t+1}$ we have 


$$
\operatorname{Var}\left(\ell_{N, t+1} \mid \mathbf{f}_{t+1}, \mathcal{I}_{t}\right)=\sum_{i=1}^{N} w_{i t}^{2} \operatorname{Var}\left(z_{i, t+1} \mid \mathbf{f}_{t+1}, \mathcal{I}_{t}\right) \leq \frac{1}{4}\left(\sum_{i=1}^{N} w_{i t}^{2}\right) .
$$

Hence, under (18)

$$
E\left[\operatorname{Var}\left(\ell_{N, t+1} \mid \mathbf{f}_{t+1}, \mathcal{I}_{t}\right)\right] \leq \frac{1}{4}\left(\sum_{i=1}^{N} w_{i t}^{2}\right) \rightarrow 0, \text { as } N \rightarrow \infty,
$$

and in the limit the loss variance, $\operatorname{Var}\left(\ell_{N, t+1} \mid \mathcal{I}_{t}\right)$, is dominated by the second term in (37). Namely, we have

$$
\lim _{N \rightarrow \infty} \operatorname{Var}\left(\ell_{N, t+1} \mid \mathcal{I}_{t}\right)=\lim _{N \rightarrow \infty}\left\{\operatorname{Var}\left[E\left(\ell_{N, t+1} \mid \mathbf{f}_{t+1}, \mathcal{I}_{t}\right)\right]\right\}
$$

which is similar to Proposition 2 in Gordy (2003). This result clearly shows that when the portfolio weights satisfy the granularity condition, (18), the limit behavior of the unexpected loss does not depend on the weights $w_{i t}$. Furthermore, this result holds irrespective of whether $a_{i}$ and $\boldsymbol{\delta}_{i}$ are homogeneous, or vary across $i$.

Under the random coefficient model, (34), asymptotic loss variance, given by (41), can be obtained by integrating out the heterogeneous effects of $a_{i}$ and $\boldsymbol{\delta}_{i}$. First note that $\ell_{N, t+1}=$ $\sum_{i=1}^{N} w_{i t} I\left(a_{i}-\boldsymbol{\delta}_{i}^{\prime} \mathbf{f}_{t+1}-\varepsilon_{i, t+1}\right)$, which under (34) can be written as

$$
\ell_{N, t+1}=\sum_{i=1}^{N} w_{i t} I\left(a-\boldsymbol{\delta}^{\prime} \mathbf{f}_{t+1}-\zeta_{i, t+1}\right)
$$

where

$$
\zeta_{i, t+1}=\varepsilon_{i, t+1}-\mathbf{v}_{i}^{\prime} \mathbf{g}_{t+1}
$$

and $\mathbf{g}_{t+1}=\left(1,-\mathbf{f}_{t+1}^{\prime}\right)^{\prime}$. Conditional on $\mathbf{f}_{t+1}, \zeta_{i, t+1}$ is distributed independently across $i$ with zero mean and the variance

$$
\omega_{t+1}^{2}=1+\mathbf{g}_{t+1}^{\prime} \Omega_{v v} \mathbf{g}_{t+1}
$$

where $\mathbf{g}_{t+1}^{\prime} \Omega_{v v} \mathbf{g}_{t+1}$ is the variance contribution arising from the random coefficients model (i.e. due to parameter heterogeneity). The expected loss conditional on $\mathbf{f}_{t+1}$ is given by

$$
\begin{aligned}
E\left(\ell_{N, t+1} \mid \mathbf{f}_{t+1}, \mathcal{I}_{t}\right) & =\sum_{i=1}^{N} w_{i t} \operatorname{Pr}\left(\zeta_{i, t+1} \leq a-\boldsymbol{\delta}^{\prime} \mathbf{f}_{t+1} \mid \mathbf{f}_{t+1}, \mathcal{I}_{t}\right) \\
& =\sum_{i=1}^{N} w_{i t} F_{\varkappa}\left(\frac{\boldsymbol{\theta}^{\prime} \mathbf{g}_{t+1}}{\omega_{t+1}}\right),
\end{aligned}
$$

and since $\sum_{i=1}^{N} w_{i t}=1$, then

$$
E\left(\ell_{N, t+1} \mid \mathbf{f}_{t+1}, \mathcal{I}_{t}\right)=F_{\varkappa}\left(\frac{\boldsymbol{\theta}^{\prime} \mathbf{g}_{t+1}}{\omega_{t+1}}\right)
$$


where $F_{\varkappa}(\cdot)$ is the cumulative distribution function of the standardized composite innovations

$$
\varkappa_{i, t+1}=\frac{\zeta_{i, t+1}}{\omega_{t+1}} \mid \mathbf{f}_{t+1}, \mathcal{I}_{t} \sim \operatorname{iid}(0,1) .
$$

Therefore, using (41), we have ${ }^{20}$

$$
\lim _{N \rightarrow \infty} \operatorname{Var}\left(\ell_{N, t+1} \mid \mathcal{I}_{t}\right)=\operatorname{Var}\left[F_{\varkappa}\left(\frac{\boldsymbol{\theta}^{\prime} \mathbf{g}_{t+1}}{\omega_{t+1}}\right) \mid \mathcal{I}_{t}\right],
$$

which does not depend on the exposure weights, $w_{i t}$. This result represents a generalization of the limit variance obtained for the homogeneous case, given above by (29).

As in the homogeneous case, it is also clear that the limit of $\operatorname{Var}\left(\ell_{N, t+1} \mid \mathcal{I}_{t}\right)$ as $N \rightarrow \infty$ vanishes if and only if $\mathbf{f}_{t+1}$ conditional on $\mathcal{I}_{t}$ is non-stochastic. Restated, allowing the portfolio to grow without bound, i.e. $N \rightarrow \infty$, eliminates idiosyncratic but not systematic risk. In general, when the returns are cross-sectionally correlated, $\ell_{N, t+1}$ converges to a random variable with a non-degenerate probability distribution.

The implication for credit risk management is clear: changing the exposure weights that satisfy (18) will have no risk diversification impact so long as all firms in the portfolio have the same risk factor loading distribution. To achieve systematic diversification one needs different firm types, e.g. along industry or country lines, and we treat this in Section 5 below.

\subsection{Implications of Parameter Heterogeneity for the Loss Distribution}

Parameter heterogeneity can significantly affect the shape of the loss distribution as well as expected and unexpected losses. An analysis of the effects of heterogeneity on loss distribution in the general case, however, is analytically complicated and is best carried out via stochastic simulations, an approach that we consider in Section 7 below. But useful insights can be gained by limiting the analysis to the effects of heterogeneity of the mean returns and/or default thresholds across firms, assuming the factor loadings and the error variances are the same across firms. ${ }^{21}$ This amounts to a single factor model with $\gamma_{i}=\gamma$ and $\sigma_{i}=\sigma$, and using (33) we have

$$
\ell_{N, t+1}=\sum_{i=1}^{N} w_{i t} I\left(a_{i}-\delta f_{t+1}-\varepsilon_{i, t+1}\right),
$$

where $\delta=\gamma / \sigma$, and $a_{i}=\left(\lambda_{i}-\mu_{i}\right) / \sigma$. This set-up is sufficiently general to allow for possible heterogeneity in the mean returns, $\mu_{i}$, and/or default thresholds, $\lambda_{i}$. Suppose that $a_{i}$ follows the random coefficient model

$$
a_{i}=a+v_{i}, \quad v_{i} \sim \text { iid } N\left(0, \sigma_{v}^{2}\right) .
$$

\footnotetext{
${ }^{20}$ Numerical values of $\lim _{N \rightarrow \infty} \operatorname{Var}\left(\ell_{N, t+1} \mid \mathcal{I}_{t}\right)$ can be obtained by stochastic simulations, taking independent draws from any given distribution of $\varkappa_{i, t+1}$.

${ }^{21}$ Further details for the fully heterogeneous case can be found in Appendix B.2.
} 
It is then easily seen that

$$
E\left(\ell_{N, t+1}\right)=\pi=\sum_{i=1}^{N} w_{i t} \operatorname{Pr}\left(\delta f_{t+1}+\varepsilon_{i, t+1}-v_{i} \leq a\right)=\Phi\left(\frac{a}{\sqrt{1+\delta^{2}+\sigma_{v}^{2}}}\right)
$$

and

$$
\lim _{N \rightarrow \infty}\left[\operatorname{Var}\left(\ell_{N, t+1}\right) \mid \mathcal{I}_{t}\right]=\operatorname{Var}_{f}\left[\Phi\left(\frac{a-\delta f_{t+1}}{\sqrt{1+\sigma_{v}^{2}}}\right) \mid \mathcal{I}_{t}\right] .
$$

These results clearly show that both expected and unexpected losses are affected by mean return/threshold heterogeneity.

In this relatively simple example the degree of heterogeneity is unambiguously measured by the size of $\sigma_{v}^{2}$, and it is easily seen that,

$$
\frac{\partial \pi}{\partial \sigma_{v}^{2}}=\phi\left(\frac{a}{\sqrt{1+\delta^{2}+\sigma_{v}^{2}}}\right) \frac{-a / 2}{\left(1+\delta^{2}+\sigma_{v}^{2}\right)^{3 / 2}}
$$

which is positive since in practice one would expect $a<0$. Notice that the distance to default is

$$
\frac{a}{\sqrt{1+\delta^{2}+\sigma_{v}^{2}}}=\Phi^{-1}(\pi)
$$

and for values of $\pi$ relevant in credit risk management, $\Phi^{-1}(\pi)<0$. Therefore, for typical values of $\pi$, the effect of heterogeneity would be to increase expected losses. The dependence of $\pi$ on $\sigma_{v}^{2}$ is monotonic, and the higher the degree of heterogeneity the larger will be $\pi$.

To examine the effect of heterogeneity on unexpected losses, we first control for the effect of changes in $\sigma_{v}^{2}$ on expected losses by setting $a=\sqrt{1+\delta^{2}+\sigma_{v}^{2}} \Phi^{-1}(\pi)$. From (49) it is clear that this choice of $a$ ensures that $E\left(\ell_{N, t+1}\right)=\pi$, irrespective of the value of $\sigma_{v}^{2}$. Using (50) it now follows that

$$
\lim _{N \rightarrow \infty}\left[\operatorname{Var}\left(\ell_{N, t+1}\right) \mid \mathcal{I}_{t}\right]=\operatorname{Var}_{f}\left[\Phi\left(\Phi^{-1}(\pi) \sqrt{1+\kappa^{2}}-\kappa f_{t+1}\right) \mid \mathcal{I}_{t}\right] .
$$

where $\kappa=\delta / \sqrt{1+\sigma_{v}^{2}}$. Also, the pair-wise correlation coefficient, $\rho_{i j}$, in this case is given by

$$
\rho_{i j}=\rho=\frac{\delta^{2}}{1+\delta^{2}+\sigma_{v}^{2}}=\frac{\kappa^{2}}{1+\kappa^{2}}
$$

and as in the homogeneous case is the same across all $i$ and $j$. Hence, noting that $\kappa^{2}=\rho /(1-\rho)$, we have

$$
\lim _{N \rightarrow \infty}\left[\operatorname{Var}\left(\ell_{N, t+1}\right) \mid \mathcal{I}_{t}\right]=\operatorname{Var}_{f}\left[\Phi\left(\frac{\Phi^{-1}(\pi)}{\sqrt{1-\rho}}-\sqrt{\frac{\rho}{1-\rho}} f_{t+1}\right) \mid \mathcal{I}_{t}\right] .
$$

Therefore, under $E\left(\ell_{N, t+1}\right)=\pi$, in the limit as $N \rightarrow \infty$ the loss variance depends on the degree of parameter heterogeneity, $\sigma_{v}^{2}$, only through the return correlation coefficient, $\rho$. From (52) note that for a given value of $\delta$ (the standardized factor loading), $\rho$ is a decreasing function of $\sigma_{v}^{2}$. A rise in 
heterogeneity (or an increases in $\sigma_{v}^{2}$ ) reduces $\rho$, which in turn results in a reduction of unexpected losses. So, once expected losses are appropriately corrected to take account of the increased firstorder risk of dealing with a heterogeneous sample, that very heterogeneity widens the scope for diversification of the credit risk portfolio. Indeed as we shall see in Section 7.4, simulation reveals that once expected losses are controlled for, ignoring parameter heterogeneity results in significant overestimation of credit risk, especially in the tails.

\section{Possible Sectoral or Geographic Diversification}

The results obtained so far provides the limits to risk diversification through inclusion of additional firms with different idiosyncratic characteristics. For the homogeneous case there is a lower bound to the loss variance given by $\operatorname{Var}\left[F_{\varepsilon}\left(a-\delta f_{t+1}\right) \mid \mathcal{I}_{t}\right]$, and for the heterogeneous case by $\operatorname{Var}\left[F_{\varkappa}\left(\frac{a-\delta^{\prime} \mathbf{f}_{t+1}}{\omega_{t+1}}\right) \mid \mathcal{I}_{t}\right]$, where $\omega_{t+1}$ is the volatility of the composite innovation. In both cases as $N \rightarrow \infty$, unexpected losses do not depend on the exposure weights, $w_{i t}$. Furthermore, if the factors $\mathbf{f}_{t+1}$ are serially independent (as is often assumed in the finance literature), then the above bounds hold unconditionally, namely the lower bound to risk diversification is given by

$$
\operatorname{Var}\left(\ell_{N, t+1}\right)>\operatorname{Var}\left[F_{\varkappa}\left(\frac{a-\boldsymbol{\delta}^{\prime} \mathbf{f}_{t+1}}{\omega_{t+1}}\right)\right]=\operatorname{Var}\left[F_{\varkappa}\left(\frac{\boldsymbol{\theta}^{\prime} \mathbf{g}_{t+1}}{\omega_{t+1}}\right)\right] .
$$

Once idiosyncratic risk vanishes, there is no scope for further risk reduction so long as $N$ is sufficiently large and $w_{i t}$ satisfy the granularity conditions, (18).

There may, however, be important possibilities for further diversification if we could group the firms into different categories with the parameters of each category having different distributions. One might think of these categories as different industries, sectors, or countries, for instance, whose sensitivities to the systematic risk factors can be viewed as draws from different distributions. As a simple example suppose there are $N=N_{A}+N_{B}$ firms grouped into country $A$ (say Japan) and country $B$ (say U.S.) such that

$$
\begin{aligned}
& A: \quad r_{A i, t+1}=\mu_{A i}+\gamma_{A i}^{\prime} \mathbf{f}_{t+1}+\sigma_{A i} \varepsilon_{A i, t+1}, i=1,2, \ldots, N_{A}, \\
& B:
\end{aligned}
$$

where

$$
\begin{aligned}
& \mu_{A i}=\mu_{A}+v_{A \mu i}, \quad \mu_{B i}=\mu_{B}+v_{B \mu i} \\
& \gamma_{A i}=\gamma_{A}+\mathbf{v}_{A \gamma i}, \quad \gamma_{B i}=\gamma_{B}+\mathbf{v}_{B \gamma i}
\end{aligned}
$$

Thus, for example, fixed effects for Japanese firms $(A)$ are randomly distributed around a country mean, $\mu_{A}$, and the Japanese systematic factor loading is also randomly distributed around a country 
effect, $\gamma_{A}$. Suppose further that those errors $\left(v_{A \mu i}, \mathbf{v}_{A \gamma i}^{\prime}\right)^{\prime}$ and $\left(v_{B \mu i}, \mathbf{v}_{B \gamma i}^{\prime}\right)^{\prime}$ are independently distributed:

$$
\left(\begin{array}{c}
v_{A \mu i} \\
\mathbf{v}_{A \gamma i}
\end{array}\right) \sim i i d\left(\mathbf{0}, \boldsymbol{\Omega}_{v v}^{A}\right) \text {, and }\left(\begin{array}{c}
v_{B \mu i} \\
\mathbf{v}_{B \gamma i}
\end{array}\right) \sim i i d\left(\mathbf{0}, \boldsymbol{\Omega}_{v v}^{B}\right) .
$$

Therefore, cross-country or -sector dependence arises only through $\mathbf{f}_{t+1}$ and not through the parameter distributions themselves, although it is now possible that different factors could affect the firm returns in different countries or sectors.

Consider now the following credit portfolio composed of two separate portfolios each with weights $\varpi_{t}$ and $\left(1-\varpi_{t}\right)$ :

$$
\ell_{N, t+1}^{(A, B)}=\varpi_{t} \sum_{i=1}^{N_{A}} w_{i A} I\left(\lambda_{i A}-r_{i A, t+1}\right)+\left(1-\varpi_{t}\right) \sum_{i=1}^{N_{B}} w_{i B} I\left(\lambda_{i B}-r_{i B, t+1}\right),
$$

where

$$
\sum_{i=1}^{N_{A}} w_{i A}=\sum_{i=1}^{N_{B}} w_{i B}=1
$$

and

$$
\sum_{i=1}^{N_{A}} w_{i A}^{2} \rightarrow 0, \sum_{i=1}^{N_{B}} w_{i B}^{2} \rightarrow 0, \text { as } N_{A} \text { and } N_{A} \rightarrow \infty
$$

meaning the two sub-portfolios have a large number of relatively small exposures. We may compare the "joint" portfolio to the following "single-country" portfolios

$$
\ell_{N_{A}, t+1}^{(A)}=\sum_{i=1}^{N_{A}} w_{i A} I\left(\lambda_{i A}-r_{i A, t+1}\right), \text { and } \ell_{N_{B}, t+1}^{(B)}=\sum_{i=1}^{N_{B}} w_{i B} I\left(\lambda_{i B}-r_{i B, t+1}\right) .
$$

It is now easily seen that the limit of the unexpected losses associated with these portfolios as $N_{A}, N_{B} \rightarrow \infty$, are given by

$$
\begin{aligned}
\lim _{N_{A} \rightarrow \infty} \operatorname{Var}\left[\ell_{N_{A}, t+1}^{(A)} \mid \mathcal{I}_{t}\right] & =\operatorname{Var}\left[F_{\varkappa}\left(\frac{\boldsymbol{\theta}_{A}^{\prime} \mathbf{g}_{t+1}}{\omega_{A, t+1}}\right) \mid \mathcal{I}_{t}\right]=V_{t A}, \\
\lim _{N_{B} \rightarrow \infty} \operatorname{Var}\left[\ell_{N_{B}, t+1}^{(B)} \mid \mathcal{I}_{t}\right] & =\operatorname{Var}\left[F_{\varkappa}\left(\frac{\boldsymbol{\theta}_{B}^{\prime} \mathbf{g}_{t+1}}{\omega_{B, t+1}}\right) \mid \mathcal{I}_{t}\right]=V_{t B}, \\
\lim _{N_{A}, N_{B} \rightarrow \infty} \operatorname{Var}\left[\ell_{N, t+1}^{(A, B)} \mid \mathcal{I}_{t}\right] & =\varpi_{t}^{2} V_{t A}+\left(1-\varpi_{t}\right)^{2} V_{t B}+2 \varpi_{t}\left(1-\varpi_{t}\right) \operatorname{Cov}\left[\ell_{N, t+1}^{(A)}, \ell_{N, t+1}^{(B)}\right],
\end{aligned}
$$

where $\boldsymbol{\theta}_{A}=\left(a_{A}, \boldsymbol{\delta}_{A}^{\prime}\right)^{\prime}, \boldsymbol{\theta}_{B}=\left(a_{B}, \boldsymbol{\delta}_{B}^{\prime}\right)^{\prime}$, and $\omega_{s, t+1}^{2}=1+\mathbf{g}_{t+1}^{\prime} \Omega_{v v}^{s} \mathbf{g}_{t+1}$, for $s=A, B$. Note that both $N_{A}$ and $N_{B}$ individually need to be sufficiently large for idiosyncratic risk to vanish. 
Unexpected losses of the combined portfolio will be minimized by choosing ${ }^{22}$

$$
\varpi_{t}^{*}=\frac{V_{t B}-\operatorname{Cov}\left[\ell_{N, t+1}^{(A)}, \ell_{N, t+1}^{(B)}\right]}{V_{t A}+V_{t B}-2 \operatorname{Cov}\left[\ell_{N, t+1}^{(A)}, \ell_{N, t+1}^{(B)}\right]} .
$$

Not surprisingly it is optimal to place a larger weight on the portfolio with a smaller unexpected loss conditional on $\mathcal{I}_{t}$. Using $\varpi_{t}^{*}$ we have

$$
\lim _{N \rightarrow \infty} \operatorname{Var}\left[\ell_{N, t+1}^{(A, B)} \mid \mathcal{I}_{t}\right]=\frac{V_{t A} V_{t B}-\operatorname{Cov}^{2}\left[\ell_{N, t+1}^{(A)}, \ell_{N, t+1}^{(B)}\right]}{V_{t A}+V_{t B}-2 \operatorname{Cov}\left[\ell_{N, t+1}^{(A)}, \ell_{N, t+1}^{(B)}\right]},
$$

which is at least as small as both $V_{t A}$ or $V_{t B}$. Therefore, the joint sectorally or geographically diversified portfolio will almost always be less risky than both standalone portfolios $A$ or $B$.

\section{Specification and Identification of Default Thresholds}

The probability of default for the $i^{\text {th }}$ firm, given by equation (6) and repeated here for convenience,

$$
\pi_{i, t+h}=\Phi\left(\frac{\lambda_{i, t+h}-h \mu_{i}}{\sigma_{\xi_{i}} \sqrt{h}}\right),
$$

provides a functional relationship between a firm's equity returns (as characterized by $\mu_{i}$ and $\sigma_{\xi_{i}}$ ), its default threshold, $\lambda_{i, t+h}$, and the default probability, $\pi_{i, t+h}$. In the case of publicly traded companies, $\mu_{i}$ and $\sigma_{\xi_{i}}$ can be consistently estimated from market returns based on historical data using either rolling or expanding observation windows. In general, however, $\lambda_{i, t+h}$ and $\pi_{i, t+h}$ can not be directly observed. One possibility would be to use balance sheet and other accounting data to estimate $\lambda_{i, t+h}$. This approach is taken up by KMV, for example. But as argued in PSTW, the accounting information is likely to be noisy and might not be all that reliable due to information asymmetries and agency problems between managers, share-, and debtholders. ${ }^{23}$ Moreover, in a multi-country setting, the accounting based route presents additional challenges such as different accounting standards and bankruptcy rules that exist across countries. In addition to accounting data, other firm characteristics, such as leverage, firm age and perhaps size, and management quality could also be important in the determination of default thresholds that are quite difficult to observe. In view of these measurement problems, PSTW propose an alternative estimation

\footnotetext{
${ }^{22}$ This solution assumes that it is possible to take a short positition in sub-portfolio $A$ (e.g. by offering default protection on that portfolio). If we rule out the possibility of short positions, we must consider possible corner solutions. Specifically, suppose that $V_{t B} \leq V_{t A}$, then if $V_{t B}<\operatorname{Cov}\left[\ell_{N, t+1}^{(A)}, \ell_{N, t+1}^{(B)}\right]$, we have $\varpi_{t}^{*}=0$ and the smallest attainable variance for the combined portfolio is $V_{t B}$. Otherwise, if $\operatorname{Cov}\left[\ell_{N, t+1}^{(A)}, \ell_{N, t+1}^{(B)}\right] \leq V_{t A}$, we can use the above formula for $\varpi_{t}^{*}$.

${ }^{23}$ With this in mind, Duffie and Lando (2001) allow for the possibility of imperfect information about the firm's assets and default threshold in the context of a first-passage model.
} 
approach where firm-specific default thresholds are obtained using firm-specific credit ratings and historical default frequencies.

Suppose that at the end of period $t$ firm $i$ is assigned a credit rating which we denote by $\mathcal{R}_{t}$. Typically $\mathcal{R}_{t}$ may take on values such as 'Aaa', 'Aa', 'Baa',..., 'Caa' in Moody's terminology, or 'AAA', 'AA', 'BBB',..., 'CCC' in Standard \& Poor's (S\&P) and Fitch's terminology. Suppose also that over a period of length $h$, the observed default frequency of $\mathcal{R}$-rated firms is given by $\hat{\pi}_{\mathcal{R}, t+h}$. Therefore, under (3) and assuming that the number of $\mathcal{R}$-rated firms are sufficiently large, this default rate is just the weighted average probability of default of all $\mathcal{R}$-rated firms, namely

$$
\hat{\pi}_{\mathcal{R}, t+h}=\sum_{i \in \mathcal{R}_{t}} w_{i t} \Phi\left(\frac{\lambda_{i, t+h}-h \bar{\mu}_{i}}{\bar{\sigma}_{\xi_{i}} \sqrt{h}}\right),
$$

where $\bar{\mu}_{i}$ and $\bar{\sigma}_{\xi_{i}}$ are the unconditional estimates of $\mu_{i}$ and $\sigma_{\xi_{i}}$ obtained using observations on firm-specific returns up to the end of period $t$, and $w_{i t}$ is the weight of the $i^{t h}$ firm in the portfolio of $\mathcal{R}$-rated firms at the end of period $t$, with $\sum_{i \in \mathcal{R}_{t}} w_{i t}=1$. The number of $\mathcal{R}$-rated firms at the end of period $t$ will be denoted by $N_{t \mathcal{R}}$.

The consistency of the above estimating equation requires $w_{i t}$ to be pre-determined and nondominating. Clearly, other grouping of firms can also be entertained. For example, firms can be grouped by industry or geographical regions as well as by their credit ratings. It would also be possible to consider averaging over firms with particular rating histories. In considering these and many other "types" three important considerations ought to be born in mind. First, the types should be reasonably homogeneous from the stand-point of default. Second, the number of firms of the same type must be sufficiently large so that the estimating equation (56) holds. Third, there must be non-zero incidence of defaults across firms of the same type, namely $\hat{\pi}_{\mathcal{R}, t+h} \neq 0$. Within type homogeneity is required since equation (56) contains $N_{t \mathcal{R}}$ unknown threshold parameters, $\lambda_{i, t+h} i \in \mathcal{R}_{t}$. Their identification would require imposing homogeneity restrictions across the parameters, and/or finding new moment conditions that relate the default thresholds to the other characteristics of the empirical distribution of firm defaults. This identification problem is a direct consequence of allowing for heterogeneity in default thresholds. Recall that for the case of the homogeneous Vasicek model, the default threshold is easily identified; see (26).

In what follows we consider two alternative exact identification schemes:

1. Within type homogeneity of defaults thresholds, namely

$$
\lambda_{i, t+h}=\lambda_{\mathcal{R}, t+h}, \text { for all } i \in \mathcal{R}_{t} .
$$

2. Within type homogeneity of distance-to-default

$$
D D_{i, t+h}=\frac{\lambda_{i, t+h}-h \bar{\mu}_{i}}{\bar{\sigma}_{\xi_{i}} \sqrt{h}}=D D_{\mathcal{R}, t+h}, \text { for all } i \in \mathcal{R}_{t} .
$$


Under the first identification scheme, the common default threshold, $\lambda_{\mathcal{R}, t+h}$, can be obtained by solving the following non-linear equation in $\lambda_{\mathcal{R}, t+h}$ :

$$
\sum_{i \in \mathcal{R}_{t}} w_{i t} \Phi\left(\frac{\lambda_{\mathcal{R}, t+h}-h \bar{\mu}_{i}}{\bar{\sigma}_{\xi_{i}} \sqrt{h}}\right)-\hat{\pi}_{\mathcal{R}, t+h}=0,
$$

i.e. we solve for $\lambda_{\mathcal{R}, t+h}$ such that firms in the portfolio with rating $\mathcal{R}$ have on average the unconditional probability of default $\hat{\pi}_{\mathcal{R}, t+h}$. It is easily seen that this equation has a unique, finite solution so long as $\hat{\pi}_{\mathcal{R}, t+h} \neq 0$. Under the second identification scheme,

$$
\hat{\lambda}_{i, t+h}=D D_{\mathcal{R}, t+h} \bar{\sigma}_{\xi_{i}} \sqrt{h}+h \bar{\mu}_{i}, \text { for } i \in \mathcal{R}_{t},
$$

where

$$
D D_{\mathcal{R}, t+h}=\Phi^{-1}\left(\hat{\pi}_{\mathcal{R}, t+h}\right)
$$

and $\Phi^{-1}(\cdot)$ is the inverse of the cumulative distribution function of the standard normal. ${ }^{24}$ Once again the estimated default thresholds, $\hat{\lambda}_{i, t+h}$, will be finite so long as $\hat{\pi}_{\mathcal{R}, t+h} \neq\{0,1\}$. Condition (58) imposes the same unconditional probability of default for each $\mathcal{R}$-rated firm, whereas (57) simply imposes that this needs to hold on average across $\mathcal{R}$-rated firms in the portfolio.

Of the two, the assumption of the same distance-to-default seems more in line with the way credit ratings are established by the main rating companies. First, the idea that firms with similar distances-to-default have similar probabilities of default is central to structural models of default. For instance, KMV makes use of a one-to-one mapping from DDs to EDFs (expected default frequencies). Second, rating agencies attempt to group firms according to their (unconditional) probability of default (subject possibly to some adjustments for differences in their expected loss given defaults), and in a structural model this is equivalent to grouping firms according to distanceto-default. In our empirical analysis we shall focus on the threshold estimates given by (60), with a brief discussion of the sensitivity of the results to other identification choices for $\lambda_{i, h+t}$.

\section{An Empirical Application: Heterogeneity and Risk Diversifica- tion}

In this section we consider different types of heterogeneity across firms and illustrate their effects on the resulting loss distribution by simulating losses for credit portfolios comprised of public firms from the U.S. and Japan. We form these credit portfolios at the end of each year from 1997 to 2002 and then simulate portfolio losses for the following year. All of the simulation parameters are estimated recursively using 10-year (40-quarter) rolling windows. The simulations are out-of-sample in that the models, fitted over a ten-year sample, are used to simulate losses for the subsequent

\footnotetext{
${ }^{24}$ Note that $\Phi^{-1}\left(\pi_{i, t+h}\right)<0$ for $\pi_{i, t+h}<0.5$. In practice $\pi_{i, t+h}$ tends to be quite small.
} 
$11^{\text {th }}$ year. This recursive procedure allows us to explore possible time variation in the underlying parameters as well as the effects that such time variations might have on loss distributions.

\subsection{Data and Portfolio Construction}

The loss simulations require an estimate of the unconditional probability of default for each firm. These may be obtained at the level of the credit rating, $\mathcal{R}$, assigned to the firm by rating agencies such as Moody's, S\&P or Fitch. We estimate probabilities of default recursively for each grade using 10 -year rolling windows of all firm rating histories from S\&P. These probabilities are estimated using the time-homogeneous Markov or parametric duration estimator discussed in Lando and Skødeberg (2002) and Jafry and Schuermann (2004). We impose a minimum annual probability of default $(P D)$ of $0.001 \%$ or 0.1 basis points. Our estimated $P D$ s for both $\mathcal{A A A}$ and $\mathcal{A A}$ fall below this minimum for all six cohorts.

In order to be selected for inclusion in our portfolios, a firm needs a credit rating as well as 10 years of consecutive quarterly equity returns that match the rolling estimation window. In case both ratings are available the $\mathrm{S} \& \mathrm{P}$ rating is chosen. ${ }^{25}$ For the first sample or cohort (which ends in 1997) we have 211 Japanese firms and 628 U.S. firms, a portfolio of 839 firms in total. At the end of the following year the portfolio is rebalanced, retaining surviving firms and augmenting the portfolio with new firms that have a rating at the end of that year, i.e. 1998, and also have 40 consecutive quarters of returns. All returns are computed in U.S. dollars (USD). For Japanese firms this is done by subtracting the rate of change of yen/USD exchange rate from their yendenominated returns. ${ }^{26}$ Our analysis and conclusions are clearly conditional on the population of publicly traded firms with sufficiently long track records, and need not extend to firms that are not publicly traded or have relatively short histories.

To make the portfolio exposures representative of the rated universe in each country, we reweight the portfolio exposures (in USD) by rating in the following manner. Suppose that each obligor begins with $\$ 100$ of exposure. If $10 \%$ of all rated Japanese firms have a $\mathcal{B B}$ rating, but $15.6 \%$ of the Japanese firms in our portfolio are $\mathcal{B B}$-rated, then each of these firms will be given $\frac{10.0}{15.6} \times \$ 100=\$ 63$ of exposure. In the U.S. the difference in the ratings distribution across the two agencies is modest, but not so in Japan where Moody's rates more than twice as many firms as $\mathrm{S} \& \mathrm{P}$. To address this issue we take the average of the two agencies' ratings distributions by rating for each country. ${ }^{27}$

\footnotetext{
${ }^{25}$ The decision rule is driven by the use of S\&P ratings histories to compute the default probabilities $\pi_{\mathcal{R}}$.

${ }^{26}$ Our source of return data for U.S. firms is CRSP while for Japanese firms it is Datastream.

${ }^{27}$ The precise exposure allocation is as follows. Denote $F V_{i c}$ to be the (face value) exposure to firm $i$ in country $c$. The portfolio total nominal face value is $\$ 1 \mathrm{bn}$. Then

$$
F V_{i c}=\$ 1 b n \cdot w_{c} \cdot\left(\frac{1}{N_{c}}\right) \cdot \theta(\mathcal{R})_{c} \text { for } i \in \mathcal{R}
$$

where $w_{c}$ is the share of the total portfolio for country $c(75 \%$ for the U.S., $25 \%$ for Japan $), N_{c}$ is the number of
} 
The portfolio composition is adjusted annually, starting with 1998, to reflect defaults, upgrades and downgrades which may have occurred during the year. Since credit migration matrices even at annual frequencies are diagonally dominant, with average staying probabilities exceeding $90 \%$ for investment grades, annual portfolio rebalancing seems a reasonable compromise between accuracy and computational burden; the alternative would be quarterly rebalancing. We also update the ratings distribution each year to allow for compositional changes in the universe of rated firms. For example, at the end of $1997 \mathcal{B}$-rated firms made up only $1.54 \%$ of all rated Japanese firms, but by year-end 2002 this proportion had risen to $6.75 \%$. Below in Table 1 we show the average ratings distribution for each country for 1997 and 2002. It becomes clear that there has been a systematic deterioration in average credit quality over this period. In addition, estimated probabilities of default for non-investment grade ratings, and for $\mathcal{C C C}$ in particular, have risen noticeably over this period. As a result, the weighted average annual probability of default, $\hat{\pi}$, has increased from $1.23 \%$ for the year-end 1997 portfolio to $3.26 \%$ for the year-end 2002 portfolio.

\section{[Insert Table 1 about here.]}

Using two-digit SIC codes we group firms into seven broad sectors to ensure a sufficient number of firms per sector. The sectors and percentage of firms by sector by country at year-end 1997 are summarized below in Table 2 .

[Insert Table 2 about here.]

\subsection{Model Specifications}

To explore the role of geographic and industry or sectoral heterogeneity we introduce two new indices into the notation of the previous sections. Specifically, denote $r_{i j c, t+1}$ to be the return of firm $i$ in sector $j$ in country $c$ over the quarter $t$ to $t+1$, where $i=1, \ldots, I_{j c}, j=1, \ldots, I_{c}, c=1, \ldots, C$. The application will explore $C=2$ countries (Japan and U.S.) and $I_{c}=7$ sectors/industries in each country. Following the multi-factor return model given by (8), we employ the following return regressions adapted to our empirical applications:

$$
r_{i j c, t+1}=\alpha_{i j c}+\boldsymbol{\beta}_{i j c}^{\prime} \mathbf{f}_{t+1}+u_{i j c, t+1}
$$

where $\mathbf{f}_{t+1} \sim\left(\boldsymbol{\mu}_{f}, \boldsymbol{\Sigma}_{f}\right), \boldsymbol{\mu}_{f}$ is an $m \times 1$ vector of constants, and $\boldsymbol{\Sigma}_{f}$ is the covariance matrix of the common factors, also assumed fixed. In terms of the return parameters of (3) and (8), the expected return can be written as

$$
\mu_{i j c, t+1}=\alpha_{i j c}+\boldsymbol{\beta}_{i j c}^{\prime} \boldsymbol{\mu}_{f}
$$

firms in country $c, \theta(\mathcal{R})_{c}$ is the rating representation adjustment. Note that $\theta(\mathcal{R})_{c}$ will vary across time to reflect compositional changes in the rated universe of firms in county $c$. 
and the unexpected component as

$$
\xi_{i j c, t+1}=\boldsymbol{\beta}_{i j c}^{\prime}\left(\mathbf{f}_{t+1}-\boldsymbol{\mu}_{f}\right)+u_{i j c, t+1} .
$$

Note also that the total return variance is

$$
\sigma_{\xi i j c}^{2}=\boldsymbol{\beta}_{i j c}^{\prime} \Sigma_{f} \boldsymbol{\beta}_{i j c}+\sigma_{i j c}^{2}
$$

where $\sigma_{i j c}^{2}$ is the variance of the idiosyncratic component, $u_{i j c, t+1}$.

Following a standard approach in the finance literature, we model firm returns using an unobserved components or factor approach, either single or multiple, with increasing degrees of heterogeneity. ${ }^{28}$ One obvious source of heterogeneity is geography or country. As we have two countries, we estimate each model specification first by pooling the U.S. and Japanese firms (referred to as the "pooled model" specification) and then by estimating two separate models for each of the two countries (the "modeled separately" specification).

The empirical exercise involves a number of variations on the basic firm return equation given by (62) using market-cap weighted market returns for each country $\bar{r}_{c, t+1}$ as proxies for two of the possible $m$ common factors. Sector returns for a country $c, \bar{r}_{j c, t+1}, j=1, \ldots, I_{c}$, are computed in a similar fashion, namely using the market-cap weighted average of firm returns in that sector. ${ }^{29}$ The "global" market return index, $\bar{r}_{t+1}$, is made up of just the two countries U.S. and Japan and is simply the weighted sum of the two individual country returns,

$$
\bar{r}_{t+1}=w_{U S} \bar{r}_{U S, t+1}+\left(1-w_{U S}\right) \bar{r}_{J P, t+1},
$$

where $w_{U S}$ measures the relative size of the U.S. economy. We estimate $w_{U S}$ by taking the average U.S. share of PPP-denominated GDP over 1997-2002, and obtain $w_{U S}=0.75$. To obtain the global sector return $\bar{r}_{j, t+1}$ for a particular sector $j$ we proceed similarly to (66) and define

$$
\bar{r}_{j, t+1}=w_{U S} \bar{r}_{j, t+1, U S}+\left(1-w_{U S}\right) \bar{r}_{j, t+1, J P}
$$

The simplest model is the fully homogeneous return specification assumed by Vasicek:

$$
r_{i j c, t+1}=\alpha_{c}+\beta_{c} \bar{r}_{c, t+1}+u_{i j c, t+1},
$$

with $u_{i j c, t+1} \sim \operatorname{iidN}\left(0, \sigma_{c}^{2}\right)$. For the pooled model, $\sigma_{c}^{2}=\sigma^{2}, \alpha_{c}=\alpha, \beta_{c}=\beta$ and $\bar{r}_{c, t+1}=\bar{r}_{t+1}$ as in (66) for $c=U S$ and $J P$.

Next is the fixed effects specification where we allow $\alpha_{i j c}$ to vary across firms $i$ in each sector $j$ and country $c$ but holding the error variances fixed across all firms $\left(\sigma_{c}^{2}\right)$. The third model

\footnotetext{
${ }^{28}$ An application where the firm returns are linked to observable macroeconomic factors using a global VAR model is provided in PSTW.

${ }^{29}$ The weights for period $t+1$ are based on the average of the market capitalization (in USD) at end of periods $t$ and $t+1$.
} 
specification allows for full parameter heterogeneity where firm alphas, factor loadings and error variances are allowed to vary across firms. Here too we estimate two versions, where in the second we add an industry or sector factor so that each firm's returns is regressed on $\bar{r}_{c, t+1}$ as well as on $\bar{r}_{c j, t+1}$. To be clear, for the pooled model, $\bar{r}_{c, t+1}=\bar{r}_{t+1}$ as in (66), and $\bar{r}_{c j, t+1}=\bar{r}_{j, t+1}$ as in (67), for $c=U S$ and $J P$.

The fourth and final model specification is the principal components (PCA) model. See Appendix $\mathrm{C}$ for further detailed account of this specification. Using the procedure outlined in Bai and $\mathrm{Ng}$ (2002) we extract $\hat{m}$ relevant principal components which capture most of the in-sample variation in firm returns. In the application, the procedure resulted in two factors for the U.S., three for Japan and three for the pooled model (i.e. when firm returns from the U.S. and Japan are pooled). The procedure was conducted for the 1997 cohort of firms, using the prior ten years of quarterly data. For tractability the number of factors was kept fixed for the subsequent cohort of firms, though the actual factors were, of course, re-estimated. Table 3 summarizes all eight model specifications that we consider.

\section{[Insert Table 3 about here.]}

For simulation of loss distributions, in addition to the return equations, we also need to specify the determination of the default thresholds noted in the last column of Table 3. The first two models, I and II, do not make use of credit rating information at the firm level. The Vasicek model treats all firms identically at the country level (for the two-country pooled model, all firms are treated identically), and so imposing within type homogeneity of distance to default is identical to within type homogeneity of default thresholds. Model II uses within type homogeneity of default thresholds where firms are typed at the country level, or not at all for the pooled models. The default thresholds for the remaining models, labeled $\lambda_{i} / D D_{\mathcal{R}}$ in Table 3, use the identifying restriction (58), namely that the distance to default $D D$ is the same across all firms of a given rating. An

estimate of $\lambda_{i}$ is obtained using (60) where estimates of $\mu_{i}$ and $\sigma_{\xi_{i}}^{2}$ are obtained using (63) and (65), respectively.

We shall also consider simulation results using the alternative identification scheme for the default thresholds based on (57), which imposes the same threshold for all firms in a given rating. Further, to allow for direct comparisons, all models are calibrated to have the same expected loss within a given sample period.

\subsection{Return Regression Results}

The return regression parameters, estimated recursively using a 10-year rolling window, are summarized in Table 4. Note that these are all in-sample estimates. We focus our discussion on the average pair-wise correlation of returns and the average pair-wise correlation of residuals as they 
map naturally into our loss modeling framework. The average pair-wise correlation of residuals is of particular interest since it gives an indication of how close a particular model is to conditional independence.

\section{[Insert Table 4 about here.]}

Starting with the results in Panel A of Table 4, we note that the in-sample average pair-wise correlation of quarterly returns for the first ten years (1988-1997) is 0.1933 for the U.S. firms as compared to the much higher figure of 0.6011 for the Japanese firms. But the average pair-wise correlation for the pooled sample is very close to the U.S.-only sample at $0.1937 .^{30}$ The factor models generally do a good job of accounting for the cross-section correlation of returns, at least in-sample. Considering first the U.S. and Japan pooled results, the average pair-wise correlation of residuals for the whole portfolio is around 0.022 for the Vasicek, fixed effect and single factor CAPM models. Adding an industry factor reduces that residual correlation to 0.015, and the PCA model by construction leaves almost no cross-section residual correlation. In-sample goodness of fit across models as measured by $\bar{R}^{2}$ (not reported in the table) range from 0.135 for the Vasicek to 0.229 for the sector CAPM to 0.339 for the PCA model.

Staying with the pooled model, notice the high degree of residual correlation that remains for the Japanese firms, ranging from around $42 \%$ (fixed effect) to $39 \%$ (CAPM). The reason is simple: the "global" market weighted return, $\bar{r}_{t+1}$, is dominated by U.S. firms. The overall portfolio average is low since residuals from U.S. and Japanese firm regressions are relatively uncorrelated and in some cases even negatively correlated.

Estimating the models separately for each country helps, and this is seen clearly in the last three columns of Table 4, Panel A. While the overall average pair-wise correlation of residuals is quite similar at around $1.5 \%$ to $2 \%$, for Japanese firms it is reduced dramatically, from a range of $39 \%$ to $42 \%$ under the pooled specification to a range of $2 \%$ to $6 \%$ when estimated separately. Similarly for U.S. firms, the average pair-wise correlation is reduced from a range of $7 \%$ to $9.5 \%$ in the pooled approach to a range of $2 \%$ to $3.5 \%$ when estimated separately. Clearly geographic heterogeneity plays an important role.

The results reported in Table 4 also show the high degree of variability in the coefficient estimates that exists across firms. This is illustrated by Figure 2 where the empirical densities (smoothed histograms) of the firm betas based on the one factor or CAPM model (Model IV) are displayed separately for the two countries. The estimates of the Japanese betas are more tightly distributed around their mean than are U.S. betas. We see a similar pattern with the firm alphas. These

\footnotetext{
${ }^{30}$ For 1988-1997, the average pairwise correlation of USD-denominated returns for Japanese firms of 0.6011 is slightly higher than the average correlation of Yen-denominated returns of 0.5520 due to the common currency adjustment. However, local currency returns for Japanese firms in our sample are still noticeably more correlated than those for U.S. firms. This pattern holds for the later periods as well.
} 
results are line with our assumption in Section 5 that the parameters of the return equations across the two countries can be viewed as draws from two different distributions.

[Insert Figure 2 about here]

Panels $\mathrm{B}$ through $\mathrm{F}$ in Table 4 show the recursive estimation results using a 10-year rolling window for the next five ten-year periods. We note that average pair-wise cross-sectional correlations of firm returns remain at around 20\% through 1999 (though they show a steady decline for Japanese firms), but starting with the cohort of 1991-2000 (Panel D), the average correlation for the portfolio drops to 0.139. The sudden and substantial market reversals in the U.S. in March 2000 and the subsequent market declines probably play a strong role in explaining these results.

Turning now to the different models, the basic pattern across models remains unchanged as we move down the table (and thus forward in time). Figures 3a (U.S.) and 3b (Japan) show the empirical density plots of firm betas for three time periods: years ending 1997, 2000 and 2002. We notice for both countries that the distribution of estimated betas has been shifting subtly to the left. While the dispersion of U.S. betas has not changed much over the course of these rolling windows, the Japanese distribution appears to be widening. The (cross-sectional) firm heterogeneity we seek to explore here is thus exhibiting some time variation as well. ${ }^{31}$

[Insert Figures 3a and 3b about here]

\subsection{Impact of Heterogeneity on Credit Losses}

We simulate firm returns out-of-sample using (62), assuming that the systematic and idiosyncratic components are serially uncorrelated and independently distributed, thus imposing the conditional independence. $^{32}$ The loss distributions for the different model specifications are then simulated using appropriate default thresholds with LGD $=100 \%$. All the simulations are based on 200,000 replications.

\subsubsection{Comparison of Simulated and Asymptotic Results for the Vasicek Model}

We begin by comparing the simulated loss distributions for our finite-sized portfolio to the asymptotic portfolio results which are available for the Vasicek model. Of interest are loss volatility

\footnotetext{
${ }^{31}$ Throughout the analysis we have been assuming time invariant volatilities. While it is well known that high frequency (daily, weekly) firm returns exhibit volatility clustering, this effect tends to vanish as the data frequency declines due to temporal aggregation effects. Nonetheless, we conducted standard diagnostic tests for ARCH effects on all firm return regressions in the case of Model III(a) and calculated the percentage of firm-specific return regressions in which the ARCH effects are significant at the $5 \%$ level. For most periods the percentage of firms with significant ARCH effects fell between 5 and 10\%; the detailed results are available upon request from the authors. Overall the evidence is not sufficiently overwhelming to motivate ARCH modeling across all firms.

${ }^{32} \mathrm{~A}$ more detailed description can be found in Appendix D.
} 
or unexpected loss (UL), given by the square root of (28), and various quantiles or VaRs. The asymptotic results for this case are given in Vasicek (2002).

\section{[Insert Table 5 about here]}

Table 5 reports the loss simulation results for the "pooled" version of Model I for each of the six rolling windows A through $\mathrm{F}$. The first row in Table 5 describes the losses forecast in 1998 using the model estimated over the sample period 1988-1997. For each year we report the portfolio expected default rate, $\hat{\pi}$, which is equal to expected loss under our assumption of no loss recovery and the average portfolio return correlation, $\rho$, given by the empirical analog of (23), namely

$$
\hat{\rho}=\frac{\hat{\beta}^{2} \hat{V}\left(\bar{r}_{t+1}\right)}{\hat{\beta}^{2} \hat{V}\left(\bar{r}_{t+1}\right)+\hat{\sigma}_{u}^{2}},
$$

where $\hat{\beta}$ and $\hat{\sigma}_{u}^{2}$ are computed recursively using Model I. The estimated variance of $\bar{r}_{t+1}, \hat{V}\left(\bar{r}_{t+1}\right)$, is computed from the aggregate returns, $\bar{r}_{t+1}$, using a rolling 10 -year observation window. For the size of the portfolio we report the total number of firms, $N_{t}$, and the effective number of equal-sized exposures, $N_{t}^{*}=\left(\sum_{i=1}^{N_{t}} w_{i t}^{2}\right)^{-1}$, where $w_{i t}$ are the exposure weights. Table 5 also reports the asymptotic and simulated UL and VaRs, as well as their differences denoted as "granularity."

Looking across the first row of Table 5 we see that our two-country portfolio of 839 firms, with an effective number of 638 equal-sized exposures, is relatively close to an asymptotically diversified portfolio. Simulated UL is $1.47 \%$, only $7 \mathrm{bp}$ above the asymptotic result. Similarly for the three quantiles $99.0 \%, 99.5 \%$ and $99.9 \%$ VaR, the last corresponding to the loss calibration level of the New Basel Accord (BCBS, 2004), the simulated loss levels are never far from, though always above, their asymptotic counterparts. For instance, simulated $99.9 \%$ VaR is $12.05 \%$ of total portfolio notional, just 23bp above the level achievable with an infinitely large portfolio. Looking down the table, it is clear that the two-country portfolios for the later cohorts are also close to an asymptotically diversified portfolio.

Introduction of credit rating information in the Vasicek model affects the losses through changes to the default correlation, $\rho^{*}$, even though the pair-wise return correlations continue to be the same across all firms. From (27) and Figure 1 we know that for any given value of return correlation, $\rho$, default correlation, $\rho^{*}$, is increasing in the unconditional probability of default, $\pi$, so long as $\pi<0.5$. This can be seen clearly by computing the default correlation by credit rating, $\rho_{\mathcal{R}}^{*}$, given an estimate of a rating specific default rate, $\hat{\pi}_{\mathcal{R}}$, and the same distance to default by rating identifying restriction, $D D_{\mathcal{R}}$, given by (58). ${ }^{33}$ In Panel A of Table 6 we report default correlations by credit rating for 2003 based on estimates using the last rolling sample window, 1993-2002. ${ }^{34}$ The top two ratings, $\mathcal{A} \mathcal{A} \mathcal{A} \& \mathcal{A} \mathcal{A}$, are combined because we impose a minimum unconditional default probability of $0.001 \%$ per annum; see also the discussion in Section 7.1.

\footnotetext{
${ }^{33}$ These correlations can be easily computed using (12).

${ }^{34}$ We do not report the results for previous years as they are qualitatively very similar.
} 
[Insert Table 6 about here]

The strong differentiation of the default correlation by credit rating, $\hat{\rho}_{\mathcal{R}}^{*}$, suggests that credit rating is indeed an important characterization of default heterogeneity, even while imposing strict homogeneity of return correlations. Put differently, a high default rate for a low credit rating, say $\mathcal{B}$, is associated with high default correlation, and vice versa. Gordy (2000) reports similar steeply increasing default correlations as one descends the credit rating scale. ${ }^{35}$

\subsubsection{Loss Simulation Results}

Although most of the loss simulations we report below are calibrated to have the same EL across all models, we start by examining the impact of a simple source of heterogeneity, namely firm fixed effects, on expected and unexpected losses. Recall from the theoretical results in Section 4.7 that the introduction of heterogeneity in $a_{i}=\left(\lambda_{i}-\mu_{i}\right) / \sigma$, by assuming $a_{i}=a+v_{i}, \quad v_{i} \sim$ iid $N\left(0, \sigma_{v}^{2}\right)$, resulted in increased expected and, once EL is controlled for, decreased unexpected losses. Empirically one may introduce this heterogeneity through a firm fixed effect which impacts $\mu_{i}$ and therefore $a_{i}$. The results are displayed in Table 7, where Panel A shows the impact on EL while Panel B imposes the same EL across the two model specifications and shows the impact on UL. For the first cohort, 1998, the simulated EL increases from $1.23 \%$ to $1.72 \%$, as predicted by theory. Panel B shows that UL declines from $1.47 \%$ to $1.39 \%$, again as predicted. This pattern holds true for all six years. Then same point can be made by instead calibrating the Vasicek model to have the same EL as the fixed effects model, namely $1.72 \%$, in which case the corresponding UL would be $1.91 \%$ versus $1.79 \%$ for the fixed effects model.

\section{[Insert Table 7 about here]}

Recall from Section 7.2 that the portfolio weight based on PPP-denominated output $w_{U S}=0.75$. There is no reason to believe that this weight minimizes portfolio loss volatility - for the given portfolio EL. To illustrate the portfolio optimization results described in Section 5, we assign firm exposures so that each country sub-portfolio has the same EL as the baseline global portfolio: $3.26 \%$. We then carry out simulations for the least year, 2003, using the CAPM Model IV for the U.S. and Japan pooled model which contains a single common factor with different parameter distributions across the two countries.

The simulated UL for the baseline portfolio is $U L_{U S \& J a p a n}=1.28 \% .{ }^{36}$ Using these simulations, we also find that $U L_{U S}=1.29 \%, U L_{J a p a n}=2.18 \%$, and $\rho_{U S, J a p a n}=0.39$. Using (54) and (55), we

\footnotetext{
${ }^{35}$ Default correlations across credit ratings can also be similarly computed, and these are summarized in Panel B of Table 6. The diagonal entries are just the within-rating default correlation presented in Panel A.

${ }^{36}$ This is slightly different from the corresponding $U L$ of $1.27 \%$ reported below in Table 8 since we have altered the firm exposures to equate EL across the two country sub-portfolios.
} 
find the volatility minimizing weight assigns more exposure to U.S. firms relative to the baseline of $75 \%$, namely $\varpi_{U S}^{*}=86.5 \%$, and the resulting loss volatility $U L_{U S \& J a p a n}^{*}=1.26 \%$, somewhat lower than the volatility for the baseline portfolio of $1.28 \%$.

Before embarking on a detailed model-by-model, year-by-year discussion of the loss simulation results, it is helpful to look at Figure 4 to gain an overview of the results. In Figure 4 we show the loss densities for 2003 across the six different specifications (separate country models). It is immediately apparent that the models are grouped into two sets. While the models differ in several ways, the main distinction between the two groups is the use of credit ratings. The more skewed densities with the mode closer to the vertical axis are generated by two models (I and II) which do not make use of credit rating information while the other four (III through VI) incorporate this information. Whatever other sources of heterogeneity may be important, an estimate of the unconditional probability of default, as provided by a credit rating, clearly has a significant influence on the overall shape of the loss density.

We turn now to Table 8 where we report the loss simulations results for each of the six rolling windows. We proceed by discussing in some detail the loss simulations for the first period and then draw comparisons across years. In addition to the model number and name in Table 8, we provide the EL calibration using the default threshold $\lambda$ and distance to default, $D D$.

\section{[Insert Table 8 about here]}

For each year we report the first four simulated moments of the loss distribution (note that the first moment or expected loss is the same across all models by construction) as well as three commonly reported quantiles, $99.0 \%, 99.5 \%$ and $99.9 \%$. We also calculate expected shortfall; the results are qualitatively no different, and so we report here only the VaR results. The first set of columns is for the pooled specification while the second set is for the country specific models, analogous to the presentation of the in-sample regression results in Table 4.

The fully homogeneous model of Vasicek (Model I) generates the most extreme losses and has the largest unexpected losses. Allowing for firm fixed effects but keeping firm error variances the same, Model II, results in only a small reduction in risk (while controlling for expected losses). UL drops slightly from $1.47 \%$ to $1.39 \%$, the resulting loss distribution is somewhat less skewed (2.8 vs. 3.1) and fat-tailed (kurtosis of 16.9 vs. 19.5), and risk as measured by VaR is a bit lower as well. For instance $99.9 \%$ VaR drops from $12.05 \%$ of portfolio notional to $11.14 \%$.

The above simulations do not make use of firm rating information. ${ }^{37}$ Model III simply adds ratings in the form of a rating-specific default threshold $\lambda_{\mathcal{R}}$ and distance to default $D D_{\mathcal{R}}$ to the Vasicek specification in Model I. For the pooled model we go from one (two for the country-specific models) to seven (fourteen) $\lambda$ 's, along the lines outlined in Section 6. Comparing Model III to Model

\footnotetext{
${ }^{37}$ To be sure, the overall portfolio EL is calibrated using default rates by credit rating, but so far we have not used this information at a firm level.
} 
I, UL drops by about one-third from $1.47 \%$ to $1.07 \%$ while $99.9 \%$ VaR is reduced by nearly $80 \%$ from $12.05 \%$ to $6.72 \%$. Credit ratings seem to capture relevant firm-specific information, and this is useful even though the information is grouped together into just a few (seven) rating categories.

Models IV and (b) allow for heterogeneous slopes (factor loadings) and firm-specific error variances, with Model V also adding an industry return factor. Overall the difference in risk is small. UL and VaR increase somewhat with the addition of these parameters. Adding an industry factor above and beyond a market factor with heterogeneous slopes makes little difference to the resulting loss distribution as is clear by comparing Models IV and V. UL is nearly the same, $0.86 \%$ vs. $0.88 \%$, as are VaR levels, e.g. $5.56 \%$ vs. $5.58 \%$ at the $99.9 \%$ VaR level.

Finally, the principal components Model VI generates UL results that are similar to Model III, which is Model I with ratings information, namely $1.08 \%$ vs. $1.07 \%$. VaR, however, is higher. For instance, $99.9 \%$ VaR is $7.69 \%$, compared to $6.72 \%$ for Model III. In this way Model VI also generates tail losses which are higher than Models IV and V. Although the PCA model performs best on an in-sample basis, it is highly unlikely that the conditional independence attained by the PCA model in-sample would carry through to out-of-sample.

Allowing for geographic heterogeneity in the simple Vasicek case reduces risk as can be seen by the last set of columns labeled "U.S. \& Japan Modeled Separately." For the Vasicek model this amounts to doubling the number of parameters as there is one set for each country. UL drops by about $14 \%$ from $1.47 \%$ to $1.29 \%$, skewness and kurtosis both decline, as does VaR. For instance, $99.9 \%$ VaR declines by nearly $20 \%$ from $12.05 \%$ to $10.14 \%$.

In general, however, pooled and separate country models generate similar loss distributions. Modeling the U.S. and Japan separately usually results in lower risk for Models I and II. Once firm-specific factor loadings are allowed for, as in Models IV and V, VaR is actually slightly higher for the separate country model, although the second through fourth moments are the same. For instance, in the case of the basic CAPM model, Model IV, 99.9\% VaR increases from 5.56\% to $5.75 \%$. A similar pattern can be seen when adding an industry factor in Model V. Model VI, however, shows risk reduction by allowing for country heterogeneity. Moreover, the results for the last period shown in Panel F, Table 8, indicates that even for the simple Vasicek model, Model I, pooling need not always increase risk: $99.9 \%$ VaR is $17.47 \%$ for the pooled model but $17.81 \%$ for the country-specific model. Indeed for this last period, allowing the parameters to vary by country increases VaR for all models save the last one, Model VI. Some of these results could be due to parameter instability and the associated estimation errors. Nevertheless, the model ranking is robust to comparisons over time, i.e. comparing Panels A through F. Overall it seems that allowing for country-specific factor loadings is more important than requiring different country models to have their own specific factors.

Broadly speaking, risk, measured either by loss volatility (UL) or VaR, declines as model heterogeneity increases. The exception seems to be the PCA model (Model VI). Note that the out-of- 
sample loss simulations are performed under the maintened assumption of conditional independence. Recall from Table 4 that only Model VI had an (in-sample) average pair-wise cross-sectional correlation of residuals which was effectively zero. All other models had some remaining correlation. Put differently, while Model VI is conditionally independent on an in-sample basis, it seems that the others are not. So long as on an out-of-sample basis Model VI is still closer to conditional independence than the others, and there is currently no way of verifying this, the other models will generate risk forecasts which are biased downward, meaning that risk would be underestimated. Measuring and evaluating out-of-sample conditional dependence is an important topic which requires further investigation.

It may be useful to return to the loss densities in Figure 4. There are clearly important differences across the models. Relative to the Vasicek model which has only three parameters per country $\left(\alpha_{c}, \beta_{c}, \sigma_{c}\right)$, adding just fixed effects, Model II, does not seem to change the shape of the loss distribution. However, once credit rating information is included, the distributional shape changes dramatically. For example, Model III, which simply adds credit rating information to the Model I specification (i.e. it adds just seven parameters per country) yields a loss distribution which is remarkably similar to those generated by the fully heterogeneous model specification. Credit ratings seem indeed to be a useful and informative summary statistic for firm-level unconditional credit risk.

[Insert Figure 4 about here]

Moving down the panels in Table 8 we notice that the portfolio is getting riskier over time; expected loss rises every year. If we compare value-at-risk, say at the $99.5 \%$, for a model, say the one-factor CAPM model (Model IV) applied to the two countries separately, we see that VaR increases from $4.33 \%$ in 1998 to $6.21 \%$ in 2000 to $7.66 \%$ in 2003.

[Insert Table 9 about here]

Next we check to see if our conclusions so far are robust to the default threshold identification choice discussed in Section 6. Table 9 addresses this issue, where in Panel A we have repeated several model results from Panel $\mathrm{F}$ in Table 8, namely the loss simulation results for the final year under the basic same distance to default identification assumption given by (58). Panel B imposes an alternative identifying assumption of the same default threshold $\lambda$, as in (57). First, note that by construction the two identification procedures are identical for Models I and III. Focusing on the pooled models, we find that imposing same $D D$ (58) in Panel A generates levels of $99.9 \%$ valueat-risk that are somewhat higher than those generated by same $\lambda(57)$ in Panel B. For instance, looking at the result for U.S. \& Japan modeled separately, under same $\lambda$, Model VI yields $99.9 \%$ VaR of $9.82 \%$ as seen in Panel B, far less than $99.9 \%$ VaR of $11.11 \%$ in Panel A. We are currently 
exploring more fully these results, but initial closer examination reveals that imposing same $D D$ generates more extreme tail events for investment grade firms than does imposing same $\lambda$ while the differences for speculative grade firms are more modest. More broadly, however, we note that the risk ranking across model specifications is robust to the choice of default threshold identification.

What is clear from the discussion is that there is a rich and complex interaction between the underlying model parameters and the resulting loss distributions. Some of this complexity can be summarized more simply using the default correlation $\rho_{i j}^{*}$ between any two firms $i$ and $j$, as computed in Section 7.4.1 where we discussed the default correlation by credit rating, $\rho_{\mathcal{R}}^{*}$. We can conduct similar analysis across a broader set of models that use the same $D D$ identifying assumption, and these results are summarized in Table 10 for the year, 2003. We report the portfolio EL for the year, 3.26\%, which is the same across all models, the average return correlation, $\overline{\hat{\rho}}$, computed using (10), the average default correlation using (27), as well as portfolio loss volatility, UL, taken from Table 8. Note that for the first two models, I and III, parameter restrictions result in only one return correlation $\rho$ for all firms. Through the introduction of ratings information and consequently heterogeneity in unconditional default probabilities, we notice a sharp reduction in average default correlation, $\overline{\hat{\rho}}^{*}$, from $1.81 \%$ for Model I, to $0.26 \%$ for Model III. This reduction in average default correlation is accompanied by a reduction in UL, as seen in the last column of Table 10.

[Insert Table 10 about here]

Allowing for richer return specifications through differentiated factor loadings increases the simulated out-of-sample return correlation: $\overline{\hat{\rho}}$ increases from $9.2 \%$ for Model III to just above $10 \%$ for Models IV and V, and to nearly $15 \%$ for Model VI. Naturally the average default correlation, $\overline{\hat{\rho}^{*}}$, also rises somewhat, from $0.26 \%$ for Model III to just above $0.3 \%$ for Models IV and V and $0.8 \%$ for Model VI. Yet even with this increased default correlation, loss volatility is never higher than for Model III. Indeed, the PCA model has an implied default correlation which is triple that of the Vasicek model with rating information (Model III), but with the same loss volatility. However, looking at the last column of Table 10 we see that $99.9 \%$ VaR for Model VI at $11.15 \%$ which is noticably larger than that of Model III at $9.46 \%$.

\section{Concluding Remarks}

In this paper we have considered a simple model of credit risk and derived the limit distribution of losses under different distributional assumptions regarding the structure of systematic and idiosyncratic risks and the nature of firm heterogeneity. The analytical and simulation results point to some interesting conclusions. Theory indicates that under the maintained assumption of conditional independence, meaning that all cross-firm dependence is captured by the systematic risk factors, 
if the firm parameters are heterogeneous but come from a common distribution, asymptotically (when the number of exposures, $N$, is sufficiently large) there is no scope for further risk reduction through active credit portfolio management. However, if the firm parameters come from different distributions, say from different sectors or countries, then further risk reduction is possible, even asymptotically, by changing the portfolio weights. In either case, neglecting parameter heterogeneity can lead to underestimation of expected losses. Then once expected losses are controlled for, neglecting parameter heterogeneity can lead to overestimation of risk, whether measured by unexpected loss or value-at-risk. Effectively the loss distribution is more skewed and fat-tailed when heterogeneity is ignored.

In light of these observations a natural question is: which sources of heterogeneity are most important from the perspective of portfolio losses? Turning first to the return specification, firm fixed effects do not seem very important. However, allowing for flexible factor sensitivities does appear to be important, especially for capturing cross-firm dependence. If the maintained assumption of conditional independence is violated, i.e. if there remains cross-sectional dependence in the residuals from the return regressions, then risk will be underestimated. Thus proper specification of the return model is key by allowing for heterogenous factor loadings and the possible addition of industry return factors.

By contrast, the differences in pooled versus country-specific results suggest that further subdividing the firm return specification and error variances by country matters less. Indeed, the differences within a given model in the pooled approach compared with modeling the two countries separately are generally smaller than the differences across the different models. Thus allowing for country-specific factor loadings is important, but requiring country-specific factors is less so.

Finally, allowing for heterogeneity in unconditional probabilities of default, for instance by grouping firms according to credit ratings, appears to be of crucial importance. Even if we maintain the assumption that firm returns are equi-correlated, going from one distance-to-default to seven, one for each credit rating, with seven unconditional default probabilities, seems to capture much of the relevant heterogeneity. In this way the focus of the New Basel Accord on internal (or external) credit ratings seems well placed. 


\section{A Allowing for Correlated Loss Severity}

In this appendix we consider the loss function is given by (19) and assume that LGD variables, $\varphi_{i, t+1}$, depend on the common factors $\mathbf{f}_{t+1}$. But we assume that conditional on $\mathbf{f}_{t+1}, \varphi_{i, t+1}$ and $z_{i, t+1}$ are independently distributed. ${ }^{38} \mathrm{~A}$ common formulation for LGD is the Beta distribution, convenient because it is bounded between 0 and 1, with two shape parameters that can be expressed in terms of the average and volatility of observed LGDs. Specifically, suppose that

$$
f_{\varphi}\left(\varphi_{i, t+1} \mid \mathbf{f}_{t+1}, \mathcal{I}_{t}\right) \sim \operatorname{Beta}\left(p_{t+1}, q_{t+1}\right)
$$

where $\operatorname{Beta}\left(p_{t+1}, q_{t+1}\right)$ is a Beta distribution with parameters $p$ and $q$ that depend on $\mathbf{f}_{t+1}$, and possibly on $\mathcal{I}_{t}$. Note also that

$$
E\left(\varphi_{i, t+1} \mid \mathbf{f}_{t+1}, \mathcal{I}_{t}\right)=\frac{p_{t+1}}{p_{t+1}+q_{t+1}}
$$

We shall consider the following logistic form as an example of this mean function

$$
E\left(\varphi_{i, t+1} \mid \mathbf{f}_{t+1}, \mathcal{I}_{t}\right)=\frac{e^{\boldsymbol{\kappa}^{\prime} \mathbf{f}_{t+1}}}{1+e^{\boldsymbol{\kappa}^{\prime} \mathbf{f}_{t+1}}}
$$

where $\boldsymbol{\kappa}$ measures the degree to which mean $L G D$ varies with the business cycle indicators, here represented by $\mathbf{f}_{t+1}$. Clearly other functional forms and business cycle indicators can also be used. Note that LGD is assumed not to vary systematically across exposures $i$ but only over $t .^{39}$

Since $\left|\varphi_{i, t+1} z_{i, t+1}\right| \leq 1$, firstly the results (40) and (41) continue to hold. Also under the random coefficient model (34) we have

$$
E\left(\ell_{N, t+1} \mid \mathbf{f}_{t+1}, \mathcal{I}_{t}\right)=\left(\frac{e^{\boldsymbol{\kappa}^{\prime} \mathbf{f}_{t+1}}}{1+e^{\boldsymbol{\kappa}^{\prime} \mathbf{f}_{t+1}}}\right) F_{\varkappa}\left(\frac{\boldsymbol{\theta}^{\prime} \mathbf{g}_{t+1}}{\omega_{t+1}}\right)
$$

where $\boldsymbol{\theta}=\left(a, \boldsymbol{\delta}^{\prime}\right)^{\prime}, \mathbf{g}_{t+1}=\left(1,-\mathbf{f}_{t+1}^{\prime}\right)^{\prime}$, and hence

$$
\lim _{N \rightarrow \infty} \operatorname{Var}\left(\ell_{N, t+1} \mid \mathcal{I}_{t}\right)=\operatorname{Var}\left[\left(\frac{e^{\boldsymbol{\kappa}^{\prime} \mathbf{f}_{t+1}}}{1+e^{\boldsymbol{\kappa}^{\prime} \mathbf{f}_{t+1}}}\right) F_{\varkappa}\left(\frac{\boldsymbol{\theta}^{\prime} \mathbf{g}_{t+1}}{\omega_{t+1}}\right) \mid \mathcal{I}_{t}\right] .
$$

Finally, the limit distribution in this case can also be derived noting that

$$
\ell_{N, t+1} \mid \mathbf{f}_{t+1}, \mathcal{I}_{t} \stackrel{a . s .}{\rightarrow}\left(\frac{e^{\boldsymbol{\kappa}^{\prime} \mathbf{f}_{t+1}}}{1+e^{\boldsymbol{\kappa}^{\prime} \mathbf{f}_{t+1}}}\right) F_{\varkappa}\left(\frac{\boldsymbol{\theta}^{\prime} \mathbf{g}_{t+1}}{\omega_{t+1}}\right) .
$$

\footnotetext{
${ }^{38}$ For empirical evidence of procyclical LGD, see Frye (2000), Altman et al. (2003) and Hu and Perraudin (2002).

${ }^{39}$ This formulation ties the two random variables of interest, default and $L G D$, to the same systematic risk factor(s) while allowing the factor loadings to be different. Again, the basic idea is that credit risk correlations/dependence, difficult if not impossible to observe directly, are modeled indirectly through the systematic factors. This is both conceptually desirable because we are using a structural model, as well as pragmatically and empirically useful since we focus the modeling effort where the data is dense and not sparse.
} 


\section{B Limit Behavior of Credit Loss Distribution}

\section{B.1 Loss Densities under Homogeneous Parameters}

In order to show how our approach relates to that of Vasicek, here we consider the homogeneous parameter case but do not require $\mathbf{f}_{t+1}$ and $\varepsilon_{i, t+1}$ to have Gaussian distributions. Since in the homogeneous case the multifactor model is equivalent to a single factor model, we consider scalar values for $\boldsymbol{\delta}_{i}$ and $\mathbf{f}_{t+1}$ and denote them by $\delta$ and $f_{t+1}$, respectively. In this case we note that conditional on $f_{t+1}$, the random variables $z_{i, t+1}$ are identically and independently distributed as well as being integrable. (Recall that $\left|w_{i} z_{i, t+1}\right| \leq 1$ for all $i$ and $t$.) Hence, conditional on $f_{t+1}$ and as $N \rightarrow \infty$, we have

$$
\ell_{N, t+1} \mid f_{t+1}, \mathcal{I}_{t} \stackrel{a . s .}{\rightarrow} F_{\varepsilon}\left(a-\delta f_{t+1}\right) .
$$

In the limit the probability density function of $\ell_{N, t+1} \mid \mathcal{I}_{t}$ can be obtained from the probability density functions of $f_{t+1}$ and $\varepsilon_{i, t+1}$, which we denote here by $f_{f}(\cdot)$ and $f_{\varepsilon}(\cdot)$, respectively. It will be helpful to write the loss density $f_{\ell}(\cdot)$ in terms of the systematic risk factor density $f_{f}(\cdot)$ and the standardized idiosyncratic shock density $f_{\varepsilon}(\cdot)$.

Therefore, conditional on $\mathcal{I}_{t}$ and denoting the limit of $\ell_{N, t+1}$ as $N \rightarrow \infty$, by $\ell_{t+1}$ we have (with probability 1)

$$
\ell_{t+1}=F_{\varepsilon}\left(a-\delta f_{t+1}\right) .
$$

Now making use of standard results on transformation of probability densities, for $\delta \neq 0$ we have

$$
f_{\ell}\left(\ell_{t+1} \mid \mathcal{I}_{t}\right)=\left|\frac{\partial F_{\varepsilon}\left(a-\delta f_{t+1}\right)}{\partial f_{t+1}}\right|^{-1} f_{f}\left(f_{t+1} \mid \mathcal{I}_{t}\right),
$$

where $f_{t+1}$ is given in terms of $\ell_{t+1}$, via (70), namely

$$
f_{t+1}=\frac{a-F_{\varepsilon}^{-1}\left(\ell_{t+1}\right)}{\delta}
$$

and $\left|\partial F_{\varepsilon}\left(a-\delta f_{t+1}\right) / \partial f_{t+1}\right|$ is the Jacobian of the transformation which is given by

$$
\frac{\partial F_{\varepsilon}\left(a-\delta f_{t+1}\right)}{\partial f_{t+1}}=-\delta f_{\varepsilon}\left(a-\delta f_{t+1}\right)=-\delta f_{\varepsilon}\left[F_{\varepsilon}^{-1}\left(\ell_{t+1}\right)\right]
$$

Hence

$$
f_{\ell}\left(\ell_{t+1} \mid \mathcal{I}_{t}\right)=\frac{f_{f}\left(\frac{a-F_{\varepsilon}^{-1}\left(\ell_{, t+1}\right)}{\delta} \mid \mathcal{I}_{t}\right)}{|\delta| f_{\varepsilon}\left[F_{\varepsilon}^{-1}\left(\ell_{t+1}\right)\right]}, \text { for } 0<\ell_{t+1} \leq 1
$$

\section{B.1.1 Relation to Vasicek's Loss Distribution}

The above results provide a simple generalization of Vasicek's one-factor loss density distribution given by (30), and reduces to it when $\mu_{f t}=0$, and assuming that the innovations, $f_{t+1}$ and $\varepsilon_{i, t+1}$ 
are both Gaussian. In this case

$$
\begin{aligned}
f_{f}\left(f_{t+1} \mid \mathcal{I}_{t}\right) & =\phi\left(f_{t+1}\right), \\
f_{\varepsilon}\left(\varepsilon_{i, t+1} \mid \mathcal{I}_{t}\right) & =\phi\left(\varepsilon_{i, t+1}\right), F_{\varepsilon}(\cdot)=\Phi(\cdot),
\end{aligned}
$$

and

$$
f_{\ell}\left(x \mid \mathcal{I}_{t}\right)=\frac{1}{|\delta|}\left\{\frac{\phi\left[\frac{a-\Phi^{-1}(x)}{\delta}\right]}{\phi\left[\Phi^{-1}(x)\right]}\right\}, \text { for } 0<x \leq 1,|\delta| \neq 0
$$

where we have used $x$ for $\ell_{t+1}$. Furthermore, in the homogeneous case

$$
\delta=\sqrt{\frac{\rho}{1-\rho}}, \text { for } \rho>0,
$$

and

$$
\pi=\Phi\left(\frac{a}{\sqrt{1+\delta^{2}}}\right)
$$

Hence

$$
a=\frac{\Phi^{-1}(\pi)}{\sqrt{1-\rho}} .
$$

Using (73) and (75) in (72) now yields Vasicek's loss density given by (30) (note that $\phi(x)=\phi(-x)$ ).

Under the double-Gaussian assumption, the distribution of $\delta f_{t+1}+\varepsilon_{t+1}$ (conditional on $\mathcal{I}_{t}$ ) is also Gaussian with mean $\delta \mu_{f t}$ and variance $1+\delta^{2}$. Therefore,

$$
E\left(\ell_{N, t+1} \mid \mathcal{I}_{t}\right)=\Phi\left(\frac{a-\delta \mu_{f t}}{\sqrt{1+\delta^{2}}}\right)
$$

Using (75) and (73) the conditional mean loss can therefore be written as

$$
E\left(\ell_{N, t+1} \mid \mathcal{I}_{t}\right)=\Phi\left[\Phi^{-1}(\pi)-\sqrt{\rho} \mu_{f t}\right]
$$

and reduces to $\pi$ only when $\mu_{f t}=0$. It is also interesting to note that under $\mu_{f t} \neq 0$, Vasicek's loss density and distributions become

$$
f_{\ell}\left(x \mid \mathcal{I}_{t}\right)=\sqrt{\frac{1-\rho}{\rho}}\left\{\frac{\phi\left[\sqrt{\frac{1-\rho}{\rho}} \Phi^{-1}(x)-\sqrt{\frac{1}{\rho}} \Phi^{-1}(\pi)+\mu_{f t}\right]}{\phi\left[\Phi^{-1}(x)\right]}\right\}, \text { for } 0<x \leq 1, \rho>0 .
$$

For $\rho>0$, the cumulative distribution function associated with this density is given by

$$
F_{\ell}\left(x \mid \mathcal{I}_{t}\right)=\Phi\left(\sqrt{\frac{1-\rho}{\rho}} \Phi^{-1}(x)-\sqrt{\frac{1}{\rho}} \Phi^{-1}(\pi)+\mu_{f t}\right) .
$$

Also

$$
\frac{\partial F_{\ell}\left(x \mid \mathcal{I}_{t}\right)}{\partial \mu_{f t}}=\phi\left(\sqrt{\frac{1-\rho}{\rho}} \Phi^{-1}(x)-\sqrt{\frac{1}{\rho}} \Phi^{-1}(\pi)+\mu_{f t}\right)>0,
$$

which shows that good news (a rise in $\mu_{f t}$ ) reduces the probability of losses above a given thresholds, i.e. reduces value-at-risk, as to be expected. 


\section{B.1.2 Non-Gaussian Innovations}

It is interesting to note that Vasicek and others in this literature first derive the loss distribution function and then obtain the density - while we obtain the density first and then integrate to obtain the distribution function. One of the advantages of our procedure (aside from lending itself readily to heterogeneous generalizations) is that it can be used to derive analytic loss densities for non-Gaussian idiosyncratic shocks as well as non-Gaussian conditional distributions of $f_{t+1}$. For example, in the case where idiosyncratic shocks are Gaussian but the conditional distribution of the common factor is $t$ distributed with $v$ degrees of freedom, we have

$$
f_{\ell}\left(x \mid \mathcal{I}_{t}\right)=\frac{t_{v}\left(\sqrt{\frac{v}{v-2}}\left[\frac{a-\Phi^{-1}(x)}{\delta}-\mu_{f t}\right]\right)}{|\delta| \phi\left[\Phi^{-1}(x)\right]}, \text { for } 0<x \leq 1, \quad|\delta| \neq 0, v>2
$$

where

$$
t_{v}(u)=\frac{1}{\sqrt{v} B(v / 2,1 / 2)}\left[1+v^{-1} u^{2}\right]^{-(v+1) / 2},
$$

and $B(v / 2,1 / 2)$ is the beta function. ${ }^{40}$

Using (71), other loss distributions can also be generated for different choices of the probability densities of $f_{t+1}$ and $\varepsilon_{i, t+1}$, although they might not be analytically tractable. In such cases the loss distribution can be generated by stochastic simulations.

\section{B.2 Loss Densities under Heterogeneous Parameters}

Here we consider the credit loss distribution under the heterogeneous model, introduced in Section 4.5. In this case, $\ell_{N, t+1}$, is given by (42): $\ell_{N, t+1}=\sum_{i=1}^{N} w_{i} I\left(a-\boldsymbol{\delta}^{\prime} \mathbf{f}_{t+1}-\zeta_{i, t+1}\right)$. Since conditional on $\mathbf{f}_{t+1}$, the composite errors, $\zeta_{i, t+1}=\varepsilon_{i, t+1}-v_{i a}+\mathbf{v}_{i \delta}^{\prime} \mathbf{f}_{t+1}$, are independently distributed across $i$, then

$$
\ell_{N, t+1} \mid \mathbf{f}_{t+1}, \mathcal{I}_{t} \stackrel{a . s .}{\rightarrow} F_{\varkappa}\left(\frac{\boldsymbol{\theta}^{\prime} \mathbf{g}_{t+1}}{\omega_{t+1}}\right)
$$

where as before $F_{\varkappa}(\cdot)$ denotes the cumulative distribution function of the standardized composite errors, $\varkappa_{i, t+1}$, defined by (46), $\mathbf{g}_{t+1}=\left(1,-\mathbf{f}_{t+1}^{\prime}\right)^{\prime}$ and $\omega_{t+1}$ is given by (44). Once again the limiting distribution of credit loss depends on the conditional densities of $\zeta_{i, t+1}$ and $\mathbf{f}_{t+1}$. For example, if $\left(\varepsilon_{i, t+1}, v_{i a}, \mathbf{v}_{i \delta}^{\prime}\right)$ follows a multivariate Gaussian distribution, then $\varkappa_{i, t+1} \mid \mathbf{f}_{t+1}, \mathcal{I}_{t} \sim i i d N(0,1)$.

The probability density of the fraction of the portfolio lost, $x$, over the range $(0,1)$, can be derived from the (conditional) joint probability density function assumed for the factors, $\mathbf{f}$, by application of standard change-of-variable techniques to the non-linear transformation

$$
x=F_{\varkappa}\left(\frac{a-\boldsymbol{\delta}^{\prime} \mathbf{f}}{\sqrt{1+\omega_{a a}-2 \boldsymbol{\omega}_{\alpha \delta}^{\prime} \mathbf{f}+\mathbf{f}^{\prime} \Omega_{\delta \delta} \mathbf{f}}}\right) .
$$

\footnotetext{
${ }^{40}$ We verified that this loss density (and its CDF, computed numerically using quadrature methods) generates very similar values for the Gaussian in (72) for $v=30$, and is nearly indistinguishable for $v=60$.
} 
For a general $m$ factor set up analytical derivations are quite complicated and will not be attempted here. Instead, we consider the relatively simple case of a single factor model, where $\mathbf{f}$ is a scalar, $f$. Suppose $f=\psi(x)$ satisfies the transformation, (79), and note that

$$
f_{\ell}\left(x \mid \mathcal{I}_{t}\right)=\left|\psi^{\prime}(x)\right| f_{f}\left[\psi(x)-\mu_{f t}\right], \text { for } 0<x \leq 1,
$$

where $\left|\psi^{\prime}(x)\right|=\left|x^{\prime}(f)\right|^{-1}$. In other words, $\psi(x)$ is that value of the systematic factor $f$ which generated loss of $x$. In the double-Gaussian case, for example, we have

$$
\begin{aligned}
x^{\prime}(f)= & \left(\frac{f\left(\delta \omega_{a \delta}-a \omega_{\delta \delta}\right)+a \omega_{a \delta}-\delta\left(1+\omega_{a a}\right)}{\left(1+\omega_{a a}-2 \omega_{a \delta} f+\omega_{\delta \delta} f^{2}\right)^{3 / 2}}\right) \\
& \times \phi\left(\frac{a-\delta f}{\sqrt{1+\omega_{a a}-2 \omega_{a \delta} f+\omega_{\delta \delta} f^{2}}}\right) .
\end{aligned}
$$

Hence

$$
\left|\psi^{\prime}(x)\right|=\left(\frac{1}{\phi\left[\Phi^{-1}(x)\right]}\right)\left|\frac{\left[1+\omega_{a a}-2 \omega_{a \delta} \psi(x)+\omega_{\delta \delta} \psi^{2}(x)\right]^{3 / 2}}{\psi(x)\left(\delta \omega_{a \delta}-a \omega_{\delta \delta}\right)+a \omega_{a \delta}-\delta\left(1+\omega_{a a}\right)}\right| .
$$

and for $0<x \leq 1$ we have

$$
f_{\ell}\left(x \mid \mathcal{I}_{t}\right)=\left|\frac{\left[1+\omega_{a a}-2 \omega_{a \delta} \psi(x)+\omega_{\delta \delta} \psi^{2}(x)\right]^{3 / 2}}{\psi(x)\left(\delta \omega_{a \delta}-a \omega_{\delta \delta}\right)+a \omega_{a \delta}-\delta\left(1+\omega_{a a}\right)}\right|\left\{\frac{\phi\left[\psi(x)-\mu_{f t}\right]}{\phi\left[\Phi^{-1}(x)\right]}\right\},
$$

This generalizes the result obtained for the homogeneous case, (72), and reduces to it if we set $\omega_{a a}=\omega_{a \delta}=\omega_{\delta \delta}=0$. It is also interesting to note that the above limiting loss distribution does not depend on the individual values of the portfolio weights, $w_{i}, i=1,2, \ldots, N$, so long as the granularity conditions in (18) are satisfied.

\section{Principal Components Model}

For the principal components model where

$$
r_{i, t+1}=\alpha_{i}+\boldsymbol{\beta}_{i}^{\prime} \mathbf{f}_{t+1}+u_{i, t+1}, t=1, \ldots, T
$$

the estimates of $\mathbf{f}_{t+1}$ can be computed by application of principal component techniques to the standardized returns defined by $\left(r_{i, t+1}-\bar{r}_{i}\right) / \hat{\sigma}_{i}$, where $\bar{r}_{i}=\sum_{t=1}^{T} r_{i, t+1} / T$, and $\hat{\sigma}_{i}^{2}=\sum_{t=1}^{T}\left(r_{i, t+1}-\bar{r}_{i}\right)^{2} /(T-$ 1 ). The number of factors, $m$, can be selected using the Bai and $\mathrm{Ng}$ (2002) procedure. Denote the number of selected factors by $\hat{m}$ and estimated factors by $\hat{\mathbf{f}}_{t+1}$, and suppose that they are subject to the orthonormalization restrictions such that ${ }^{41}$

$$
T^{-1} \sum_{t=1}^{T} \hat{\mathbf{f}}_{t+1} \hat{\mathbf{f}}_{t+1}^{\prime}=\mathbf{I}_{\hat{m}}, T^{-1} \sum_{t=1}^{T} \hat{\mathbf{f}}_{t+1}=\mathbf{0} .
$$

\footnotetext{
${ }^{41}$ For computational convenience, we actually impose the in-sample restrictions that the estimated factors form an orthonormal set, namely $(T-1)^{-1} \sum_{t=1}^{T} \hat{\mathbf{f}}_{t+1} \hat{\mathbf{f}}_{t+1}^{\prime}=\mathbf{I}_{\hat{m}}$.
} 
The estimates of $\alpha_{i}$ and $\boldsymbol{\beta}_{i}$ will be given by $\hat{\alpha}_{i}=T^{-1} \sum_{t=1}^{T} r_{i, t+1}=\bar{r}_{i}, \hat{\boldsymbol{\beta}}_{i}=T^{-1} \sum_{t=1}^{T} r_{i, t+1} \hat{\mathbf{f}}_{t+1}$, and

$$
\hat{\sigma}_{i}^{2}=(T-\hat{m}-1)^{-1} \sum_{t=1}^{T}\left(r_{i, t+1}-\hat{a}_{i}-\hat{\boldsymbol{\beta}}_{i}^{\prime} \hat{\mathbf{f}}_{t+1}\right)^{2} .
$$

\section{Simulation of Returns and Associated Loss Distributions}

To simulate $h$-period ahead individual firm returns, $R_{i, t+h} \equiv \sum_{l=1}^{h} r_{i, t+l}$, according to (62) we need to simulate $\mathbf{f}_{t+l}$, and $u_{i, t+l}$, for $l=1,2, . ., h$. We assume that the common factors are serially uncorrelated. This seems justified in our application where market returns are only very weakly autocorrelated. Taking first the case of a single market factor, suppose that $\bar{r}_{t+l} \sim i i d N\left(\bar{r}, s_{\bar{r}}^{2}\right)$, where $\bar{r}=T^{-1} \sum_{t=1}^{T} \bar{r}_{t}, \quad s_{\bar{r}}^{2}=(T-1)^{-1} \sum_{t=1}^{T}\left(\bar{r}_{t}-\bar{r}\right)^{2}$, and $u_{i, t+l} \sim i i d N\left(0, \hat{\sigma}_{i}^{2}\right)$. Then return for the $i^{\text {th }}$ firm can be simulated as

$$
\begin{gathered}
r_{i, t+l}^{(s)}=\hat{\alpha}_{i}+\hat{\beta}_{i} \bar{r}_{t+l}^{(s)}+\hat{\sigma}_{i} \varepsilon_{i, t+l}^{(s)}, \\
\bar{r}_{t+l}^{(s)} \sim \operatorname{iidN}\left(\bar{r}, s_{\bar{r}}^{2}\right), \varepsilon_{i, t+l}^{(s)} \sim \operatorname{iidN}(0,1)
\end{gathered}
$$

where $s=1,2, . ., S$ are the replications.

For the principal components model where the factors satisfy the orthonormalization restrictions (80), returns for the $i^{\text {th }}$ firm can be simulated as

$$
\begin{gathered}
r_{i, t+l}^{(s)}=\hat{\alpha}_{i}+\boldsymbol{\beta}_{i}^{\prime} \mathbf{f}_{t+l}^{(s)}+\hat{\sigma}_{i} \varepsilon_{i, t+l}^{(s)} \\
\mathbf{f}_{t+l}^{(s)} \sim \operatorname{iidN}\left(\mathbf{0}, \mathbf{I}_{\hat{m}}\right), \varepsilon_{i, t+l}^{(s)} \sim \operatorname{iidN}(0,1) .
\end{gathered}
$$

For the more general multi-factor case, let $\boldsymbol{\mu}_{f}$ denote the mean and $\boldsymbol{\Sigma}_{f}$ the covariance matrix of $\mathbf{f}_{t+l}$. Then returns for the $i^{t h}$ firm can be simulated as

$$
\begin{gathered}
r_{i, t+l}^{(s)}=\hat{\alpha}_{i}+\boldsymbol{\beta}_{i}^{\prime} \mathbf{f}_{t+l}^{(s)}+\hat{\sigma}_{i} \varepsilon_{i, t+l}^{(s)} \\
\mathbf{f}_{t+l}^{(s)} \sim i i d N\left(\boldsymbol{\mu}_{f}, \boldsymbol{\Sigma}_{f}\right), \varepsilon_{i, t+l}^{(s)} \sim \operatorname{iidN}(0,1) .
\end{gathered}
$$

Portfolio loss at horizon $h$ can now be simulated using

$$
l_{t+h}^{(s)}=V_{p}\left[\sum_{i=1}^{N} w_{i} I\left(\hat{\lambda}_{i, t+h}-R_{i, t+h}^{(s)}\right)\right],
$$

where $R_{i, t+h}^{(s)} \equiv \sum_{l=1}^{h} r_{i, t+l}^{(s)}$ is the $h$-period cumulative return, $\hat{\lambda}_{i, t+h}$ is the $h$-period default return threshold, $V_{p}$ is the face value of the whole portfolio (e.g. $\$ 1 \mathrm{bn}$ ) and $w_{i}$ is the fraction of exposure to obligor $i$. We assume for simplicity that defaulted instruments have no recovery value. Simulated expected loss due to default is given by

$$
\bar{l}_{S, t+h}=\frac{1}{S} \sum_{s=1}^{S} l_{t+h}^{(s)} .
$$

The higher order moments of the loss distribution can be similarly simulated. 


\section{References}

[1] Altman, Edward I. (1968). "Financial Ratios, Discriminant Analysis and the Prediction of Corporate Bankruptcy." Journal of Finance 20, 589-609.

[2] Altman, Edward I., Brooks Brady, Andrea Resti and Andrea Sironi (2003). "The Link between Default and Recovery Rates: Implications for Credit Risk Models and Procyclicality." forthcoming, Journal of Business.

[3] Bai, Jushan and Serena Ng (2002). "Determine the Number of Factors in Approximate Factor Models." Econometrica, 70, 191-221.

[4] Basel Committee on Banking Supervision (2001), "The Internal Ratings Based Approach," Basel Committee on Banking Supervision, May; <http://www.bis.org/publ/bcbsca.htm>.

[5] Basel Committee on Banking Supervision (2004). "International Convergence of Capital Measurement and Capital Standards: A Revised Framework." $<$ http://www.bis.org/publ/bcbs107.htm>, June.

[6] Black, Fischer, and John C. Cox (1976). "Valuing Corporate Securities: Some Effects of Bond Indenture Provisions." Journal of Finance 31, 351-367.

[7] Broadie, Mark, Mikhail Chernov and Suresh Sundaresan (2004). "Optimal Corporate Securities Values in the Presence of Chapter 7 and Chapter 11." mimeo, Graduate School of Business, Columbia University.

[8] Crouhy, Michel, Dan Galai, and Robert Mark (2000). "A Comparative Analysis of Current Credit Risk Models." Journal of Banking ES Finance 24, 59-117.

[9] Davis, Mark and Violet Lo (2001). "Infectious Defaults." Quantitative Finance 1, 382-387.

[10] Duffie, Darrell and Nicolae Gârleanu (2001). "Risk and Valuation of Collateralized Debt Obligations." Financial Analyst Journal, January/February, 41-59.

[11] Duffie, Darrell and David Lando (2001). "Term Structures of Credit Spreads with Incomplete Accounting Information." Econometrica 69, 633-664.

[12] Duffie, Darrell and Kenneth J. Singleton (1999). "Simulating Correlated Defaults." Working Paper, Stanford Graduate School of Business.

[13] Duffie, Darrell and Kenneth J. Singleton (2003), Credit Risk: Pricing, Measurement and Management, Princeton, NJ: Princeton University Press. 
[14] Duffie, Darrell and Ke Wang (2004). "Multi-Period Corporate Failure Prediction with Stochastic Covariates." Working Paper, Stanford Graduate School of Business.

[15] Embrechts, Paul, Alexander J. McNeil and D. Straumann (2001). "Correlation and Dependency in Risk Management: Properties and Pitfalls." pp.176-223 in M.A.H. Dempster and H.K Moffat (eds.) Risk Management: Value at Risk and Beyond, Cambridge, UK: Cambridge University Press.

[16] Fernholz, Robert, Ioannis Karatzas and Constantinos Kardaras (2003). "Diversity and Relative Arbitrage in Financial Markets." Department of Mathematics and Statistics, Columbia University.

[17] Frey, Rüdiger and Alexander J. McNeil (2003). "Dependent Defaults in Models of Portfolio Credit Risk." Journal of Risk 6, 59-92.

[18] Frye, Jon (2000). "Depressing Recoveries," Risk 13, April, 91-94.

[19] Garbade, Kenneth (2001). Pricing Corporate Securities as Contingent Claims, Cambridge, MA: MIT Press.

[20] Giesecke, Kai and Stefan Weber (2004). "Cyclical Correlations, Credit Contagion and Portfolio Losses." Journal of Banking \& Finance 28, 3009-3036.

[21] Gordy, Michael B. (2000). "A Comparative Anatomy of Credit Risk Models." Journal of Banking \& Finance 24, 119-149.

[22] Gordy, Michael B. (2003). "A Risk-Factor Model Foundation for Ratings-Based Bank Capital Rules." Journal of Financial Intermediation 12, 199-232.

[23] Gupton, Gregory M., Christopher C. Finger and Mickey Bhatia (1997). CreditMetrics ${ }^{\text {TM }}$ Technical Document, this version: April 2, 1997. J.P. Morgan, New York.

[24] Hillegeist, Stephen A., Elizabeth K. Keating, Donald P. Cram and Kyle G. Lundsted (2004). "Assessing the Probability of Bankruptcy." Review of Accounting Studies 9, 5-34.

[25] Hu, Y-T and William Perraudin (2002). "The Dependence of Recovery Rates and Defaults." CEPR working paper.

[26] Jafry, Yusuf and Til Schuermann (2004). "Measurement, Estimation and Comparison of Credit Migration Matrices." Journal of Banking E Finance 28, 2603-2639.

[27] Koyluoglu, H. Ugur, and Andrew Hickman (1998). "Reconcilable Differences." Risk 11, October, 56-64 
[28] Lando, David (2004). Credit Risk Modeling: Theory and Applications. Princeton, NJ: Princeton University Press.

[29] Lando, David and Torben Skødeberg (2002). "Analyzing Ratings Transitions and Rating Drift with Continuous Observations." Journal of Banking \& Finance 26, 423-444.

[30] Leland, Hayne E. and Klaus Bjerre Toft (1996). "Optimal Capital Structure, Endogenous Bankruptcy, and the Term Structure of Credit Spreads." Journal of Finance 51, 987-1019.

[31] Lennox, Clive (1999). "Identifying Failing Companies: A Re-Evaluation of the Logit, Probit and DA Approaches." Journal of Economics and Business 51, 347-364.

[32] Li, David X. (2000). "Default Correlation: A Copula Approach." Journal of Fixed Income, March, 43-54.

[33] Mella-Barral, Pierre, and William Perraudin (1997). "Strategic Debt Service." Journal of Finance 52, 531-556.

[34] Merton, Robert C. (1974). "On the Pricing of Corporate Debt: The Risk Structure of Interest Rates." Journal of Finance 29, 449-470.

[35] Pesaran, M.Hashem, Til Schuermann, Björn-Jakob Treutler and Scott M. Weiner (2005) "Macroeconomic Dynamics and Credit Risk: A Global Perspective." forthcoming, Journal of Money, Credit and Banking; available as Wharton Financial Institutions Center Working Paper \#03-13B.

[36] Saunders, Anthony and Linda Allen (2002). Credit Risk Measurement- New Approaches to Value at Risk and Other Paradigms. $2^{\text {nd }}$ Ed., New York: John Wiley \& Sons.

[37] Schönbucher, Philipp J. (1998). "The Term Structure of Defaultable Bond Prices." Review of Derivatives Research 2, 161-192.

[38] Schönbucher, Philipp J. (2002). "Taken to the Limit: Simple and Not-so-Simple Loan Loss Distributions." Working Paper, Department of Statistics, Bonn Univ.

[39] Shumway, Tyler (2001). "Forecasting Bankruptcy more Accurately: A Simple Hazard Model." Journal of Business 74, 101-124.

[40] Silverman, Bernard W. (1986). Density Estimation for Statistics and Data Analysis. New York, NY: Chapman \& Hall.

[41] Vasicek, Oldrich (1987). "Probability of Loss on Loan Portfolio." KMV Corp.; available at www.kmv.com. 
[42] Vasicek, Oldrich (1991), "Limiting Loan Loss Distribution," KMV Corp.; available at www.kmv.com.

[43] Vasicek, Oldrich (2002). "Loan Portfolio Value." Risk 15, 160-162.

[44] Wilson, Thomas (1997a). "Portfolio Credit Risk, Part I." Risk 10, September, 111-117.

[45] Wilson, Thomas (1997b). "Portfolio Credit Risk, Part II." Risk 10, October, 56-61. 


\section{Table 1}

Ratings Distributions and Probabilities of Default

\begin{tabular}{|c|c|c|c|c|c|c|c|c|}
\hline \multirow[b]{3}{*}{ Credit Rating } & \multicolumn{4}{|c|}{1997} & \multicolumn{4}{|c|}{2002} \\
\hline & \multicolumn{3}{|c|}{$\underline{\text { Ratings Distribution (\%) }}$} & \multirow[b]{2}{*}{$\hat{\pi}_{R}(\%)$} & \multicolumn{3}{|c|}{ Ratings Distribution (\%) } & \multirow[b]{2}{*}{$\hat{\pi}_{R}(\%)$} \\
\hline & Japan & U.S. & Both & & Japan & U.S. & Both & \\
\hline $\mathcal{A A \mathcal { A }}$ & 4.8 & 2.86 & 3.35 & 0.001 & 0.75 & 2.37 & 1.97 & 0.001 \\
\hline $\mathcal{A A}$ & 22.62 & 10.81 & 13.76 & 0.001 & 16.03 & 9.25 & 10.95 & 0.001 \\
\hline $\mathcal{A}$ & 37.93 & 25.61 & 28.69 & 0.005 & 29.38 & 21.49 & 23.46 & 0.006 \\
\hline $\mathcal{B B B}$ & 23.16 & 22.33 & 22.54 & 0.064 & 34.89 & 25.67 & 27.97 & 0.106 \\
\hline $\mathcal{B B}$ & 9.94 & 16.3 & 14.71 & 0.481 & 11.85 & 15.72 & 14.75 & 0.63 \\
\hline $\mathcal{B}$ & 1.54 & 19.79 & 15.22 & 3.343 & 6.75 & 19.62 & 16.4 & 5.429 \\
\hline $\mathcal{C C C}$ & 0 & 2.31 & 1.73 & 36.49 & 0.35 & 5.89 & 4.5 & 49.78 \\
\hline Portfolio & & & & 1.23 & & & & 3.26 \\
\hline
\end{tabular}

Note: The table presents the distribution of firms by rating for U.S. and Japan as of year-end 1997 and 2002. These distributions are calculated by taking the average of the distribution for Moody's and the distribution for Standard and Poor's. We construct our portfolios so that the exposure weights for each country are consistent with that country's rating distribution. The column label "Both" represents the exposure weights by rating for the combined portfolio (75\% U.S. / $25 \%$ Japan). The final column, $\hat{\pi}_{R}(\%)$, contains the estimated annual probabilities of default (PD) that are used in the simulation exercises. These PDs are estimated using the timehomogeneous Markov or parametric duration estimator discussed in Lando and Skødeberg (2002) and Jafry and Schuermann (2004). A minimum annual PD of $0.001 \%$ or 0.1 basis points is imposed.

\section{Table 2}

\section{Industry Breakdowns by Country}

\begin{tabular}{lrr}
\hline \multirow{2}{*}{ Industry } & \multicolumn{2}{c}{$\begin{array}{c}\text { \%o of Firms at } \\
\text { Year-End 1997 }\end{array}$} \\
\cline { 2 - 3 } & \multicolumn{1}{c}{ U.S. } & Japan \\
\hline Agriculture, Mining \& Construction & 5.3 & 8.5 \\
Communication, Electric \& Gas & 16.7 & 6.2 \\
Durable Manufacturing & 22.1 & 34.1 \\
Finance, Insurance \& Real Estate & 23.1 & 14.7 \\
Non-durable Manufacturing & 18.2 & 24.6 \\
Service & 4.8 & 6.6 \\
Wholesale \& Retail Trade & 9.9 & 5.2 \\
\hline Total & $\mathbf{1 0 0 . 0}$ & $\mathbf{1 0 0 . 0}$ \\
\hline
\end{tabular}

Note: The table presents the distribution of firms by industry group for both the U.S. and Japan sub-portfolios as of year-end 1997. 
Table 3

\section{Specifications of Return Equations and Default Thresholds for Separate Country Models, $c=U S, J P$}

\begin{tabular}{lllc}
\hline Models & Descriptions & Return Specification & Default Thresholds \\
\hline I & Vasicek & $r_{i j c, t+1}=\alpha_{c}+\beta_{c} \bar{r}_{c, t+1}+u_{i j c, t+1}$ & $\lambda_{c} / D D_{c}$ \\
II & Vasicek + FE & $r_{i j c, t+1}=\alpha_{i j c}+\beta_{c} \bar{r}_{c, t+1}+u_{i j c, t+1}$ & $\lambda_{c} / D D_{i}$ \\
III & Vasicek + Rating & $r_{i j c, t+1}=\alpha_{c}+\beta_{c} \bar{r}_{c, t+1}+u_{i j c, t+1}$ & $\lambda_{\mathcal{R}, c} / D D_{\mathcal{R}}$ \\
IV & CAPM & $r_{i j c, t+1}=\alpha_{i j c}+\beta_{i j c} \bar{r}_{c, t+1}+u_{i j c, t+1}$ & $\lambda_{i} / D D_{\mathcal{R}}$ \\
V & CAPM + Sector & $r_{i j c, t+1}=\alpha_{i j c}+\beta_{1, i j c} \bar{r}_{c, t+1}$ & $\lambda_{i} / D D_{\mathcal{R}}$ \\
& & $+\beta_{2, i j c} \bar{r}_{c j, t+1}+u_{i j c, t+1}$ & \\
VI & PCA & $r_{i j c, t+1}=\alpha_{i j c}+\boldsymbol{\beta}_{i j c}^{\prime} \mathbf{f}_{c, t+1}+u_{i j c, t+1}$ & $\lambda_{i} / D D_{\mathcal{R}}$ \\
\hline
\end{tabular}

Note: For the "pooled" models the $c$ subscript is dropped from all expressions.

Note: The table summarizes the return equations and default thresholds for the "separate country" models presented in Table $8 . \quad r_{i j, t+1}$ denotes the return of firm $i$ in sector $j$ in country $c$ over the quarter $t$ to $t+1$. In Models I through $\mathrm{V}, \bar{r}_{c, t+1}$ denotes the market-cap weighted return in country $c$ over the quarter $t$ to $t+1$ and $\bar{r}_{c j, t+1}$ is the market-cap weighted return for sector $j$ in country $c$ over the same period. Model VI, the principal components model ( PCA ), is discussed in greater detail in Appendix C. For the Vasicek model all firms in country $c$ have the same default threshold, $\lambda_{c}$. Default thresholds for Model II, Vasicek + Fixed Effects (FE), are identified using an analog of (57) under the assumption that all firms in country $c$ have the same threshold, $\lambda_{c}$ (note that this results in firm-specific distances-to-default, $D D_{i}$ ). Models III through VI use identifying assumption (58), namely that all firms in rating $\mathcal{R}$ have the same distance-to-default $D D_{\mathcal{R}}$, to determine default thresholds. This assumption generates fourteen different $\lambda$ 's for Model III (one for each country/rating pair) and firm specific $\lambda_{i}$ 's for Models IV through VI. For the "pooled" country models we drop the $c$ subscript on $\bar{r}_{c, t+1}, \bar{r}_{c j, t+1}$, and $f_{c, t+1}$ so that the common factors are global factors as opposed to country-specific factors. We also omit the $c$ subscript on $\lambda_{c}$ and $\lambda_{R, c}$, meaning that for Model I and II there is a single default threshold for all firms and that there are only seven thresholds for Model III - one for each rating. 


\section{Table 4 \\ Average Pair-wise Correlation of Returns and In-sample Residuals Based on Ten-Year Rolling Windows}

\begin{tabular}{|c|c|c|c|c|c|c|c|c|c|c|c|c|}
\hline & \multirow{3}{*}{$\begin{array}{c}\text { Sample } \\
\text { Window }\end{array}$} & & & & & & \multicolumn{6}{|c|}{ Average Pair-wise Correlation of Residuals } \\
\hline & & \multicolumn{3}{|c|}{ Average Pair-wise Correlation of Returns } & \multirow{2}{*}{\multicolumn{2}{|c|}{ Model Specifications }} & \multicolumn{3}{|c|}{ US \& Japan Pooled } & \multicolumn{3}{|c|}{ US \& Japan Modeled Separately } \\
\hline & & US\&JP & US & JP & & & US\&JP & US & JP & US\&JP & US & JP \\
\hline \multirow[t]{5}{*}{ Panel A } & 1988-1997 & 0.1937 & 0.1933 & 0.6011 & I & Vasicek & 0.0222 & 0.0951 & 0.4217 & 0.0239 & 0.0365 & 0.0607 \\
\hline & & & & & II & Vascicek + FE & 0.0222 & 0.0951 & 0.4217 & 0.0239 & 0.0365 & 0.0607 \\
\hline & Sample Size & 839 & 628 & 211 & IV & CAPM & 0.0218 & 0.0797 & 0.3868 & 0.0242 & 0.0374 & 0.0639 \\
\hline & & & & & $\mathrm{V}$ & CAPM + Sector & 0.0147 & 0.0711 & 0.3869 & 0.0142 & 0.0221 & 0.0227 \\
\hline & & & & & VI & PCA & -0.0001 & 0.0016 & 0.0037 & 0.0000 & 0.0005 & -0.0045 \\
\hline \multirow[t]{5}{*}{ Panel B } & 1989-1998 & 0.2150 & 0.2114 & 0.5913 & I & Vasicek & 0.0235 & 0.0940 & 0.3793 & 0.0249 & 0.0440 & 0.0633 \\
\hline & & & & & II & Vascicek + FE & 0.0235 & 0.0940 & 0.3793 & 0.0249 & 0.0440 & 0.0633 \\
\hline & Sample Size & 854 & 633 & 221 & IV & CAPM & 0.0237 & 0.0825 & 0.3553 & 0.0255 & 0.0456 & 0.0666 \\
\hline & & & & & V & CAPM + Sector & 0.0177 & 0.0773 & 0.3582 & 0.0193 & 0.0324 & 0.0258 \\
\hline & & & & & $\mathrm{VI}$ & PCA & 0.0003 & 0.0011 & 0.0028 & 0.0000 & 0.0004 & -0.0041 \\
\hline \multirow[t]{5}{*}{ Panel C } & 1990-1999 & 0.2097 & 0.2237 & 0.5666 & I & Vasicek & 0.0533 & 0.1282 & 0.3917 & 0.0627 & 0.0731 & 0.1391 \\
\hline & & & & & II & Vascicek + FE & 0.0533 & 0.1282 & 0.3917 & 0.0627 & 0.0731 & 0.1391 \\
\hline & Sample Size & 842 & 613 & 229 & IV & CAPM & 0.0568 & 0.1246 & 0.3807 & 0.0661 & 0.0778 & 0.1473 \\
\hline & & & & & $\mathrm{V}$ & CAPM + Sector & 0.0419 & 0.1168 & 0.3817 & 0.0417 & 0.0621 & 0.0390 \\
\hline & & & & & $\mathrm{VI}$ & PCA & 0.0000 & 0.0005 & 0.0010 & -0.0003 & -0.0001 & -0.0036 \\
\hline \multirow[t]{5}{*}{ Panel D } & 1991-2000 & 0.1391 & 0.1691 & 0.4638 & I & Vasicek & 0.0533 & 0.1207 & 0.3427 & 0.0633 & 0.0783 & 0.1359 \\
\hline & & & & & II & Vascicek + FE & 0.0533 & 0.1207 & 0.3427 & 0.0633 & 0.0783 & 0.1359 \\
\hline & Sample Size & 816 & 588 & 228 & IV & CAPM & 0.0559 & 0.1206 & 0.3442 & 0.0649 & 0.0821 & 0.1428 \\
\hline & & & & & $\mathrm{V}$ & CAPM + Sector & 0.0379 & 0.1039 & 0.3470 & 0.0392 & 0.0615 & 0.0427 \\
\hline & & & & & $\mathrm{VI}$ & PCA & 0.0000 & 0.0018 & 0.0030 & 0.0002 & 0.0008 & -0.0041 \\
\hline \multirow[t]{5}{*}{ Panel E } & $1992-2001$ & 0.1309 & 0.1633 & 0.4411 & I & Vasicek & 0.0482 & 0.1132 & 0.3282 & 0.0578 & 0.0740 & 0.1277 \\
\hline & & & & & II & Vascicek + FE & 0.0482 & 0.1132 & 0.3282 & 0.0578 & 0.0740 & 0.1277 \\
\hline & Sample Size & 811 & 585 & 226 & IV & CAPM & 0.0501 & 0.1135 & 0.3324 & 0.0583 & 0.0772 & 0.1339 \\
\hline & & & & & $\mathrm{V}$ & CAPM + Sector & 0.0378 & 0.1077 & 0.3361 & 0.0381 & 0.0624 & 0.0421 \\
\hline & & & & & $\mathrm{VI}$ & PCA & -0.0007 & 0.0001 & 0.0009 & -0.0004 & -0.0003 & -0.0042 \\
\hline \multirow[t]{5}{*}{ Panel F } & 1993-2002 & 0.1545 & 0.1999 & 0.4191 & I & Vasicek & 0.0549 & 0.1098 & 0.3332 & 0.0628 & 0.0772 & 0.1254 \\
\hline & & & & & II & Vascicek + FE & 0.0549 & 0.1098 & 0.3332 & 0.0628 & 0.0772 & 0.1254 \\
\hline & Sample Size & 818 & 600 & 218 & IV & CAPM & 0.0569 & 0.1157 & 0.3488 & 0.0641 & 0.0811 & 0.1324 \\
\hline & & & & & $\mathrm{V}$ & CAPM + Sector & 0.0439 & 0.1099 & 0.3543 & 0.0426 & 0.0658 & 0.0391 \\
\hline & & & & & $\mathrm{VI}$ & PCA & -0.0008 & -0.0006 & 0.0001 & -0.0007 & -0.0009 & -0.0043 \\
\hline
\end{tabular}

Note: This table presents the results of recursive estimation of return equations using quarterly return data. All estimation results are calculated using a 40-quarter rolling window. The results for the "pooled" country models are given in the first set of columns and the "separate" country models in the second set of columns. Portfolio determination and sample construction are discussed in Section 7.1. Specification of the return models is discussed in Section 7.2 (see Table 3 for further detail). The data source for returns of U.S. firms is CRSP. The source for Japanese firms is Datastream. Yen-denominated Japanese returns are converted to USD-denominated returns by subtracting the percentage change in the Yen/USD exchange rate. See Table 3 for more detail on model specifications. 
Table 5

\section{Analytical and Simulated Loss Distribution Results for Vasicek Model Based on U.S. \& Japan Pooled Return Specifications}

\begin{tabular}{|c|c|c|c|c|c|c|c|c|c|c|c|c|c|c|c|c|c|}
\hline \multirow{2}{*}{$\begin{array}{c}\text { Simulation } \\
\text { Year }\end{array}$} & \multirow[b]{2}{*}{$\hat{\pi}$} & \multirow[b]{2}{*}{$\hat{\rho}$} & \multirow[b]{2}{*}{$\hat{\rho}^{*}$} & \multicolumn{2}{|c|}{ Portfolio Size } & \multicolumn{3}{|c|}{ UL } & \multicolumn{3}{|c|}{ 99.0\% VaR } & \multicolumn{3}{|c|}{ 99.5\% VaR } & \multicolumn{3}{|c|}{$99.9 \% \mathrm{VaR}$} \\
\hline & & & & $\mathbf{N}$ & $\mathbf{N}^{*}$ & Anal. & Simul. & Granul. & Anal. & Simul. & Granul. & Anal. & Simul. & Granul. & Anal. & Simul. & Granul. \\
\hline 1998 & $1.23 \%$ & $13.83 \%$ & $1.63 \%$ & 839 & 638 & $1.40 \%$ & $1.47 \%$ & $0.07 \%$ & $6.81 \%$ & $7.00 \%$ & $0.19 \%$ & $8.23 \%$ & $8.48 \%$ & $0.26 \%$ & $11.82 \%$ & $12.05 \%$ & $0.23 \%$ \\
\hline 1999 & $1.60 \%$ & $15.69 \%$ & $2.26 \%$ & 854 & 635 & $1.89 \%$ & $1.94 \%$ & $0.05 \%$ & $9.17 \%$ & $9.30 \%$ & $0.13 \%$ & $11.07 \%$ & $11.13 \%$ & $0.06 \%$ & $15.84 \%$ & $15.91 \%$ & $0.07 \%$ \\
\hline 2000 & $2.10 \%$ & $13.71 \%$ & $2.23 \%$ & 842 & 613 & $2.14 \%$ & $2.22 \%$ & $0.08 \%$ & $10.35 \%$ & $10.65 \%$ & $0.30 \%$ & $12.25 \%$ & $12.59 \%$ & $0.33 \%$ & $16.92 \%$ & $17.34 \%$ & $0.42 \%$ \\
\hline 2001 & $2.27 \%$ & $8.00 \%$ & $1.23 \%$ & 816 & 619 & $1.65 \%$ & $1.75 \%$ & $0.10 \%$ & $8.08 \%$ & $8.39 \%$ & $0.31 \%$ & $9.24 \%$ & $9.66 \%$ & $0.42 \%$ & $12.01 \%$ & $12.72 \%$ & $0.71 \%$ \\
\hline 2002 & $2.73 \%$ & $7.71 \%$ & $1.32 \%$ & 811 & 642 & $1.88 \%$ & $1.98 \%$ & $0.10 \%$ & $9.22 \%$ & $9.48 \%$ & $0.26 \%$ & $10.47 \%$ & $10.74 \%$ & $0.27 \%$ & $13.42 \%$ & $13.71 \%$ & $0.29 \%$ \\
\hline 2003 & $3.26 \%$ & $9.20 \%$ & $1.80 \%$ & 818 & 654 & $2.38 \%$ & $2.48 \%$ & $0.10 \%$ & $11.61 \%$ & $11.92 \%$ & $0.31 \%$ & $13.23 \%$ & $13.59 \%$ & $0.36 \%$ & $17.06 \%$ & $17.47 \%$ & $0.41 \%$ \\
\hline
\end{tabular}

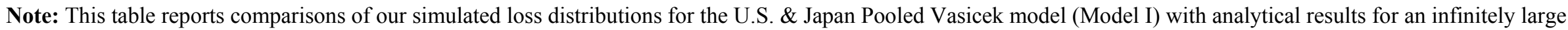

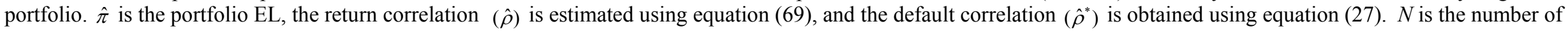

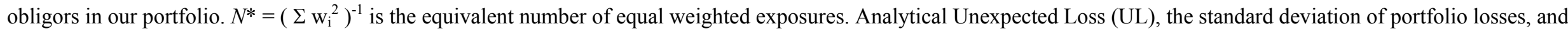
Value-at-Risk (VaR), the $\alpha$-percent quantiles of the loss distribution, are computed using similar expressions to those given in Vasicek (2002). Specifically,

$$
\begin{aligned}
& \lim _{n \rightarrow \infty} U L\left(\ell_{N, t+1}\right)=\sqrt{\pi(1-\pi) \rho^{*}(\pi, \rho)}=\sqrt{\Phi_{2}\left[\Phi^{-1}(\pi), \Phi^{-1}(\pi), \rho\right]-\pi^{2}}
\end{aligned}
$$

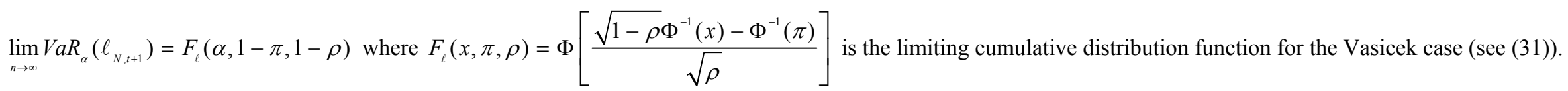

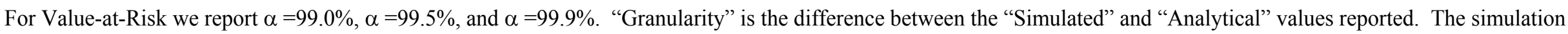
procedure is discussed in Appendix D. All simulations are carried out using 200,000 replications. 
Table 6

Simulated (Out-of-Sample) Default Correlations

\section{Based on Model II(b) for U.S. \& Japan Pooled Return Specification}

(2003)

Panel A: Default Probabilities (in basis points) and Correlations by Credit Rating

\begin{tabular}{l|ccc|}
\multicolumn{1}{c}{} & $\hat{\pi}_{R}$ & $\hat{\rho}$ & $\hat{\rho}_{R}^{*}$ \\
\cline { 2 - 4 } $\mathcal{A} \mathcal{A} \mathcal{A} \& \mathcal{A} \mathcal{A}$ & 0.10 & $9.20 \%$ & $0.004 \%$ \\
$\mathcal{B B B}$ & 0.58 & $9.20 \%$ & $0.018 \%$ \\
$\mathcal{B B}$ & 10.59 & $9.20 \%$ & $0.170 \%$ \\
$\mathcal{B}$ & 63.03 & $9.20 \%$ & $0.615 \%$ \\
$\mathcal{C C C}$ & 542.88 & $9.20 \%$ & $2.437 \%$ \\
& $4,977.60$ & $9.20 \%$ & $5.865 \%$ \\
\hline
\end{tabular}

Panel B: $\quad$ Default Correlations by Credit Rating

\begin{tabular}{l|cccccc|}
\multicolumn{1}{c}{} & $\mathcal{A} \mathcal{A} \mathcal{A} \& \mathcal{A A}$ & $\mathcal{A}$ & $\mathcal{B B B}$ & $\mathcal{B B}$ & $\mathcal{B}$ & $\mathcal{C C C}$ \\
\cline { 2 - 7 } $\mathcal{A} \mathcal{A} \mathcal{A} \& \mathcal{A A}$ & $0.004 \%$ & - & - & - & - & - \\
$\mathcal{A}$ & $0.009 \%$ & $0.018 \%$ & - & - & - & - \\
$\mathcal{B B B}$ & $0.026 \%$ & $0.054 \%$ & $0.170 \%$ & - & - & - \\
$\mathcal{B B}$ & $0.048 \%$ & $0.100 \%$ & $0.320 \%$ & $0.615 \%$ & - & - \\
$\mathcal{B}$ & $0.086 \%$ & $0.183 \%$ & $0.607 \%$ & $1.199 \%$ & $2.437 \%$ & - \\
$\mathcal{C C C}$ & $0.102 \%$ & $0.224 \%$ & $0.792 \%$ & $1.636 \%$ & $3.560 \%$ & $5.865 \%$ \\
\hline
\end{tabular}

Note: This table reports simulated (out-of-sample) default correlations by rating for Model III for the final simulation year, 2003. Recall that for the pooled version of Model III the pair-wise correlation of simulated (out-of-sample) returns is the same for all firms and is the same as in the Vasicek model (i.e. $\hat{\rho}_{i, j}=\hat{\rho} \forall i, j$ where $\hat{\rho}$ is given by equation (69)). Pair-wise correlations of simulated (out-of-sample) defaults are obtained as described in Section 7.4.1, using equation (16) in (12). 
Table 7

The Impact of Parameter Heterogeneity on the Loss Distribution

Panel A

The Impact on Expected Losses (EL) of Allowing for Fixed Effects

\begin{tabular}{|ccc|}
\multicolumn{1}{c}{ Year } & \multicolumn{2}{c}{ Simulated EL } \\
\cline { 2 - 3 } $\mathbf{1 9 9 8}$ & Vasicek & Fixed Effect \\
$\mathbf{1 9 9 9}$ & $1.23 \%$ & $1.72 \%$ \\
$\mathbf{2 0 0 0}$ & $1.60 \%$ & $2.17 \%$ \\
$\mathbf{2 0 0 1}$ & $2.10 \%$ & $2.67 \%$ \\
$\mathbf{2 0 0 2}$ & $2.28 \%$ & $2.93 \%$ \\
$\mathbf{2 0 0 3}$ & $2.74 \%$ & $3.28 \%$ \\
\hline
\end{tabular}

Panel B

The Impact on Unexpected Losses (UL) of Allowing for Fixed Effects

\begin{tabular}{|ccc|}
\multicolumn{1}{c}{ Year } & \multicolumn{2}{c}{ Simulated UL } \\
\cline { 2 - 3 } $\mathbf{1 9 9 8}$ & Vasicek & Fixed Effect \\
$\mathbf{1 9 9 9}$ & $1.47 \%$ & $1.39 \%$ \\
$\mathbf{2 0 0 0}$ & $1.94 \%$ & $1.84 \%$ \\
$\mathbf{2 0 0 1}$ & $2.22 \%$ & $2.10 \%$ \\
$\mathbf{2 0 0 2}$ & $1.75 \%$ & $1.68 \%$ \\
$\mathbf{2 0 0 3}$ & $1.98 \%$ & $1.90 \%$ \\
\hline
\end{tabular}

Note: The results in Panel A compare Expected Losses (EL) for the U.S. \& Japan Pooled version of Model I (Vasicek) with EL allowing for firm fixed effects, $\alpha_{i}$, where we have deliberately not equalized EL with Model I. The results in Panel B compare Unexpected Losses (UL) for the U.S. \& Japan Pooled version of the Vasicek model (Model I) with UL for Model II - Vasicek with Fixed Effect. In Panel B, we have equalized EL across the two models for each year. The simulation procedure is discussed in Appendix D. All simulations are carried out using 200,000 replications. 
Table 8

Out-of-Sample Simulated Annual Losses Based on 10-Year Rolling Return Regressions

200,000 replications

\begin{tabular}{|c|c|c|c|c|c|c|c|c|c|c|c|c|c|c|c|c|c|}
\hline & \multirow{3}{*}{$\begin{array}{c}\text { Simulation } \\
\text { Year }\end{array}$} & \multirow{3}{*}{$\begin{array}{c}\text { Using } \\
\text { Sample }\end{array}$} & & & \multirow{3}{*}{$\begin{array}{c}\text { Default } \\
\text { Thresholds }\end{array}$} & \multicolumn{6}{|c|}{ US \& Japan Pooled } & \multicolumn{6}{|c|}{ US \& Japan Modeled Separately } \\
\hline & & & & & & \multirow[b]{2}{*}{ UL } & \multirow[b]{2}{*}{ Skew. } & \multirow[b]{2}{*}{ Kurt. } & \multicolumn{3}{|c|}{ Value-at-Risk } & \multirow[b]{2}{*}{ UL } & \multirow[b]{2}{*}{ Skew. } & \multirow[b]{2}{*}{ Kurt. } & \multicolumn{3}{|c|}{ Value-at-Risk } \\
\hline & & & & del Specifications & & & & & $99.0 \%$ & $99.5 \%$ & $99.9 \%$ & & & & $\mathbf{9 9 . 0} \%$ & $99.5 \%$ & $99.9 \%$ \\
\hline \multirow[t]{6}{*}{ Panel A } & 1998 & 1988-1997 & I & Vasicek & $\lambda_{c} / \mathrm{DD}_{c}$ & $1.47 \%$ & 3.1 & 19.5 & $7.00 \%$ & $8.48 \%$ & $12.05 \%$ & $1.29 \%$ & 2.6 & 15.5 & $6.10 \%$ & $7.22 \%$ & $10.14 \%$ \\
\hline & & & II & Vasicek + FE & $\lambda_{c} / \mathrm{DD}_{c, i}$ & $1.39 \%$ & 2.8 & 16.9 & $6.57 \%$ & $7.86 \%$ & $11.14 \%$ & $1.23 \%$ & 2.5 & 14.2 & $5.80 \%$ & $6.82 \%$ & $9.51 \%$ \\
\hline & $\hat{\pi}=$ & $1.23 \%$ & III & Vasicek + Rating & $\lambda_{i} / \mathrm{DD}_{R}$ & $1.07 \%$ & 1.3 & 5.8 & $4.57 \%$ & $5.19 \%$ & $6.72 \%$ & $1.01 \%$ & 1.1 & 5.1 & $4.30 \%$ & $4.81 \%$ & $6.17 \%$ \\
\hline & & & IV & CAPM & $\lambda_{i} / \mathrm{DD}_{R}$ & $0.86 \%$ & 1.0 & 5.9 & $3.73 \%$ & $4.19 \%$ & $5.56 \%$ & $0.88 \%$ & 1.0 & 5.7 & $3.82 \%$ & $4.33 \%$ & $5.75 \%$ \\
\hline & & & $\mathrm{V}$ & CAPM + Sector & $\lambda_{i} / \mathrm{DD}_{R}$ & $0.88 \%$ & 1.0 & 6.1 & $3.81 \%$ & $4.32 \%$ & $5.58 \%$ & $0.90 \%$ & 1.1 & 5.9 & $3.89 \%$ & $4.42 \%$ & $5.81 \%$ \\
\hline & & & VI & PCA & $\lambda_{i} / \mathrm{DD}_{R}$ & $1.08 \%$ & 1.6 & 8.8 & $4.82 \%$ & $5.62 \%$ & $7.69 \%$ & $1.07 \%$ & 1.5 & 7.8 & $4.74 \%$ & $5.47 \%$ & $7.30 \%$ \\
\hline \multirow[t]{6}{*}{ Panel B } & 1999 & 1989-1998 & I & Vasicek & $\lambda_{c} / \mathrm{DD}_{c}$ & $1.94 \%$ & 3.0 & 18.1 & $9.30 \%$ & $11.13 \%$ & $15.91 \%$ & $1.73 \%$ & 2.8 & 17.9 & $8.25 \%$ & $9.77 \%$ & $14.04 \%$ \\
\hline & & & II & Vasicek + FE & $\lambda_{c} / \mathrm{DD}_{c, i}$ & $1.84 \%$ & 2.8 & 16.3 & $8.76 \%$ & $10.43 \%$ & $14.75 \%$ & $1.65 \%$ & 2.7 & 16.3 & $7.86 \%$ & $9.31 \%$ & $13.12 \%$ \\
\hline & $\hat{\pi}=$ & $1.60 \%$ & III & Vasicek + Rating & $\lambda_{i} / \mathrm{DD}_{R}$ & $1.28 \%$ & 1.4 & 6.7 & $5.80 \%$ & $6.62 \%$ & $8.52 \%$ & $1.21 \%$ & 1.4 & 6.7 & $5.50 \%$ & $6.23 \%$ & $7.95 \%$ \\
\hline & & & IV & CAPM & $\lambda_{i} / \mathrm{DD}_{R}$ & $0.95 \%$ & 1.3 & 8.2 & $4.53 \%$ & $5.16 \%$ & $6.93 \%$ & $0.98 \%$ & 1.4 & 8.7 & $4.67 \%$ & $5.35 \%$ & $7.06 \%$ \\
\hline & & & V & CAPM + Sector & $\lambda_{i} / \mathrm{DD}_{R}$ & $0.99 \%$ & 1.2 & 7.4 & $4.64 \%$ & $5.31 \%$ & $7.06 \%$ & $1.04 \%$ & 1.5 & 8.9 & $4.88 \%$ & $5.59 \%$ & $7.67 \%$ \\
\hline & & & VI & PCA & $\lambda_{i} / \mathrm{DD}_{R}$ & $1.20 \%$ & 1.7 & 9.3 & $5.69 \%$ & $6.58 \%$ & $8.88 \%$ & $1.20 \%$ & 1.8 & 10.4 & $5.72 \%$ & $6.70 \%$ & $8.95 \%$ \\
\hline \multirow[t]{6}{*}{ Panel C } & 2000 & 1990-1999 & I & Vasicek & $\lambda_{c} / \mathrm{DD}_{c}$ & $2.22 \%$ & 2.6 & 14.7 & $10.65 \%$ & $12.59 \%$ & $17.34 \%$ & $2.06 \%$ & 2.4 & 12.7 & $9.78 \%$ & $11.61 \%$ & $15.87 \%$ \\
\hline & & & II & Vasicek + FE & $\lambda_{c} / \mathrm{DD}_{c, i}$ & $2.10 \%$ & 2.4 & 13.1 & $10.03 \%$ & $11.81 \%$ & $16.17 \%$ & $1.97 \%$ & 2.3 & 11.7 & $9.34 \%$ & $10.97 \%$ & $14.87 \%$ \\
\hline & $\hat{\pi}=$ & $2.10 \%$ & III & Vasicek + Rating & $\lambda_{i} / \mathrm{DD}_{R}$ & $1.43 \%$ & 1.2 & 5.5 & $6.56 \%$ & $7.35 \%$ & $9.18 \%$ & $1.39 \%$ & 1.1 & 5.3 & $6.37 \%$ & $7.17 \%$ & $8.91 \%$ \\
\hline & & & IV & CAPM & $\lambda_{i} / \mathrm{DD}_{R}$ & $1.05 \%$ & 1.0 & 6.3 & $5.23 \%$ & $5.85 \%$ & $7.54 \%$ & $1.12 \%$ & 1.1 & 6.1 & $5.51 \%$ & $6.21 \%$ & $7.99 \%$ \\
\hline & & & V & CAPM + Sector & $\lambda_{i} / \mathrm{DD}_{R}$ & $1.09 \%$ & 1.0 & 5.7 & $5.33 \%$ & $5.94 \%$ & $7.56 \%$ & $1.19 \%$ & 1.1 & 6.2 & $5.74 \%$ & $6.45 \%$ & $8.25 \%$ \\
\hline & & & VI & PCA & $\lambda_{i} / \mathrm{DD}_{R}$ & $1.39 \%$ & 1.5 & 7.7 & $6.68 \%$ & $7.69 \%$ & $10.16 \%$ & $1.40 \%$ & 1.6 & 8.4 & $6.77 \%$ & $7.79 \%$ & $10.46 \%$ \\
\hline
\end{tabular}


Table 8 (continued)

\section{Out-of-Sample Simulated Annual Losses Based on 10-Year Rolling Return Regressions}

200,000 replications

US \& Japan Pooled

\begin{tabular}{|c|c|c|c|c|c|c|c|c|c|c|c|c|c|c|c|c|c|}
\hline & \multirow{3}{*}{$\begin{array}{c}\text { Simulation } \\
\text { Year }\end{array}$} & \multirow{3}{*}{$\begin{array}{c}\text { Using } \\
\text { Sample } \\
\end{array}$} & & & \multirow{3}{*}{$\begin{array}{c}\text { Default } \\
\text { Thresholds } \\
\end{array}$} & \multicolumn{6}{|c|}{ us \& Japan Pooled } & \multicolumn{6}{|c|}{ US \& Japan Modeled Separately } \\
\hline & & & \multirow{2}{*}{\multicolumn{2}{|c|}{ Model Specifications }} & & \multirow[b]{2}{*}{$\mathbf{U L}$} & \multirow[b]{2}{*}{ Skew. } & \multirow[b]{2}{*}{ Kurt. } & \multicolumn{3}{|c|}{ Value-at-Risk } & \multirow[b]{2}{*}{$\mathbf{U L}$} & \multirow[b]{2}{*}{ Skew. } & \multirow[b]{2}{*}{ Kurt. } & \multicolumn{3}{|c|}{ Value-at-Risk } \\
\hline & & & & & & & & & $99.0 \%$ & $99.5 \%$ & $99.9 \%$ & & & & $99.0 \%$ & $99.5 \%$ & $99.9 \%$ \\
\hline \multirow[t]{6}{*}{ Panel D } & 2001 & 1991-2000 & I & Vasicek & $\lambda_{c} / \mathrm{DD}_{c}$ & $1.75 \%$ & 1.8 & 8.6 & $8.39 \%$ & $9.66 \%$ & $12.72 \%$ & $1.72 \%$ & 1.7 & 8.2 & $8.20 \%$ & $9.38 \%$ & $12.04 \%$ \\
\hline & & & II & Vasicek $+\mathrm{FE}$ & $\lambda_{c} / \mathrm{DD}_{c, i}$ & $1.68 \%$ & 1.7 & 7.8 & $8.00 \%$ & $9.22 \%$ & $12.05 \%$ & $1.65 \%$ & 1.6 & 7.4 & $7.81 \%$ & $8.91 \%$ & $11.31 \%$ \\
\hline & $\hat{\pi}=$ & $2.28 \%$ & III & Vasicek + Rating & $\lambda_{i} / \mathrm{DD}_{R}$ & $1.22 \%$ & 0.7 & 3.8 & $5.71 \%$ & $6.23 \%$ & $7.38 \%$ & $1.23 \%$ & 0.7 & 3.9 & $5.71 \%$ & $6.23 \%$ & $7.40 \%$ \\
\hline & & & IV & CAPM & $\lambda_{i} / \mathrm{DD}_{R}$ & $1.13 \%$ & 0.8 & 4.4 & $5.54 \%$ & $6.09 \%$ & $7.46 \%$ & $1.20 \%$ & 0.8 & 4.5 & $5.76 \%$ & $6.31 \%$ & $7.69 \%$ \\
\hline & & & $\mathrm{V}$ & CAPM + Sector & $\lambda_{i} / \mathrm{DD}_{R}$ & $1.18 \%$ & 0.7 & 4.2 & $5.64 \%$ & $6.20 \%$ & $7.57 \%$ & $1.27 \%$ & 0.8 & 4.4 & $5.96 \%$ & $6.58 \%$ & $8.06 \%$ \\
\hline & & & VI & PCA & $\lambda_{i} / \mathrm{DD}_{R}$ & $1.44 \%$ & 1.1 & 5.4 & $6.74 \%$ & $7.55 \%$ & $9.49 \%$ & $1.44 \%$ & 1.1 & 5.5 & $6.75 \%$ & $7.57 \%$ & $9.66 \%$ \\
\hline \multirow[t]{6}{*}{ Panel E } & 2002 & $1992-2001$ & I & Vasicek & $\lambda_{c} / \mathrm{DD}_{c}$ & $1.98 \%$ & 1.6 & 7.3 & $9.48 \%$ & $10.74 \%$ & $13.71 \%$ & $1.96 \%$ & 1.6 & 7.5 & $9.45 \%$ & $10.62 \%$ & $13.65 \%$ \\
\hline & & & II & Vasicek + FE & $\lambda_{c} / \mathrm{DD}_{c, i}$ & $1.90 \%$ & 1.6 & 6.9 & $9.15 \%$ & $10.32 \%$ & $12.97 \%$ & $1.90 \%$ & 1.6 & 7.0 & $9.17 \%$ & $10.28 \%$ & $13.06 \%$ \\
\hline & $\hat{\pi}=$ & $2.74 \%$ & III & Vasicek + Rating & $\lambda_{i} / \mathrm{DD}_{R}$ & $1.34 \%$ & 0.5 & 3.4 & $6.32 \%$ & $6.80 \%$ & $7.91 \%$ & $1.35 \%$ & 0.6 & 3.5 & $6.39 \%$ & $6.91 \%$ & $8.07 \%$ \\
\hline & & & IV & CAPM & $\lambda_{i} / \mathrm{DD}_{R}$ & $1.16 \%$ & 0.5 & 3.7 & $5.87 \%$ & $6.38 \%$ & $7.55 \%$ & $1.22 \%$ & 0.6 & 3.9 & $6.08 \%$ & $6.61 \%$ & $7.89 \%$ \\
\hline & & & $\mathrm{V}$ & CAPM + Sector & $\lambda_{i} / \mathrm{DD}_{R}$ & $1.19 \%$ & 0.6 & 3.8 & $5.98 \%$ & $6.50 \%$ & $7.73 \%$ & $1.26 \%$ & 0.7 & 4.1 & $6.25 \%$ & $6.82 \%$ & $8.23 \%$ \\
\hline & & & VI & PCA & $\lambda_{i} / \mathrm{DD}_{R}$ & $1.42 \%$ & 0.9 & 4.8 & $6.95 \%$ & $7.68 \%$ & $9.43 \%$ & $1.44 \%$ & 1.0 & 5.2 & $7.03 \%$ & $7.81 \%$ & $9.86 \%$ \\
\hline \multirow[t]{6}{*}{ Panel F } & 2003 & 1993-2002 & I & Vasicek & $\lambda_{c} / \mathrm{DD}_{c}$ & $2.48 \%$ & 1.8 & 8.0 & $11.92 \%$ & $13.59 \%$ & $17.47 \%$ & $2.56 \%$ & 1.8 & 8.2 & $12.20 \%$ & $13.89 \%$ & $17.81 \%$ \\
\hline & & & II & Vasicek $+\mathrm{FE}$ & $\lambda_{c} / \mathrm{DD}_{c, i}$ & $2.40 \%$ & 1.7 & 7.5 & $11.54 \%$ & $13.06 \%$ & $16.84 \%$ & $2.48 \%$ & 1.7 & 7.8 & $11.84 \%$ & $13.46 \%$ & $17.07 \%$ \\
\hline & $\hat{\pi}=$ & $3.26 \%$ & III & Vasicek + Rating & $\lambda_{i} / \mathrm{DD}_{R}$ & $1.51 \%$ & 0.6 & 3.7 & $7.46 \%$ & $8.06 \%$ & $9.46 \%$ & $1.56 \%$ & 0.7 & 3.9 & $7.65 \%$ & $8.28 \%$ & $9.86 \%$ \\
\hline & & & IV & CAPM & $\lambda_{i} / \mathrm{DD}_{R}$ & $1.27 \%$ & 0.8 & 4.7 & $6.98 \%$ & $7.64 \%$ & $9.21 \%$ & $1.27 \%$ & 0.8 & 5.0 & $7.00 \%$ & $7.66 \%$ & $9.30 \%$ \\
\hline & & & $\mathrm{V}$ & CAPM + Sector & $\lambda_{i} / \mathrm{DD}_{R}$ & $1.28 \%$ & 0.8 & 4.7 & $7.01 \%$ & $7.64 \%$ & $9.20 \%$ & $1.30 \%$ & 0.9 & 5.2 & $7.15 \%$ & $7.83 \%$ & $9.60 \%$ \\
\hline & & & VI & PCA & $\lambda_{i} / \mathrm{DD}_{R}$ & $1.51 \%$ & 1.1 & 5.9 & $7.96 \%$ & $8.93 \%$ & $11.15 \%$ & $1.49 \%$ & 1.2 & 6.2 & $7.91 \%$ & $8.85 \%$ & $11.11 \%$ \\
\hline
\end{tabular}

Note: This table presents results for simulated out-of-sample annual loss distributions (4-quarter ahead loss distributions). The table presents simulation results for the "pooled" country models in the first set of columns and the "separate" country models in the second set of columns. Model specifications, including the return regressions and determination of default thresholds, are discussed in Section 7.2 (see Table 3 for more detail on the model specifications). The simulation routine is discussed in Appendix D. Simulation are carried out using 200,000 replications. For each year all models are calibrated to have the same Expect Loss given by $\hat{\pi}$. For each simulation, the table reports the standard deviation of losses (denoted Unexpected Losses - UL), the $3^{\text {rd }}$ and $4^{\text {th }}$ moments of the loss distributions, as well as the $99.0 \%, 99.5 \%$ and $99.9 \%$ quantiles of the distribution (denoted Value-at-Risk). 
Table 9

\section{Comparison of Alternative Methods of Identification of Default Thresholds}

(2003)

200,000 replications

Panel A: Same Distance to Default by Rating: $\mathrm{DD}_{\mathrm{R}}$

\begin{tabular}{|c|c|c|c|c|c|c|c|c|c|c|c|c|c|c|}
\hline \multirow{3}{*}{$\begin{array}{c}\text { Simulation } \\
\text { Year }\end{array}$} & \multirow{3}{*}{$\begin{array}{c}\text { Using } \\
\text { Sample } \\
\end{array}$} & \multirow[b]{3}{*}{ Model Specifications } & \multicolumn{6}{|c|}{ US \& Japan Pooled } & \multicolumn{6}{|c|}{ US \& Japan Modeled Separately } \\
\hline & & & \multirow[b]{2}{*}{$\mathbf{U L}$} & \multirow[b]{2}{*}{ Skew. } & \multirow[b]{2}{*}{ Kurt. } & \multicolumn{3}{|c|}{ Value-at-Risk } & \multirow[b]{2}{*}{$\mathbf{U L}$} & \multirow[b]{2}{*}{ Skew. } & \multirow[b]{2}{*}{ Kurt. } & \multicolumn{3}{|c|}{ Value-at-Risk } \\
\hline & & & & & & $99.0 \%$ & $99.5 \%$ & $99.9 \%$ & & & & $99.0 \%$ & $99.5 \%$ & $99.9 \%$ \\
\hline \multirow[t]{2}{*}{2003} & 1993-2002 & I Vasicek & $2.48 \%$ & 1.8 & 8.0 & $11.92 \%$ & $13.59 \%$ & $17.47 \%$ & $2.56 \%$ & 1.8 & 8.2 & $12.20 \%$ & $13.89 \%$ & $17.81 \%$ \\
\hline & & III Vasicek + Rating & $1.51 \%$ & 0.6 & 3.7 & $7.46 \%$ & $8.06 \%$ & $9.46 \%$ & $1.56 \%$ & 0.7 & 3.9 & $7.65 \%$ & $8.28 \%$ & $9.86 \%$ \\
\hline \multirow[t]{3}{*}{$\hat{\pi}=$} & $3.26 \%$ & IV CAPM & $1.27 \%$ & 0.8 & 4.7 & $6.98 \%$ & $7.64 \%$ & $9.21 \%$ & $1.27 \%$ & 0.8 & 5.0 & $7.00 \%$ & $7.66 \%$ & $9.30 \%$ \\
\hline & & V CAPM + Sector & $1.28 \%$ & 0.8 & 4.7 & $7.01 \%$ & $7.64 \%$ & $9.20 \%$ & $1.30 \%$ & 0.9 & 5.2 & $7.15 \%$ & $7.83 \%$ & $9.60 \%$ \\
\hline & & VI PCA & $1.51 \%$ & 1.1 & 5.9 & $7.96 \%$ & $8.93 \%$ & $11.15 \%$ & $1.49 \%$ & 1.2 & 6.2 & $7.91 \%$ & $8.85 \%$ & $11.11 \%$ \\
\hline
\end{tabular}

Panel B: Same Default Threshold by Rating: $\lambda_{R}$

US \& Japan Pooled

\begin{tabular}{|c|c|c|c|c|c|c|c|c|c|c|c|c|c|c|}
\hline \multirow{3}{*}{$\begin{array}{c}\text { Simulation } \\
\text { Year } \\
\end{array}$} & \multirow{3}{*}{$\begin{array}{c}\text { Using } \\
\text { Sample }\end{array}$} & \multirow[b]{3}{*}{ Model Specifications } & & & & & & & \\
\hline & & & & & & & lue-at-Ri & & \multirow[b]{2}{*}{ UL } & \multirow[b]{2}{*}{ Skew. } & \multirow[b]{2}{*}{ Kurt. } & \multicolumn{3}{|c|}{ Value-at-Risk } \\
\hline & & & $\mathbf{U L}$ & Skew. & Kurt. & $99.0 \%$ & $99.5 \%$ & $99.9 \%$ & & & & $99.0 \%$ & $99.5 \%$ & $99.9 \%$ \\
\hline \multirow[t]{2}{*}{2003} & 1993-2002 & I Vasicek & $2.48 \%$ & 1.8 & 8.0 & $11.92 \%$ & $13.59 \%$ & $17.47 \%$ & $2.56 \%$ & 1.8 & 8.2 & $12.20 \%$ & $13.89 \%$ & $17.81 \%$ \\
\hline & & III Vasicek + Rating & $1.51 \%$ & 0.6 & 3.7 & $7.46 \%$ & $8.06 \%$ & $9.46 \%$ & $1.56 \%$ & 0.7 & 3.9 & $7.65 \%$ & $8.28 \%$ & $9.86 \%$ \\
\hline \multirow[t]{3}{*}{$\hat{\pi}=$} & $3.26 \%$ & IV CAPM & $1.23 \%$ & 0.7 & 4.1 & $6.76 \%$ & $7.36 \%$ & $8.63 \%$ & $1.21 \%$ & 0.6 & 4.1 & $6.64 \%$ & $7.19 \%$ & $8.53 \%$ \\
\hline & & V CAPM + Sector & $1.25 \%$ & 0.7 & 4.2 & $6.81 \%$ & $7.42 \%$ & $8.76 \%$ & $1.24 \%$ & 0.7 & 4.4 & $6.83 \%$ & $7.43 \%$ & $8.86 \%$ \\
\hline & & VI PCA & $1.42 \%$ & 0.8 & 4.6 & $7.44 \%$ & $8.18 \%$ & $9.83 \%$ & $1.39 \%$ & 0.9 & 4.8 & $7.39 \%$ & $8.13 \%$ & $9.82 \%$ \\
\hline
\end{tabular}

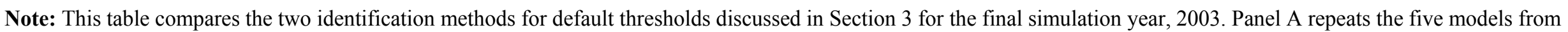

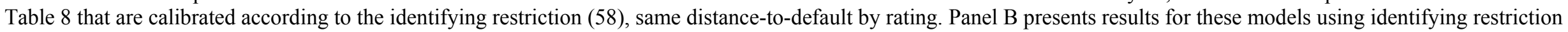

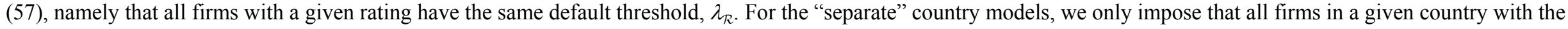

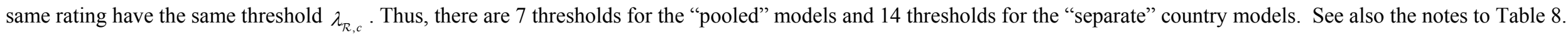
Fore more details on the model specifications, please see Table 3. 


\section{Table 10}

\section{Comparison of $\overline{\hat{\rho}}$ and $\bar{\rho}^{*}$ for Models Using Same Distance to Default Identification Restrictions Based on U.S. and Japan Pooled Return Specifications \\ (2003)}

\begin{tabular}{|c|c|c|c|c|c|c|c|c|}
\hline \multirow{2}{*}{$\begin{array}{c}\text { Simulation } \\
\text { Year }\end{array}$} & \multirow{2}{*}{$\begin{array}{c}\text { Using } \\
\text { Sample }\end{array}$} & \multirow{2}{*}{\multicolumn{2}{|c|}{ Model Specifications }} & \multirow[b]{2}{*}{ Parameter Restrictions } & \multirow[b]{2}{*}{$\overline{\hat{\rho}}$} & \multirow[b]{2}{*}{$\hat{\rho}^{*}$} & \multicolumn{2}{|c|}{ Simulated } \\
\hline & & & & & & & $\mathbf{U L}$ & 99.9\% VaR \\
\hline \multirow[t]{2}{*}{2003} & 1993-2002 & I & Vasicek & $\hat{\pi}_{i}=\hat{\pi} \forall i ; \hat{\rho}_{i, j}=\hat{\rho}, \hat{\rho}_{i, j}^{*}=\hat{\rho}^{*} \forall i, j$ & $9.20 \%$ & $1.80 \%$ & $2.48 \%$ & $17.47 \%$ \\
\hline & & III & Vasicek + Rating & $\hat{\pi}_{i}=\hat{\pi}_{R} \forall i \in R ; \hat{\rho}_{i, j}=\hat{\rho} \forall i, j ; \hat{\rho}_{i, j}^{*}=\hat{\rho}_{R, R^{\prime}}^{*} \forall i \in R, j \in R^{\prime}$ & $9.20 \%$ & $0.26 \%$ & $1.51 \%$ & $9.46 \%$ \\
\hline \multirow[t]{3}{*}{$\hat{\pi}=$} & $3.26 \%$ & IV & CAPM & $\hat{\pi}_{i}=\hat{\pi}_{R} \forall i \in R$ & $10.09 \%$ & $0.32 \%$ & $1.27 \%$ & $9.21 \%$ \\
\hline & & $\mathrm{V}$ & CAPM + Sector & $\hat{\pi}_{i}=\hat{\pi}_{R} \forall i \in R$ & $10.35 \%$ & $0.33 \%$ & $1.28 \%$ & $9.20 \%$ \\
\hline & & VI & PCA & $\hat{\pi}_{i}=\hat{\pi}_{R} \forall i \in R$ & $14.77 \%$ & $0.80 \%$ & $1.51 \%$ & $11.15 \%$ \\
\hline
\end{tabular}

Note: This table compares the average pair-wise correlation of simulated (out-of-sample) returns, $\overline{\hat{\rho}}$, where the average is take over $\hat{\rho}_{i, j} \forall i>j$, and the average pair-wise correlation of simulated (out-of-sample) defaults, $\overline{\hat{\rho}^{*}}$, across models for the final simulation year, 2003. These results are only presented for the six models that use the same distance-to-default identifying restriction, equation (58). Pair-wise correlations of simulated (out-of-sample) returns, $\hat{\rho}_{i, j}$, are given by equation (10). Pair-wise correlations of simulated (out-of-sample) defaults, $\hat{\rho}_{i, j}^{*}$, are obtained using equation (16) in (12) as described in Section 7.4.1. For more detail on the model specifications, please see Table 3. 


\section{Figure 1}

Relationship between Default Correlation ( $\rho^{*}$ ) and Return Correlation $(\rho)$ for different values of the degrees of freedom of the Student t-distribution $(v)$ and default probability $(\pi)$
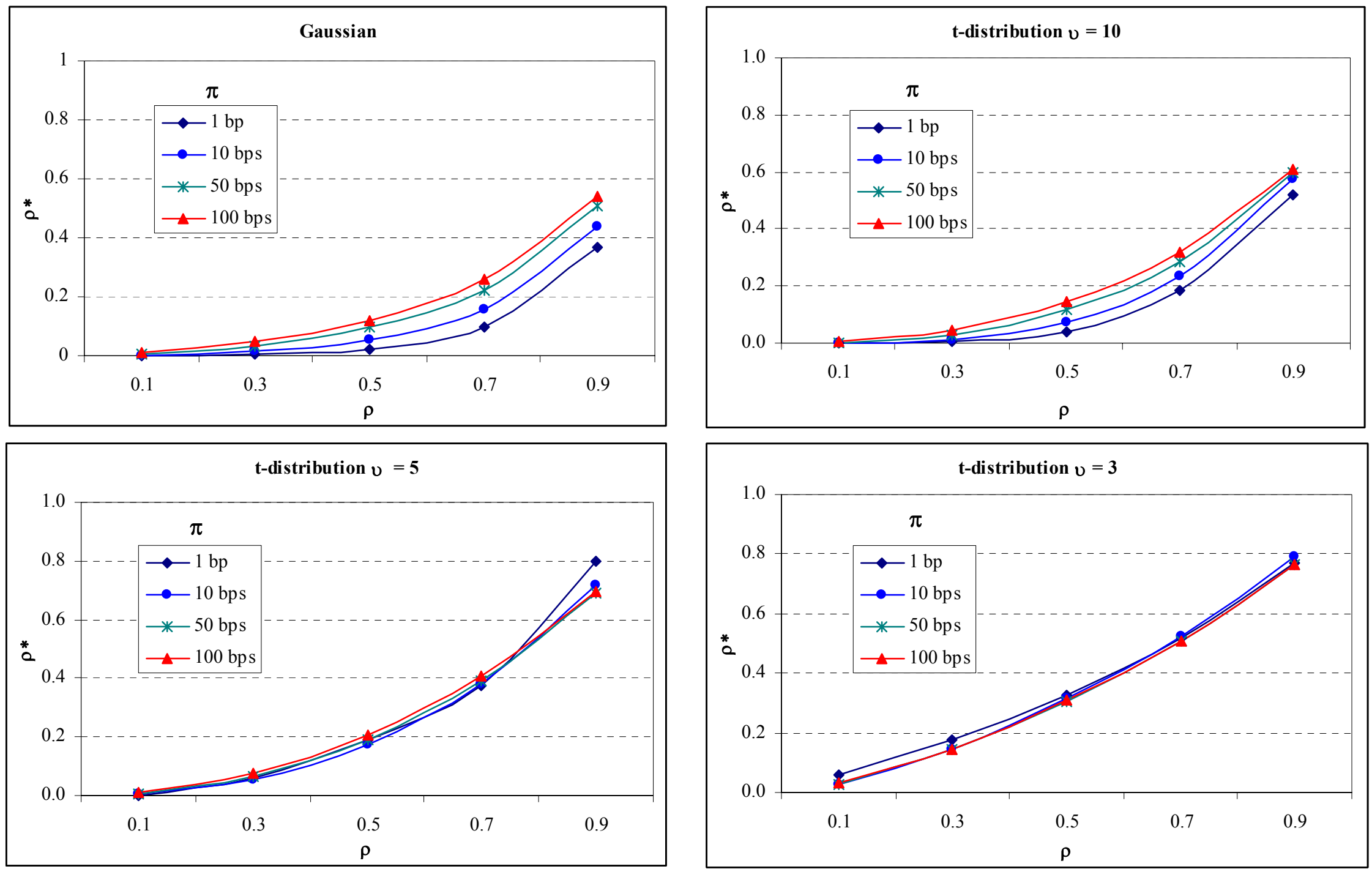

Note: $\rho^{*}=\rho^{*}(\pi, \rho, v)$ is calculated using equation (32) for the Student t-distribution with $v$ degrees of freedom and using equation (27) for the Gaussian case. The expectations in equations (32) are evaluated using 1 million draws of $f_{\mathrm{t}+1}$. 
Figure 2

Kernel Density Estimates of Estimated Betas

(U.S. versus Japan, 1988-1997)

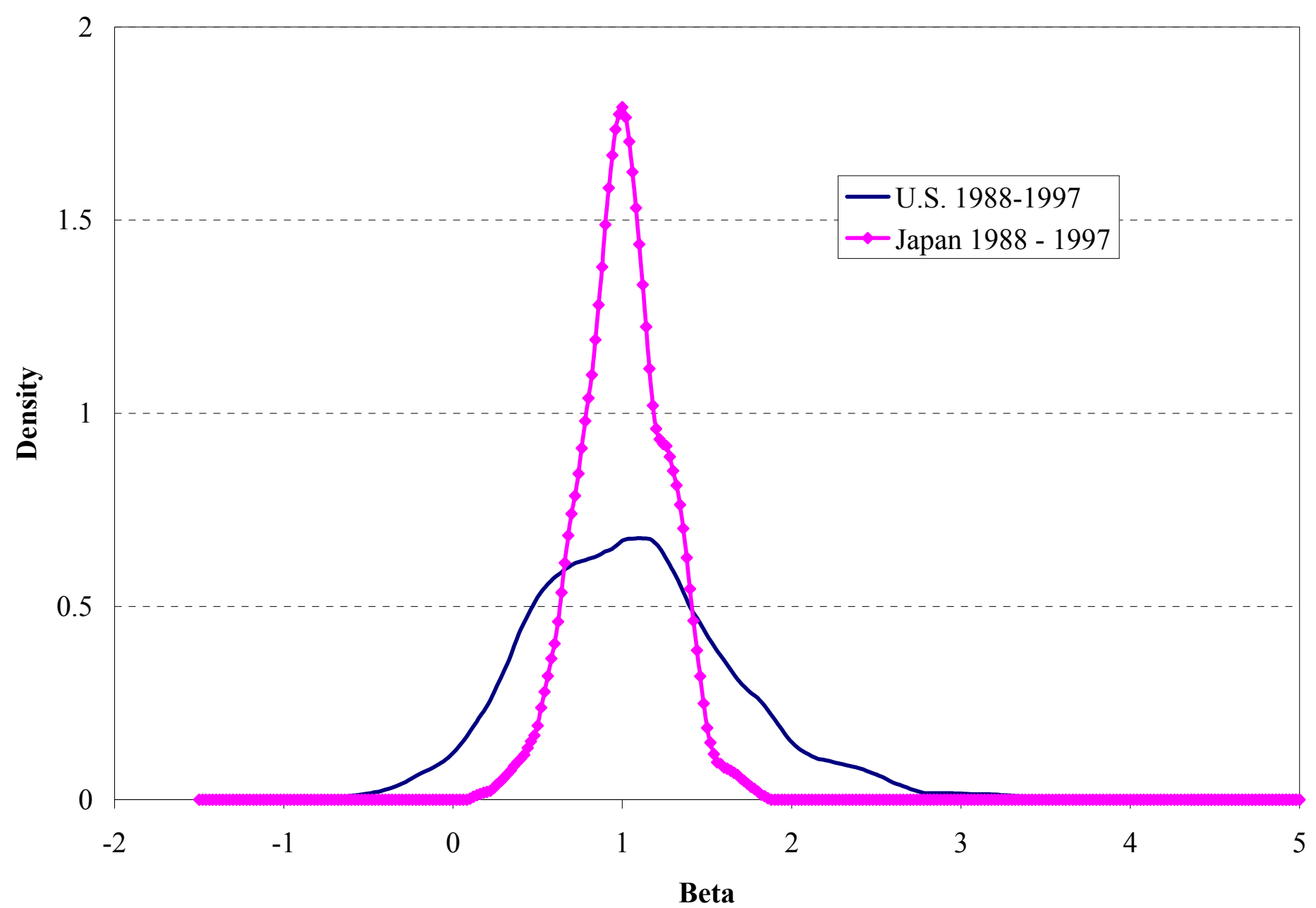

Note: Estimated betas are from Model IV - CAPM where U.S. \& Japan are modeled separately. All densities are estimated with an Epanechnikov kernel using Silverman's (1986) optimal bandwidth. 


\section{Figure 3a}

\section{Kernel Density Estimates of Estimated Betas}

(U.S. Betas over Time)

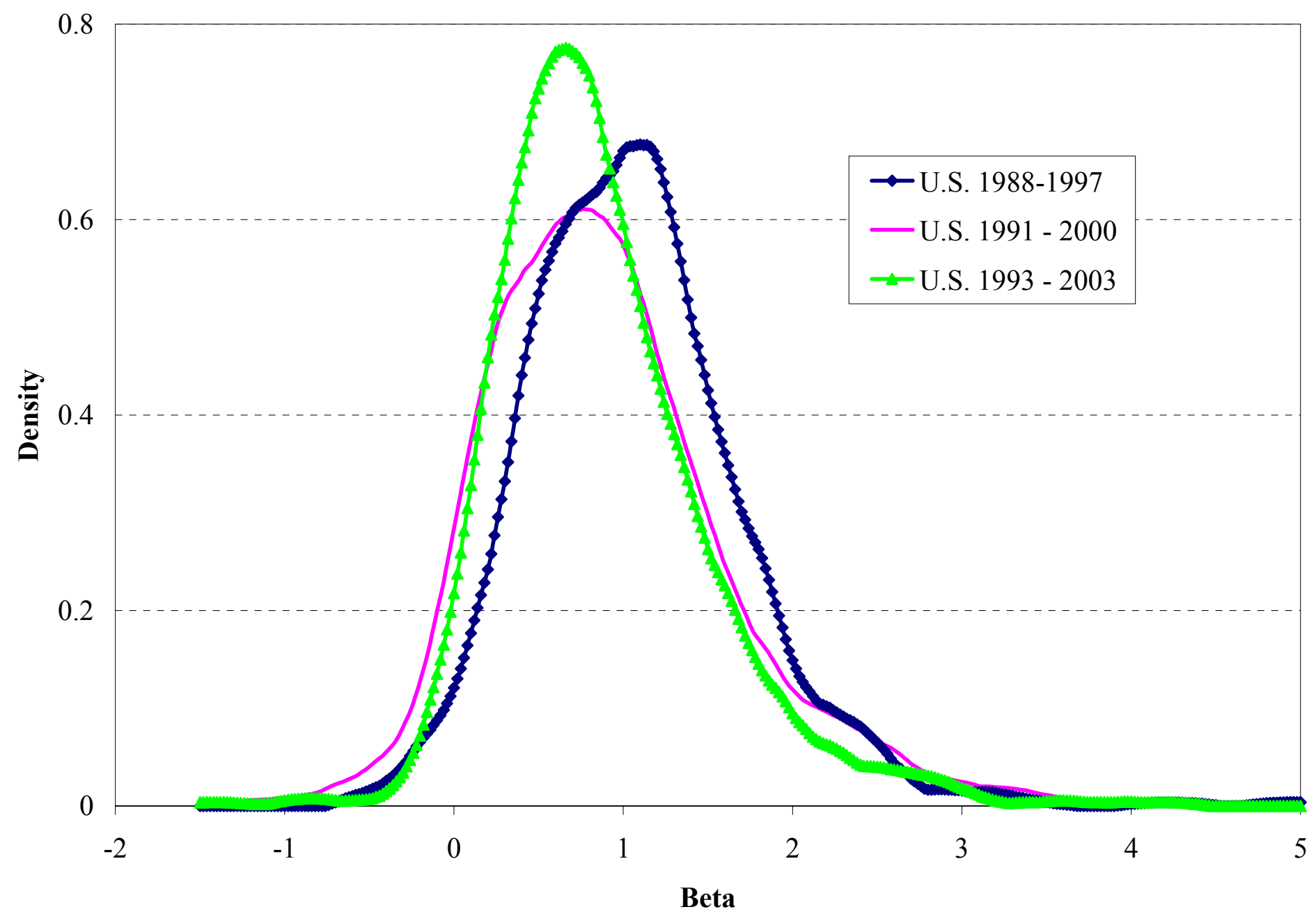

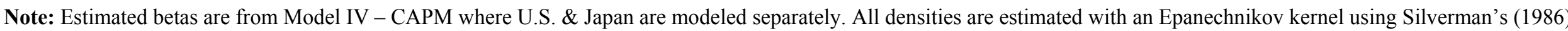
optimal bandwidth. 


\section{Figure 3b}

Kernel Density Estimates of Estimated Betas

(Japanese Betas over Time)

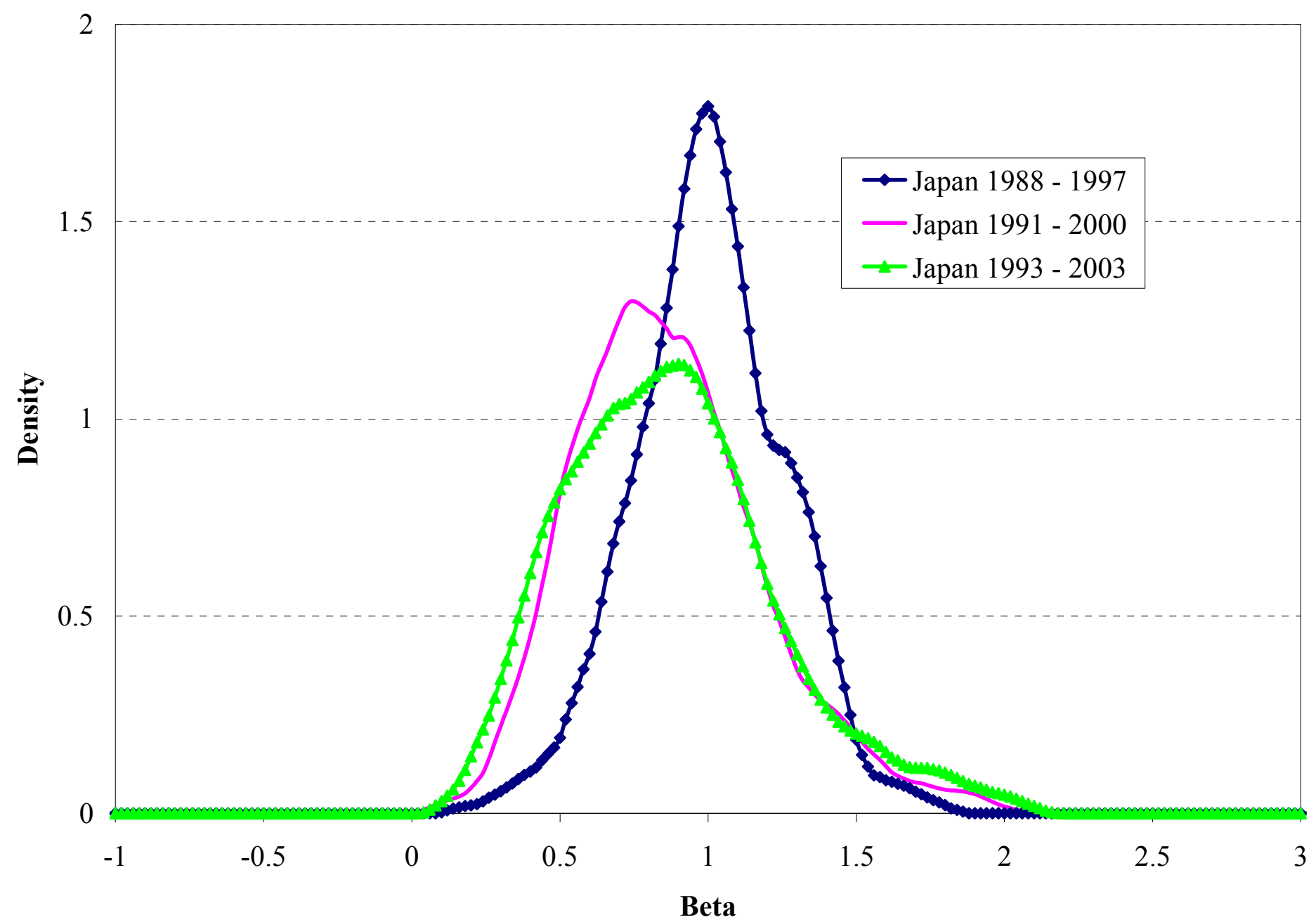

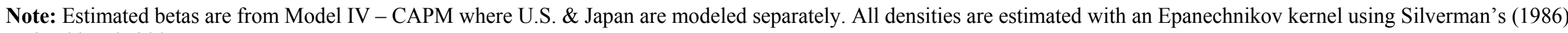
optimal bandwidth. 
Figure 4

Alternative Simulated Loss Densities

(U.S. and Japan Modeled Separately, 2003)

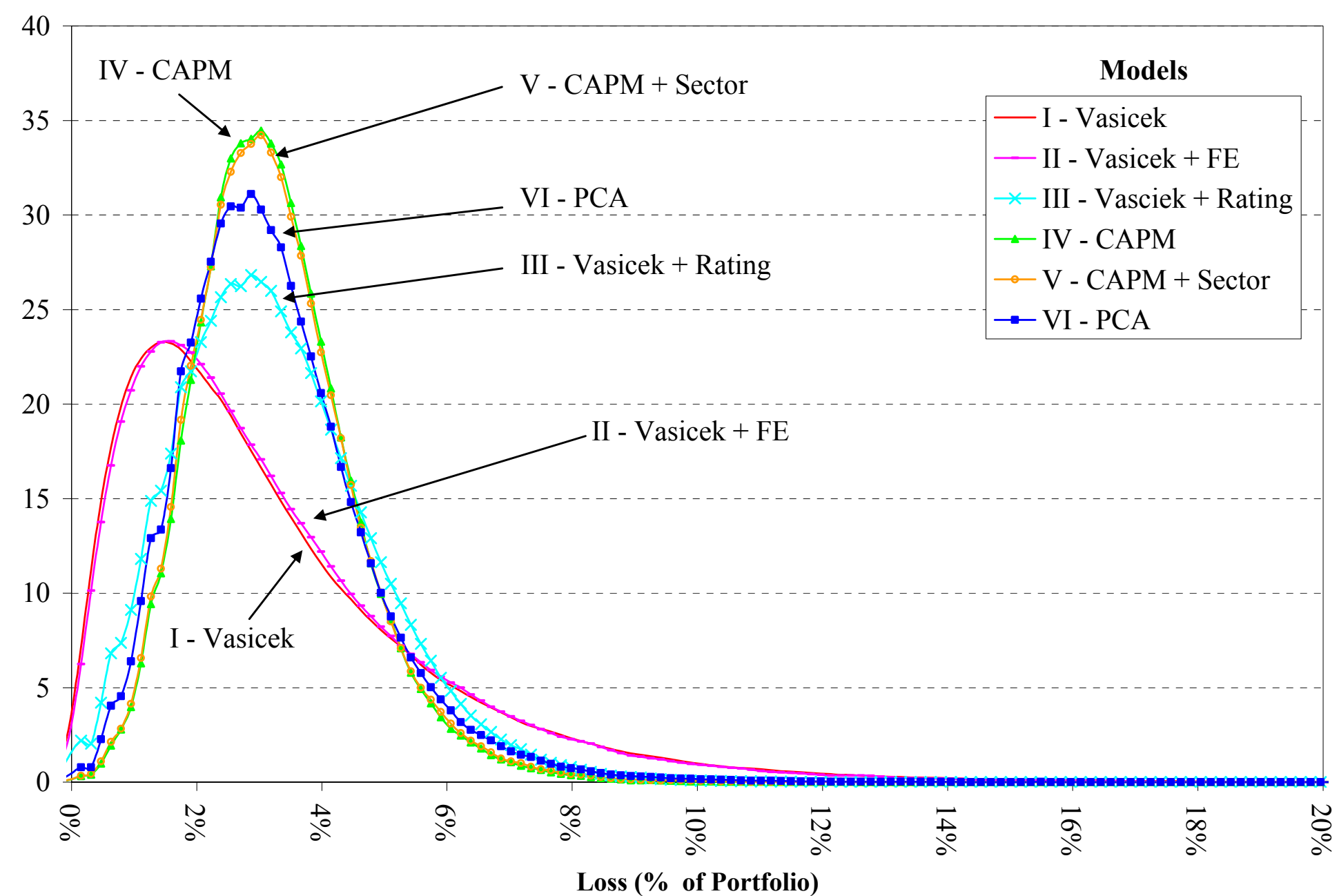

Note: All densities are estimated with an Epanechnikov kernel using Silverman's (1986) optimal bandwidth. For more details on the model specifications, please see Table 3. 


\section{CESifo Working Paper Series}

(for full list see www.cesifo-group.de)

1469 Torberg Falch and Marte Rønning, The Influence of Student Achievement on Teacher Turnover, May 2005

1470 John Komlos and Peter Salamon, The Poverty of Growth with Interdependent Utility Functions, May 2005

1471 Hui Huang, Yi Wang, Yiming Wang, John Whalley and Shunming Zhang, A Trade Model with an Optimal Exchange Rate Motivated by Current Discussion of a Chinese Renminbi Float, May 2005

1472 Helge Holden, Lars Holden and Steinar Holden, Contract Adjustment under Uncertainty, May 2005

1473 Kai A. Konrad, Silent Interests and All-Pay Auctions, May 2005

1474 Ingo Vogelsang, Electricity Transmission Pricing and Performance-Based Regulation, May 2005

1475 Spiros Bougheas and Raymond Riezman, Trade and the Distribution of Human Capital, June 2005

1476 Vesa Kanniainen, Seppo Kari and Jouko Ylä-Liedenpohja, The Start-Up and Growth Stages in Enterprise Formation: The "New View" of Dividend Taxation Reconsidered, June 2005

1477 M. Hashem Pesaran, L. Vanessa Smith and Ron P. Smith, What if the UK had Joined the Euro in 1999? An Empirical Evaluation Using a Global VAR, June 2005

1478 Chang Woon Nam and Doina Maria Radulescu, Effects of Corporate Tax Reforms on SMEs' Investment Decisions under the Particular Consideration of Inflation, June 2005

1479 Panos Hatzipanayotou, Sajal Lahiri and Michael S. Michael, Globalization, CrossBorder Pollution and Welfare, June 2005

1480 John Whalley, Pitfalls in the Use of Ad valorem Equivalent Representations of the Trade Impacts of Domestic Policies, June 2005

1481 Edward B. Barbier and Michael Rauscher, Trade and Development in a Labor Surplus Economy, June 2005

1482 Harrie A. A. Verbon and Cees A. Withagen, Tradable Emission Permits in a Federal System, June 2005

1483 Hendrik Hakenes and Andreas Irmen, On the Long-Run Evolution of Technological Knowledge, June 2005 
1484 Nicolas Schmitt and Antoine Soubeyran, A Simple Model of Brain Circulation, June 2005

1485 Carsten Hefeker, Uncertainty, Wage Setting and Decision Making in a Monetary Union, June 2005

1486 Ondřej Schneider and Jan Zápal, Fiscal Policy in New EU Member States - Go East, Prudent Man!, June 2005

1487 Christian Schultz, Virtual Capacity and Competition, June 2005

1488 Yvan Lengwiler and Elmar Wolfstetter, Bid Rigging - An Analysis of Corruption in Auctions, June 2005

1489 Johannes Becker and Clemens Fuest, Does Germany Collect Revenue from Taxing Capital Income?, June 2005

1490 Axel Dreher and Panu Poutvaara, Student Flows and Migration: An Empirical Analysis, June 2005

1491 Bernd Huber and Marco Runkel, Interregional Redistribution and Budget Institutions under Asymmetric Information, June 2005

1492 Guido Tabellini, Culture and Institutions: Economic Development in the Regions of Europe, July 2005

1493 Kurt R. Brekke and Michael Kuhn, Direct to Consumer Advertising in Pharmaceutical Markets, July 2005

1494 Martín Gonzalez-Eiras and Dirk Niepelt, Sustaining Social Security, July 2005

1495 Alfons J. Weichenrieder, (Why) Do we need Corporate Taxation?, July 2005

1496 Paolo M. Panteghini, S-Based Taxation under Default Risk, July 2005

1497 Panos Hatzipanayotou and Michael S. Michael, Migration, Tied Foreign Aid and the Welfare State, July 2005

1498 Agata Antkiewicz and John Whalley, BRICSAM and the Non-WTO, July 2005

1499 Petr Hedbávný, Ondřej Schneider and Jan Zápal, A Fiscal Rule that has Teeth: A Suggestion for a 'Fiscal Sustainability Council' underpinned by the Financial Markets, July 2005

1500 J. Atsu Amegashie and Marco Runkel, Sabotaging Potential Rivals, July 2005

1501 Heikki Oksanen, Actuarial Neutrality across Generations Applied to Public Pensions under Population Ageing: Effects on Government Finances and National Saving, July 2005 
1502 Xenia Matschke, Costly Revenue-Raising and the Case for Favoring Import-Competing Industries, July 2005

1503 Horst Raff and Nicolas Schmitt, Why Parallel Trade may Raise Producers Profits, July 2005

1504 Alberto Bisin and Piero Gottardi, Efficient Competitive Equilibria with Adverse Selection, July 2005

1505 Peter A. Zadrozny, Necessary and Sufficient Restrictions for Existence of a Unique Fourth Moment of a Univariate GARCH(p,q) Process, July 2005

1506 Rainer Niemann and Corinna Treisch, Group Taxation, Asymmetric Taxation and Cross-Border Investment Incentives in Austria, July 2005

1507 Thomas Christiaans, Thomas Eichner and Ruediger Pethig, Optimal Pest Control in Agriculture, July 2005

1508 Biswa N. Bhattacharyay and Prabir De, Promotion of Trade and Investments between China and India: The Case of Southwest China and East and Northeast India, July 2005

1509 Jean Hindriks and Ben Lockwood, Decentralization and Electoral Accountability: Incentives, Separation, and Voter Welfare, July 2005

1510 Michelle R. Garfinkel, Stergios Skaperdas and Constantinos Syropoulos, Globalization and Domestic Conflict, July 2005

1511 Jesús Crespo-Cuaresma, Balázs Égert and Ronald MacDonald, Non-Linear Exchange Rate Dynamics in Target Zones: A Bumpy Road towards a Honeymoon - Some Evidence from the ERM, ERM2 and Selected New EU Member States, July 2005

1512 David S. Evans and Michael Salinger, Curing Sinus Headaches and Tying Law: An Empirical Analysis of Bundling Decongestants and Pain Relievers, August 2005

1513 Christian Keuschnigg and Martin D. Dietz, A Growth Oriented Dual Income Tax, July 2005

1514 Fahad Khalil, David Martimort and Bruno Parigi, Monitoring a Common Agent: Implications for Financial Contracting, August 2005

1515 Volker Grossmann and Panu Poutvaara, Pareto-Improving Bequest Taxation, August 2005

1516 Lars P. Feld and Emmanuelle Reulier, Strategic Tax Competition in Switzerland: Evidence from a Panel of the Swiss Cantons, August 2005

1517 Kira Boerner and Silke Uebelmesser, Migration and the Welfare State: The Economic Power of the Non-Voter?, August 2005 
1518 Gabriela Schütz, Heinrich W. Ursprung and Ludger Wößmann, Education Policy and Equality of Opportunity, August 2005

1519 David S. Evans and Michael A. Salinger, Curing Sinus Headaches and Tying Law: An Empirical Analysis of Bundling Decongestants and Pain Relievers, August 2005

1520 Michel Beine, Paul De Grauwe and Marianna Grimaldi, The Impact of FX Central Bank Intervention in a Noise Trading Framework, August 2005

1521 Volker Meier and Matthias Wrede, Pension, Fertility, and Education, August 2005

1522 Saku Aura and Thomas Davidoff, Optimal Commodity Taxation when Land and Structures must be Taxed at the Same Rate, August 2005

1523 Andreas Haufler and Søren Bo Nielsen, Merger Policy to Promote 'Global Players'? A Simple Model, August 2005

1524 Frederick van der Ploeg, The Making of Cultural Policy: A European Perspective, August 2005

1525 Alexander Kemnitz, Can Immigrant Employment Alleviate the Demographic Burden? The Role of Union Centralization, August 2005

1526 Baoline Chen and Peter A. Zadrozny, Estimated U.S. Manufacturing Production Capital and Technology Based on an Estimated Dynamic Economic Model, August 2005

1527 Marcel Gérard, Multijurisdictional Firms and Governments' Strategies under Alternative Tax Designs, August 2005

1528 Joerg Breitscheidel and Hans Gersbach, Self-Financing Environmental Mechanisms, August 2005

1529 Giorgio Fazio, Ronald MacDonald and Jacques Mélitz, Trade Costs, Trade Balances and Current Accounts: An Application of Gravity to Multilateral Trade, August 2005

1530 Thomas Christiaans, Thomas Eichner and Ruediger Pethig, A Micro-Level 'Consumer Approach' to Species Population Dynamics, August 2005

1531 Samuel Hanson, M. Hashem Pesaran and Til Schuermann, Firm Heterogeneity and Credit Risk Diversification, August 2005 